Illinois State University

ISU ReD: Research and eData

Theses and Dissertations

8-12-2013

\title{
Agency at Hacienda Pancota: Early Colonial Daily Consumption of a Contested Age and Material Culture
}

Collin Roderick Gillenwater

Illinois State University, collingil86@hotmail.com

Follow this and additional works at: https://ir.library.illinoisstate.edu/etd

Part of the History of Art, Architecture, and Archaeology Commons

\section{Recommended Citation}

Gillenwater, Collin Roderick, "Agency at Hacienda Pancota: Early Colonial Daily Consumption of a Contested Age and Material Culture" (2013). Theses and Dissertations. 145.

https://ir.library.illinoisstate.edu/etd/145

This Thesis is brought to you for free and open access by ISU ReD: Research and eData. It has been accepted for inclusion in Theses and Dissertations by an authorized administrator of ISU ReD: Research and eData. For more information, please contact ISUReD@ilstu.edu. 


\title{
AGENCY AT HACIENDA PANCOTA: EARLY COLONIAL DAILY CONSUMPTION OF A CONTESTED AGE \\ AND MATERIAL CULTURE
}

\author{
Collin R. Gillenwater
}

162 Pages

May 2014

By 1580, the Spanish Empire was controlled by King Philip II, who actively pursued colonization of New World territories inherited from his father, King Charles V. These territories comprised mostly of present day Central and South America. Similarly, Spanish colonies in the Philippines were established just prior in 1579, adding to increasingly expansionist overseas endeavors. Despite the Spanish Crown's goal of vigilantly regulating intercolonial trade, archaeological evidence at Hacienda Pancota, El Salvador suggests non-regulated Oriental goods and other imported contraband were present in the early colonial period between 1580 and 1650 . Within the context of colonial oppression, Hacienda Pancota residents adapted their material lifestyles to reinforce complex traditional consumption and production patterns while incorporating new imported technologies.

The proceeding research will analyze the social functioning and spatial patterning of household artifacts, comprised of imported contraband wares and locally produced pottery at Hacienda Pancota. Analyzed within critical approaches of a Marxian framework, this study will elucidate social patterns of exploitation, power, resistance, and 
dominance. The proportion of contraband ceramic wares was placed in the context of the entire assemblage from one household originally excavated in the 1990s. Furthermore, the assemblage was compared to other published historical haciendas dating to similar early colonial Mesoamerican time periods.

Evidence concluded that the specialization of place and its associated material culture was part of larger social adaptations influencing daily production and consumption at Hacienda Pancota. Social agency and material variability were evidenced through household artifact analysis, leading to the conclusion of a particularly indigenous spatial organization of the physical structure in the early colonial period. Material evidence supported rural working-class residents' contribution to the early colonial world economic system. 
AGENCY AT HACIENDA PANCOTA: EARLY COLONIAL DAILY

CONSUMPTION OF A CONTESTED AGE

AND MATERIAL CULTURE

COLLIN R. GILLENWATER

A Thesis Submitted in Partial

Fulfillment of the Requirements

for the Degree of

MASTER OF SCIENCE

Department of Sociology and Anthropology

ILLINOIS STATE UNIVERSITY

2014 
Copyright 2014 Collin R. Gillenwater 
AGENCY AT HACIENDA PANCOTA: EARLY COLONIAL DAILY CONSUMPTION OF A CONTESTED AGE AND MATERIAL CULTURE

COLLIN R. GILLENWATER

COMMITTEE MEMBERS:

Kathryn Sampeck, Chair

Elizabeth Scott 


\section{ACKNOWLEDGEMENTS}

There are many people in my life who helped make this research possible-I simply cannot name them all. Without the help of Dr. Kathryn Sampeck, her guidance, data, and motivation, this thesis would never be complete. Secondly, Dr. Elizabeth Scott encouraged me to push myself through analysis and keep me consistently writing. Spending time excavating at her field school undoubtedly helped me get to know her at a new level, allowing me to create a lasting academic relationship with her that has aided me in research analysis.

For a wider perspective in understanding and interpreting my archaeological data, thank you to Dee Ann Watt and Dr. Terry Martin of Illinois State Museum's Research and Collections Center. Your pleasant work environment and warm personalities reaffirmed my commitment to an archaeological career and its people. A sincere thank you to Professora Toro-Morn, Director of Latin American and Latino Studies at Illinois State University. Your two years of commitment and dedication to me was undeniably inspiring when I felt like graduate school was too heavy a burden.

Thank you to my mother and father for your emotional—and financial—support. You both allowed me to pursue a lifestyle some people never have the chance to experience. I appreciate everything you've given me and could not be more grateful. You both are key contributors to my success as a student of archaeology.

Lastly, to all of my fellow friends and colleagues at Illinois State University who inspired me, argued against me, or pushed me in new directions I never thought 
possible — thank you. A special thanks to Susan Kooiman and Montana Martin—two of the most unique and dedicated archaeologists I know. Good luck in future pursuits.

C.R.G. 


\section{CONTENTS}

$\begin{array}{lr} & \text { Page } \\ \text { ACKNOWLEDGEMENTS } & \text { i } \\ \text { CONTENTS } & \text { iii } \\ \text { TABLES } & \text { vii } \\ \text { FIGURES } & \text { ix }\end{array}$

CHAPTER

I. EXAMINING THE PAST: FROM WESTERN EUROPE TO MESOAMERICA

Research Question $\quad 2$

A Brief Understanding of Mesoamerica 3

Historical Settlement Patterns and

Reducción Policies

Western El Salvador and the Izalcos Pipil

II. THE EARLY MODERN PERIOD IN THE SPANISH OLD AND NEW WORLDS

The Early Modern Period Setting 8

Piracy, Privateering, and Tension in the West Indies 11

The Manila-Acapulco Galleons and the Spanish House of Trade 14

Ceramic History in the Early Modern Spanish New World 17

Chinese Porcelain in Early Colonial Latin America 18

Evidence of Exchange Relationships 20

Archaeology of Contraband Trade in the New World 21

Illicit Activity Represented by Contraband Ceramics 23

III. REVIEW OF ARCHAEOLOGICAL INVESTIGATIONS INTO DOMESTIC LIFE AND CONSUMPTION

The Archaeology of Haciendas 
Household Archaeology 28

Archaeology at Hacienda Pancota, El Salvador 33

Description of Vessel Forms at Hacienda Pancota 34

Indigenous Tradition Storage Vessel Forms 35

Indigenous Tradition Cooking Vessel Forms 36

Indigenous Tradition Serving Vessel Forms 36

European Tradition and Other Imported Vessel Forms 37

IV. ADDRESSED RESEARCH QUESTIONS AND THEORETICAL PERSPECTIVES

Review of Research Agenda 38

$\begin{array}{ll}\text { Theoretical Perspectives } & 39\end{array}$

V. METHODS FOR ANALYSIS 44

Ceramic Analysis $\quad 44$

Typological Analysis of Ceramics $\quad 45$

Indigenous Pottery: Coarse Earthenwares 45

Local and Imported Majolica 46

Refined Earthenwares $\quad 47$

Oriental Porcelain 48

Qualitative Minimum Number of Vessels (MNV) 48

Decorative Analysis of Pottery 49

Other Analyzed Material Culture $\quad 50$

Site Comparisons $\quad 51$

Artifact and Structural Spatial Analysis $\quad 51$

Small Scale Variation in Darío Group Ceramics 52

VI. RESULTS OF MATERIAL REMAINS ANALYSIS

AT HACIENDA PANCOTA 54

Pottery Assemblage Analysis $\quad 57$

Indigenous Tradition Pottery $\quad 59$

Late Classic and Late Postclassic Pottery 60

Talcomunca Group $\quad 61$

Cipriano Red-on-Gray $\quad 62$

Contact Period Pottery $\quad 62$

Gines Group $\quad 62$

Teshcal Red-on-Natural 63

Cuscatlán Group 64 
Teofilo Group $\quad 65$

Raimundo Group $\quad 66$

Apolonio Group $\quad 67$

Telesforo Brown $\quad 68$

Darío Group 68

$\begin{array}{ll}\text { Special Pottery Types } & 70\end{array}$

Darío Plain Variety One $\quad 70$

Darío Plain Variety Two 71

Darío Plain Variety Three $\quad 71$

Darío Plain Variety Four $\quad 72$

European Tradition Pottery $\quad 73$

Majolica and Spanish Colonial Pottery

Lead Glazed Redware $\quad 75$

Unglazed Coarse Earthenwares: Olive Jars 76

$\begin{array}{ll}\text { Refined Earthenwares } & 77\end{array}$

Other Imported Pottery: Oriental Porcelain $\quad 78$

Summary of Pottery Type Results 80

Overall Vessel Form Results and

Minimum Number of Vessel Results $\quad 82$

Vessel Form Results of Indigenous Tradition Pottery 83

Results of a Pantaleón Brown Refitted Vessel 85

European Tradition Vessel Forms and

Porcelain Vessel Forms $\quad 87$

Vessel Form Stratigraphy $\quad 89$

Examining Decorative Pottery 91

Early Colonial Water Bottles: Variation Results of
Darío Plain and Bibiana Red

Faunal Remains Analysis $\quad 99$

Lithic Assemblage Analysis 100

Spatial Artifact Distribution Analysis 101

Spatial Pottery Distributions 106

Spatial Bajareque Distribution $\quad 109$

Spatial Faunal Remains Distribution $\quad 111$

Spatial Lithic Distribution 113

$\begin{array}{ll}\text { Comparative Site Data Analysis } & 115\end{array}$

VII. DISCUSSION OF RESULTS 117

The Basics: Cooking Food, Storing Drink, 
and Working Fields

Spatial Analysis of Midden Locations

The Household as a Building Block to World

Economic Systems

Agency as an Alternative to Resistance

Ceramics at Hacienda Pancota: Product and Producer of Social Relationships

Hacienda Pancota and World Cyclical Patterns

Discussion of Comparative Site Assemblages 


\section{TABLES}

Table $\quad$ Page

1. Total Percentages of Analyzed Artifact Remains 55

2. Raw Counts for All Analyzed Artifact Types in Each Level 56

3. Raw Totals and Minimum Number of Vessels in Each Diagnostic Period 59

4. Selected Pottery Traditions from Each Level 81

5. Thickness (mm) Measurements for Olive Jar Sherds 88

6. Raw Counts of MNVs for all Decorated Pottery 95

7. Results of Darío Plain Sherd Thickness 97

8. Darío Plain Sherd Thickness Classes by Spatiality 98

9. Darío Plain Sherds by Excavated Level 98

10. Bibiana Red Thickness (mm) 99

11. Bibiana Red Sherd Thickness by Spaitality 99

12. Eastern Structure Artifact Distribution 103

13. Western Structure Artifact Distribution 103

14. Total Artifact Distribution 104

15. Vessel Form Distribution 107

16. Total Vessel Form Distribution of Structure 108 
17. Comparative Pottery Data Total 


\section{FIGURES}

Figure $\quad$ Page

1. Darío Group Variants 73

2. Relative Frequencies of Pottery Traditions 82

3. Exterior of Refitted Panataleón Brown Vessel 86

4. Interior of Refitted Panataleón Brown Vessel 87

5. Vessel Form Stratigraphy 90

6. UID Classic Period Decorated Sherd $\quad 91$

7. Postclassic and Contact Period Decorated Sherds 92

8. Early Colonial Decorated Sherds 93

9. Decorated Porcelain and Whiteware 94

10. Total Artifact Distribution Chloropleth Map 105

11. Pottery Distribution Chloropleth Map 109

12. Bajareque Distribution Chloropleth Map 111

13. Faunal Remains Distribution Chloropleth Map 113

14. Lithic Distribution Chloropleth Map 114 


\section{CHAPTER I}

\section{EXAMINING THE PAST: FROM WESTERN \\ EUROPE TO MESOAMERICA}

Mesoamerica is a natural crossroads - a physical and cultural convergence of ideas, technologies, and people adapting to a wide spectrum of environments. Defined by Mexico and the American southwest to the North with resource rich and bountiful countries extending to the south. Guatemala, Belize, El Salvador and parts of El Salvador, Honduras and Nicaragua are located in the southern arm, all while resting in between the world's two largest oceans. This natural geographic doorway, named Mesoamerica, is the center of unique peoples, technologies, fauna, flora, and what seems to be an exponentially diverse array of cultures. It is also the primary study area for investigating daily consumption at western El Salvador's Hacienda Pancota.

Hacienda Pancota's rich history dates to the contact period (1502-1580), through the early colonial period (1580-1650), though some evidence dates human occupation in the area much earlier. Examining residents' consumption and production patterns through material culture makeup allow social patterns to be witnessed in the context of class and society in early colonial Mesoamerica. Examining this thesis's research questions and area history will set the stage for Hacienda Pancota's role in a very important historical socioeconomic context. 


\section{Research Question}

To investigate daily consumption and the results of agency at the household level, ceramic evidence was selected as the best candidate due to its availability and extensive theoretical literature. All material culture was tabulated and given spatial provenience, but the ceramic assemblage played the singular and primary role of this research. Lithic, faunal, glassware, metal, and construction materials supported the driving force of ceramic data and their critical role into meaning of place and agency at Hacienda Pancota.

The following questions were addressed: 1) What are the indigenous, imported, and contraband ceramics in the Hacienda Pancota sample? I identified all types ceramic wares and used Sampeck (2007) as a guide; 2) What is the proportion of contraband ceramics to the rest of the ceramics in the sample? How do they fit into the assemblage as a whole? I analyzed the form and decoration of recovered Chinese ceramics in order to see how they relate to the form and decoration of other ceramics in the assemblage; 3 ) How does Hacienda Pancota compare to other early colonial Mesoamerican households? I compared the ceramic assemblages and total artifact collections reported from sites of the same time period reported in Deagan (2002), Gasco (1992), and Morandi (2010). Sample questions for comparative site analysis included: What is the spatial patterning of the ceramics in the Hacienda Pancota assemblage as compared to other sites? Which ceramic types occur together? In what proportions did they occur together? Are there significant differences/similarities in the spatial patterning of artifacts in relation to the household? 4) Does the possession and trade of contraband ceramics say anything about domination, resistance, or agency at the household or community level? Dawdy (2008) 
suggested that such things were simply part of daily life, even encouraged by some colonial powers. Does this assemblage suggest open display, like serving wares, or more personal artifacts (shown by artifact size and or location) used as part of a personal rebellion? 5) What does the general daily consumption pattern suggest about the lifestyle of Hacienda Pancota residents?

\section{A Brief Understanding of Mesoamerica}

People of Mesoamerica have an exceptionally long history with agricultural farming and the domestication of plants. Communal approaches in farming aided in the growth and development of society. Historically, Mesoamerican productive agriculture influenced the local economy, in turn influencing regional trade networks and the spread of ideas. Mesoamericans mainly used slash and burn techniques, but irrigated fields when necessary for more populous cities. Modern day corn traces its roots back to Zea mays around 5,000bp (Pope et al. 2001). Central Mexicans and Maya groups most famously grew maize, beans, and squash. Dog, peccary, and turkey were domesticated proteins Mesoamericans consumed (MacLeod 1979). They diversified their diet by adding cacao

drinks, fruit, and domesticated animals (MacLeod 1979). They raised bees for honey and milled corn into flour for tortillas defining their culture as remarkably industrious (MacLeod 1979). From thousands of years of society developing into the great complex cities of the Preclassic to the Late Classic period, Mesoamerica has yielded profound specialization of a workforce to produce such vast political, religious, and social organization.

After large population declines after the Terminal Classic period, Postclassic Maya peoples increased in population and resettled to new urban populations with 
complex social hierarchies and decentralized political economies (Fox 2008; Freidel and Masson 2002; Wonderley 1985). Postclassic Mesoamerican peoples heavily populated large Yucatecan lowland cities, such as the well known Mayapán. An increased diversity of new trade commodities and interaction with central Mexican cultures defined much of a complicated and important Maya period.

At the beginning of the sixteenth century, Spanish conquistadors encountered a greatly populated and organized region in the process of environmental adaptation and political reshaping. No longer flourishing Classic period cities, monumental architecture laid dormant in much of the central lowlands, though an increase in massive architecture still existed in the highlands. Mesoamericans were already well suited at adaptation processes from much of their prehistory and most recent Postclassic shift. The first Spanish conquistadors became yet another dominating variable by which indigenous peoples altered their production and consumption patterns. Warfare, trade, disease, and an exchange of ideas were external oppressive variables aiding the indigenous peoples of Mesoamerica to adapt to different survival methods. These methods both preserved their profound history and implemented new tactics to counter, understand, and internalize European influence.

\section{Historical Settlement Patterns and Reducción Policies}

1502 was the year mainland Mesoamericans first encountered Europeans. In the midst of the contact period, establishing order required the systematic organization, symmetry, and power of revivalist ideas stemming from the European Renaissance. The Spanish government believed indigenous Central and South American communities reflected outdated medieval European society. Spanish authorities desired to alter 
landscapes—physical, social, and mental—in order to achieve economic and religious control (Johnson 2006).

For this research, historic period consumption and settlement patterns in Mesoamerica are critical to understand in order to interpret residents' agency at Hacienda Pancota. Indigenous peoples lived in a variety of places during the contact and early colonial periods. Towns, large villages, and cities existed in early historical Mesoamerica, but according to MacLeod (1979) settlement patterns most often remained as rural and dispersed settlements, small villages, or ranches, rancherías. Organizational levels of communities were much more influenced and limited by political factors, rather than population alone (MacLeod 1979). Other historians argued that Mesoamerican permanent communities consisted of four defined settlements: ciudades (communities with a population that exceed 10,000 people), villas (communities with a population that exceed 5,000 people), pueblos (communities that have a population exceeding 100 people), and rancherías/caseríos (these are settlements with less than 100 people) (Andrews 1981). The aforementioned organizational patterns did not necessarily present a fluid transition for the Spanish to control lifeways, ideologies, and probably most important, production. To better increase output from a population deemed unorganized and sometimes unruly, Indians were forcibly resettled into locations with better Spanish control, called congregaciónes. Through reducción policies first implemented by the Spanish Crown in the early 1540s, indigenous peoples would thus become more civilized, better workers, and follow Christ. Reorganizing people and reducing their agency was thought to aid in their Christianizing and simplification of lifeways, more easily controlled by the Spanish. Hanks (2010) argued reducción was a culture-altering project. 
It systematically and aggressively coordinated transformations of space, conduct, and language (Hanks 2010).

According to MacLeod (1979:122), Indians made three distinct reactions to reducción policies being thrust upon them: they either moved willingly, others moved reluctantly after coaxing or persuasion which was likely the lure of a better life, and some resisted until coerced. Although lawful reducción policies were officially ended by the Spanish Crown's orders in 1550, they were renewed throughout the early eighteenth century, spreading their social and cultural impact throughout historical colonial and Republican Mesoamerican periods (Dym 2006:39).

\section{Western El Salvador and the Izalcos Pipil}

The Izalcos Pipil had their largest settlements in the Río Ceniza Valley of western El Salvador. According to Sampeck (2007:2), the Pipil were "major participants in shaping the political economy of the fifteenth-century Aztec empire and the sixteenthcentury Spanish colonial empire." This was due to the way in which the Pipil controlled land. They pinpointed key nodes of terrestrial trade routes in Guatemala and central and western El Salvador (Earnest 1999; Sampeck 2007:83-85). The Pipil were already integral components in a pre-Columbian economic system, built by cacao production and trade. The pre-colonial and colonial Pipil have seen much less archaeological attention by modern scholars when compared to their northern kin, the widely researched Aztecs (see Fowler 1989; Fowler and Earnest 1985; Lothrop 1927, 1939; Sol 1929; Thompson 1943, 1948).

According to Fowler (1989, in Sampeck 2007:7), the Pipil first arrived in modern day El Salvador by the Early Postclassic period. They were powerful as a pre-colonial 
state, attributing to what was likely heavy involvement in the cacao trade (Sampeck 2007:7). During Spanish contact and the early colonial period, Salvadoran Pipil lived near coastal and southeastern Guatemala and covered all of El Salvador (Fowler 1985:38).

"[C]acao functioned as a kind of money in the prehispanic and posthispanic economy" for the Pipil (Sampeck 2007:7). This value system contributed to a frame of reference for future capitalist systems employed later by the Spanish colonists. This fruitful and mountainous homeland of the Pipil was coveted by the imperialistic Spanish colonial empire for its prized economic potential. El Salvador further provided port accessibility by way of Acajutla on the southwestern coast (Sampeck 2007:2).

Mesoamerica's history is undoubtedly complex, lending itself to a diverse array of interpretations from archaeologists and historians alike. This brief summary foreshadows the incredible scale of the natural and cultural environment that was focused into a smaller study sample: Hacienda Pancota. The research provided by this thesis offers insight into a sliver of human history reflecting larger social mechanisms and settlement patterns throughout the New World. These reflections were not interpreted as results of early modern period European factors described in the next chapter, but rather as a household's series of complex adaptations and adjustments to an increasingly European presence. 


\section{CHAPTER II}

\section{THE EARLY MODERN PERIOD IN THE SPANISH \\ OLD AND NEW WORLDS}

\section{The Early Modern Period Setting}

The European early modern period is most accurately associated with war, imperial expansion, and the growing outreach of modern capitalism. This period also defines the time frame of Hacienda Pancota's main residency. Since the analyzed collection dates primarily to the late sixteenth century and middle seventeenth century, a brief understanding of Europe's political history assists in the context of Hacienda Pancota archaeological material.

During Europe's tenuous period, feudalism begins to be replaced by capitalism in Europe. This transition however was not particularly smooth, especially in Latin America. The topic of whether or not Latin America was ever capitalist or always capitalist is argued by advocates of both the left and right (Laclau 1971). Mercantilism, an economic theory driven by military control of local and foreign land, raw materials, trade, and production, was the driving social force of major European countries. Catholic, Protestant, and Muslim religious ideals were in the midst of being redefined, as impacted by political ideologies and colonial expansion. This important period of time dates approximately from 1492-1800 in Europe. Early modern Europe marks the end of the Crusades and the late medieval period. Spain's almost 800 year reconquista was 
politically resolved by the signing of the Treaty of Granada in 1492 (Thomas 2010). This period defines the European Renaissance and planted the seed of the Enlightenment during its end. Factors of societal change defined by capitalist European states, technological innovations, and a reexamination of biblical literature drove much of the ideologies Europeans attempted to implement across the New World and its people (Kamen 2000; Thomas 2010).

After Columbus' great rediscovery of the Americas, the Spanish Empire decided to spread its imperialist fingers over much of the New World. Their political and warring endeavors stretched throughout the Caribbean, Central America, and South America. They were also active over a wide swath through southern North America. Exploration resulted in failed attempts and expensive endeavors. Some of these early Spanish explorers of North America were Ponce de León (1521), Lucas Vásquez de Ayllón (1526), Pánfilo de Narváez (1528), and Tristán de Luna y Arellano (1559-1560). Pedro Menéndez de Avilés was the founder of St. Augustine (Florida) and Santa Elena (South Carolina) in 1565. King Philip II financially invested in the fortification of the two sites, so further North American conquering could occur (Beck et al. 2011).

The Spanish Empire played a particularly significant role in the early modern period of Europe. During this time, Spain had enveloped itself in war. Expensive military endeavors both local and abroad ravished the Spanish economy from the fifteenth- to seventeenth-centuries. The country had more foes than friends and as a climax, King Philip II in 1596 bankrupted Spain (Allen 2000). Philip II's reign could be defined by two outstretching and ambitious goals: the defense of Catholicism in Europe and the defense of the Spanish monopoly in the New World. (Allen 2000:1) Due to ongoing wars, Spain 
was losing money throughout the late sixteenth- and early seventeenth-centuries. King Philip II financed wars both abroad and domestically — in the New World and the Low Countries (modern day Netherlands and Belgium). As material assemblages will later reflect, the story of Spain stretching itself too thin politically defined problems for residents in the New World.

Philip III took the Spanish throne in 1598 after the death of his father. Allen (2000:4) argued that Philip III undoubtedly took a less active part in the foreign-policy decision-making process than his father, yet established a much more important role in internationally through diplomats, governors, and trade policy. Philip III attempted to continue a previously stated no-trade agreement with England to Spanish New World colonies. As a solution to seemingly everything, Philip III paid war reparations to the English in order to secure the trade blocking deal, that only would encourage later contraband trade, piracy, and privateering (Allen 2000). There was an almost endless supply of money pouring out of the Caribbean and later Peru. The Spanish empire was fragmented, but its financial potential enticed government officials and the royal family to jockey for power positions throughout the early modern period (Allen 2000).

During the late sixteenth century and early seventeenth century, the Dutch were primarily interested in securing salt resources from the Caribbean. Philip III and his military advisors attempted to ensure that blocking their access to salt would prove useful as a later bargaining strategy (Allen 2000:56). While domestic war and the sacking of Spanish ships still raged between Spain and England, the Dutch wanted to ensure they remained enemies in order to wear the Spanish down long enough and force them to pull away from the Caribbean. This triangle of thievery, financial booms and busts, and 
bloodshed continued for the duration of the early modern period. The following section provides to some of the details in the New World, during a constant reorganizing of resources.

Piracy, Privateering, and Tension in the West Indies

The early modern period Spanish Empire had a powerful navy, seeking a sea route to spices in the east as well as initiating cross continental economic endeavors in Africa. Along the Barbary Coast, the Spanish Empire sought gold, ivory, slaves, and pepper (Lane 1998:11). This theme of seeking new power, but spreading the Empire too thin became a prevalent reoccurrence throughout colonization in the Americas, as well as previously mentioned as a domestic Spanish theme. The landmass of the Americas and Caribbean islands were too large to colonize easily and left many towns vulnerable to attack. Most cities occupied by the Spanish during the contact period could be better classified as small pueblos or rancherías, with populations less than 1,000 residents (Lane 1998:27; MacLeod 1979).

Lane (1998) stated that piracy and privateering are roughly the same words, and only differ in that privateering is an officially sanctioned activity. It was an activity carried out in a time of war, so it can contribute to the net of government income. However, a fine line separates the two and both are serious acts of aggression and result in displaced peoples and militarily driven settlement patterns. To understand the Caribbean and coastal towns of Central America during the contact and early colonial period, one has to become acquainted with the idea of controlled chaos (Lane 1998). That is to say, enemy states would occasionally join together to decimate a mutual adversary. Great enemies, like France and England and the Dutch and English before, united 
together against Spain in order to gain access to new profits. These imperial countries had common goals, but looting, killing, and the constant shifting of property rights made the landscape extremely volatile.

Spain was already familiar with piracy when Columbus discovered the New World. They dealt with economically draining endeavors in the Mediterranean and Northern Europe throughout the early modern period, losing much land (Lane 1998:12). In Spanish America, the French were the first bandits, fighting Spain from roughly 1530 to 1560 (Lane 1998:13). Spain began transporting goods to and from the New World in feeble ships, routinely falling prey to French pirates. From the combination of treasures recovered in Mexico by the conquistador Cortés and other delicacies from Caribbean islands, like Hispañola, Cubagua, and Margarita, ships were tempting to hungry pirates (Lane 1998:18). In response the French pirates attacking treasure ships leaving the New World, Spain decided it would be to their advantage to create armored ships. These armored ships traveled in convoys, or a flota, as early as 1552 (Lane 1998:18).

Spain took its New World settlements as an opportunity to learn military defensive techniques against its rivals. For example, it proved to be a far better strategy to abandon coastal sites subject to attack and retreat to more protected areas farther inland (Lane 1998:26). In the case of seventeenth-century Panama Vieja, attacks by the English forced its abandonment and immediate relocation from the Pacific coast, further west to inland Panama as a defensive strategy (Castillero 1994; Rovira 2001). Those critically important port cities that needed to remain near the coast defended themselves by constructing military forts, stone walls and increasing their ammunition supply (Pons 2007:26-40). This pattern was reinforced as Spanish and criollo population declined in 
coastal walled cities such as Trujillo, Honduras (Chamberlain 1966). Rebuilding cities, fortifying walls, and using heavy weaponry was too costly for Spanish Empire to keep pouring money into its New World colonial cities.

Lane (1998) synthesized a theme of community built out of the potential threats of piracy for people living in coastal cities. First, Spanish coastal cities were populated with anyone they could get to live in such a place. Spanish officials would entice people to move to knowingly dangerous places, just so they could keep a population around when the English, French, or Dutch aggressively stopped by. These cities were also filled with some of the worst criminals and poverty stricken drunks. Later, the government required African slaves to move to these cities in order to increase safety (Lane 1998). Realizing their homes could be looted and they family destroyed, a certain theme of local power and self-reliance started to develop during the contact period. If taken one step further and applied inland, this new development of community constructed out of fear, strengthened and organized town life quickly and efficiently in the communal relationships created among indigenous peoples living in coastal congregaciones.

The African slave trade throughout the Spanish colonies succeeded in promoting the circumvention of Spanish law and bureaucracy. By the middle eighteenth century, a demand to legally enter New World markets by government backed English merchants was so high that the pressure escalated to a series of battles resulting in the War of Jenkins' Ear (Woodfine 1998). Lane (1998) defined this as the "early modern spirit of enterprise" that would evidence itself throughout the remainder of the colonial period in various forms of illegal activity supplementing a broken economic system. Contraband merchants, like the Englishman John Hawkins, offered options beyond Spanish 
government and monopolists from Seville and Lisbon in the eighteenth century, creating demand for New World goods (Lane 1998:35).

\section{The Manila-Acapulco Galleons and the Spanish House of Trade}

Before contraband ceramics can be discussed effectively in their archaeological context in western El Salvador, it is necessary to understand the political implications behind the contraband nature of some archaeological materials. The multifaceted definition of contraband pottery in an archaeological context invokes a variety of possibilities for its acquisition and daily uses (Dawdy 2008; Deagan 2011; Mack 1998). Pottery was not the only item traded in the trans-Atlantic exchange, but it will be the focus of this research. The year 1580 was simultaneously the climax of the cacao trade in the Izalcos region and the creation of the Spanish-Manila Galleon trade (Sampeck 2007:530). The Manila-Acapulco galleon trade was a prodigious economic endeavor consisting of both transport and war ship fleets making predetermined stops. The routes used for navigating the seas from the American ports to Guam to Manila, Philippines solidified a routine of overseas investment.

Seville, Spain has a long history of being a world producer of agricultural products like olive oil, wine, and wheat trading to places like London, Flanders, and Genoa. This would suggest that Spain was quite familiar with international trade before the discovery of the New World (Fish 2011). Trade with some of the Spanish colonies included more than agricultural products. Items such as ceramics, furniture, portable altars, clothing, and other various household items made their way to some homes in the New World (Fish 2011). Spanish galleons carrying such necessities only traveled to their 
colonies once a year over a 40 day journey during the first few years of the early colonial period. Trips increased in annual frequency later into the colonial period (Fish 2011:28). Out of Seville, Spain a bureaucratic body named the Casa de Contratación, the House of Trade, controlled both Atlantic and Pacific traveling galleons. A powerful executive body, the House of Trade was established by Queen Isabella on February 14, 1503 (Fish 2011:18-25). The body was primarily established to control the complicated nature of overseas "commercial activities with[in] the colonies." (Fish 2011:25) A testament to its political power, the House was further recognized as an independent entity capable of working beyond tax and revenue control. The main responsibilities of the House of Trade were "the management of the direct trade with the settlements in the Americas; the organization and selection of vessels involved in this trade and sailing the colonies: the control of immigration of individuals." (Fish 2011:25) The powerful body was finally eliminated in 1790 as part of the Bourbon reforms as Spain's colonies strove to become more independent from the mother country (Fish 2011:26).

Such a large body of government, Spain's House of Trade delegated bookkeeping responsibilities to a secondary government institution - the Council of the Indies. According to Fish (2011:27) the Council was a Spanish institution responsible for maintaining "records on the commercial trade with the Indies and a registry of Spanish merchants in Spain who were involved in this activity." Furthermore, the Council would thus be deemed an important body necessary to keep trade activity legal. Recording which ships traveled to what ports mimicked the tight grasp of control Spain wanted over its New World colonies. 
After 1526, all vessels traveling from Spain to the New World were supposed to be accompanied by warships adding protection to the merchant ships and increasing the Manila Galleon fleets. This treacherous route navigated by the Spanish galleons was called the Carrera de Indias, or the Indies Road (Fish 2011:20). However, from Manila to the New World, merchant vessels were outfitted with warship attributes and traveled unaccompanied, suggesting less governmental supervision and were easy prey to contraband raiders (Fish 2011:30). Ships arriving in Manila from the Spanish colonies brought gold and silver as a trade payment for a wide variety of Asian goods that later became luxuries in the wider global economy. Commodities like silk, jade, sandalwood, and sapphires from the China area; cutlery and furniture from Japan; cloves, cinnamon, pepper, and camphor from Indonesia; dyewoods, hides, hemp, copper, and coconut products from the Philippines; and pearls, diamonds, topaz, carved ivory, and cotton goods from India all helped fuel European capitalism (Skowronek 1998). These goods part of an increasingly complex global exchange diversified economies and added pressure of competition. Trade with new areas in the Latin world opened, while landowners competed for labor and access to transportation.

According to Deagan (2011:172-173), imported goods entered the Spanish colonies legally in four different ways: through the situado; slave trade ships; Spanish licensed privateer ships; and special dispensation. Deagan (2011:171) suggested that contraband ceramics—including Chinese porcelain —-was not considered illegal until the creation of the Casa de Contratación in 1503. However, in Spanish colonies like Guatemala and Peru, contraband ceramics were undoubtedly illegal in the early 1580 s. Royal edicts made intercolonial trade illegal and established Acapulco as the only legal 
port. Because of the abundance of Oriental goods in the region and reports of ships stopping to offload cargo, we are fairly certain much of these goods must have been acquired through illegal trade via Acajutla (Deagan 2011; Sampeck 2007).

\section{Ceramic History in the Early Modern Spanish New World}

According to Lister and Lister (1978), residents living during the beginning quarter of the Spanish occupation in Mexico acquired little wealth compared to later generations. Most of their finer goods were supplemented from what little they received overseas, shipped from larger Caribbean centers like Santo Domingo or Havana, and by pilfering natives' wealth (Lister and Lister 1978). Residents' desire for ceramics mimicked this type of accumulation. They were only able to receive minimal amounts of domestic pottery from Spain, while much of it had to be made regionally during the early sixteenth century. Indians were already skilled at making pottery, although its application and durability did not particularly satisfy the European market in the New World (Kuwayama 1997). Tin glazed earthenwares were not immediately available during the initial conquest period, leaving a gap to be filled by new competition. After the early period of the initial contact and the establishment of large central American cities or pottery centers, Indian potters became skilled in ceramic techniques of glaze and paste from a Spanish technology (Lister and Lister 1978).

A newly founded and high demand for finely made, but domestic pottery was created by the early middle of the sixteenth century. This attracted skilled craftsman from Europe, specifically Italian potters who both manufactured and taught pottery making to locals in Sevilla (Lister and Lister 1978). Demand for more finely crafted pottery increased as the urban economies grew. The second and third generation Europeans 
became richer from investments in mining and large scale ranching and farming (Lister and Lister 1978). Finely made Mexican majolicas had become quite popular, allowing multiple New World styles to emerge influenced by a variety of potters throughout western Europe. These new styles also reflected an increasingly diverse social strata. Mexican majolicas were produced to suit the cultural needs of high and low classes, with levels in between (Lister and Lister 1978).

By the later portion of the sixteenth century, the New World market was already inundated with Mexican-made majolica, allowing many frontier settlements to acquire more imported pottery (Lister and Lister 1978). Hacienda Pancota's totality of imported European and Oriental tradition wares indicates its residents' level of accessibility and agency. The comparatively low, but present values of imported ceramics indicated that activities inside the household structures reflect larger ideas concerning production and usage of imported goods. Household structures were their own microeconomies, contributing to the demand of pottery and feeding early colonial workforces.

\section{Chinese Porcelain in Early Colonial Latin America}

With Manila, Philippines acting as the primary port and colony for Spanish trade in the east during the Early Colonial Period, most exported porcelain ceramics originated from China and made their way south to the Philippines. In particular, southeastern China was the specific region from which the rest of the world received their porcelain. Ceramics entering the New World usually originated from one of four locations in southeastern China: Jíngdezhen, Fujian, Zhejiang, and the Guangdong provinces (Kuwayama 1997:15). 
China has a long history of trading ceramics dating to as early as the ninth century (Kuwayama 1997). Later, around 1100 CE there was a progression of selling ceramic wares from local consumers to Muslim traders to a more global market by the sixteenth century. Beginning in the 14th century, Jíngdezhen, in the Jiangxi province of China became the "main ceramic center of China" due to an abundance of workable clay, according to Kuwayama (1997:14). The Jíngdezhen clay raw material would transform into the highly desired exported porcelains shipping out of Manila in the sixteenth and seventeenth centuries. This porcelain trade was most intense during the late Ming Dynasty, dating from 1550 - 1650. In the seventeenth century Chinese artisans began arriving in Mexico City to work (Fish 2011:39). Their residence in Mexico City possibly influenced the production and manufacturing of Chinese influenced goods throughout the Spanish colonies.

With the establishment of the Manila Galleon trade, European and New World consumers' familiarity with Chinese-Spanish ceramic motif preferences in China changed, to better suit client demand (Kuwayama 1997). Tailoring to Spanish demand, Chinese porcelains were artistically decorated with gold or silver, that strayed away from traditional motifs in order to entice more European merchants (Clunas 1991). This strategy helped further define the imported porcelain market for the New World (Clunas 1991; Kuwayama 1997:15). A variety of colors other than porcelain's standard blue and white became popular with increased Spanish trade. For example, red and green embellished enamels rose to popularity toward the end of the sixteenth century and into the seventeenth century (Kuwayama 1997:15), which is seen archaeologically in Central America, South America, and Europe. 
Although Chinese porcelain is the primary focus of contraband investigation in this research, other forms of imported pottery like Spanish majolica and equally illegal Peruvian botijas were analyzed.

\section{Evidence of Exchange Relationships}

Spain and Mesoamerica both have an extensive history with the long-distance exchange of goods (Gasco 2005:91). With their exotic commodities, the Manila Galleon trades thus easily fit into the lifestyle of both native and colonizing groups throughout this part of the Spanish colonies. Chinese porcelains and a wide variety of other imported commodities became integrated into the Spanish colonies. With the discovery of a suitable westerly sea route by Andrés de Urdaneta in 1565, the Manila Galleons traveled to and from Acapulco to Manila (Van Tilburg 2007). When arrived in Acapulco, goods were sent across land to Vera Cruz in order to make their final destination to Spain. Eventually, this led to many inland frontiers accumulating imported European and Oriental goods more easily. Lister and Lister (1978) argued that by the beginning of the seventeenth century, many Central American markets were saturated with lesser quality Oriental porcelains and Mexican made majolicas. The most common vessel forms were small teacups and rice bowls (Lister and Lister 1978). What has not been explicitly investigated is how these global exchanges operated at the level of a single household. The complete excavations of Hacienda Pancota's late sixteenth-to mid-seventeenthcentury domestic structures present a rare opportunity to examine this question. 
Archaeology of Contraband Trade in the New World

Forbidden from trading with other countries, the Spanish colonies were under strict political and economic control by the Spanish crown during colonial rule (Cohen 2003; Macleod 1973). Such social control has the potential for leading to forms of resistance, detectable archaeologically. Oftentimes the tension between newly founded social hierarchies purely based on wealth "foster[ed] a culture of violence." (Dawdy 2008:217-218) Wealth disparities affected populations coerced to work under them. Systems of control and their moneyed hierarchies demand a workforce, the movement of peoples, and ultimately the ruination of lower class families. Deagan (2011:170) argued that Spain sought strict economic control over its colonies in order to maintain "economic strength and self-sufficiency." This however tended to lead to resistance by people seeking social and economic autonomy. According to Dawdy (2008:226) the strict policies put in place by trade governing bodies throughout the New World helped "spur contraband trade as a means of survival." In fact, illegal trade among New World colonies not only provided means for economic freedom and survival, but contributed greatly to a growing cultural network of peoples (Dawdy 2008:226).

Deagan (2011:170) further contended that Spain's colonial economic policies forced subversive activity to become integrated in daily routine of the New World. Here, Deagan (2011:170) argued "Spain was consistently unable to provide the manufacturing needed by American colonists, so residents...turned to illegal trade with foreigners to survive." This economic action produced colonial residents with levels of resistance against the Spanish crown, allowing complex levels of cultural communication and selfawareness to thrive during the colonial period. Similarly, in the eighteenth century French 
colony of New Orleans, illegal trade blossomed when government officials failed to recognize the power of local elite and local economic interests (Dawdy 2008:221). Much like Spanish New World colonies, New Orleans did not necessarily abide by French law dictated from across thousands of miles of ocean. Laws being implemented in the New World were thus subject to being flexible, rejecting the static nature of the law's creators in Europe (Dawdy 2008:193). Experimentation with the law took place, pushing and searching for new social boundaries, simultaneously reinforcing existing social hierarchies and destroying others.

Lane (1998) researched the fascinating history of piracy throughout the Americas from the contact period into the eighteenth century. His research surrounds the Spanish Empire and their own acts of piracy/privateering, along with other major players such as the Portuguese, French, English, and Dutch. By the end of the age of piracy in the Americas, Lane (1998:4) argued that the Spanish Empire's finances suffered incredibly. Although not chronologically distinct, French Huguenots first provided problems for the Spanish, followed by Elizabethan period English pirates, and finally Dutch buccaneers (Lane 1998:51). In the early seventeenth century, Spain could no longer enforce the law, so the Spanish state relied on two tactics to keep illegal activities—-piracy and contrabanding — from getting out of hand. Spain shifted its governing abroad approaches from more casual to one that quite profoundly sponsored its colonists in New World terrorist activities (Lane 1998:65). Furthermore, the Spanish government used tactics to solicit information from Indians. Better understanding the terrain or any information regarding the whereabouts of enemy parts and their intent was paid for by the Spanish government (Lane 1998). Lane further argued that these information gathering techniques 
further "sew[ed] seeds of distrust" within many New World residents. The effects would eventually undermine the power and authority of the Spanish crown throughout the colonial period, lending to increased levels of distrust of Spanish policies and integrated cohesion (Lane 1998:66).

Contraband trade is detectable archaeologically as a formation of colonial experiences. Not solely a form of illicit behavior, engaging in illegal smuggling activities provided numerous avenues to allow residents a chance for autonomous behavior. Contrabanding helped confirm, reinforce, and or subvert social hierarchies.

\section{Illicit Activity Represented by Contraband Ceramics}

Deagan (2011:169) defined contraband material culture as the "smuggling and piracy as forms of illicit commerce concerned with the acquisition and exchange of goods." In Deagan's (2011:184) study of early colonial Spanish Florida, she concluded that roles of contraband tableware played varying roles depending on a household's factors of economic income, lineage, attitudinal values, and factors of local social hierarchies defined as "relative positions of social privilege." Deagan's attitudinal values can be described as the people of the household's values - their internal perspective of self, family, and of society. Furthermore in her study, Deagan (2011:176) was able to analyze temporal quantities of contraband ceramics due to a large sample size consisting of 124 undisturbed features from 6 different domestic sites. The collection totaled 5,051 ceramic tableware artifacts. A comparatively large sample size such as this allowed Deagan (2011) to investigate St. Augustine's eighteenth century household resident's income, ethnic origin, and occupation. 
Researchers argued that part of the reason New World residents took part in illicit activity was because the Spanish Empire either would or could not support its colonists (Cohen 2003; Deagan 2011; Mack 1998). Furthermore, the smuggling and the incorporation of contraband was seen throughout colonies in the Americas, though this often tends to be geographically site specific. With only minor exceptions, such as Mexico City (Lister and Lister 1982), a more consistent presence of illegally imported contraband is recovered archaeologically in urban and port periphery sites (see, Deagan 1978; Gasco 1992; Sampeck 2007). Dawdy (2008) contended that smuggling supported many local political economies and was a licit experience in French colonial Louisiana, whereas Spanish colonial rules were much more restrictive of the practice. Dawdy (2008) further stated that countries like, France, the United Kingdom, and Spain never managed to control contraband and it thus managed to become an integral part in the colonial communities.

Both Dawdy (2008) and Deagan (2011) concluded that the smuggling of illicit contraband supplemented colonists with necessary provisions, possibly aiding struggling local economies. Skowronek (1998) however, argued the presence of contrabandspecifically ceramics — had more social importance. Throughout the Spanish colonies, Chinese porcelains were ubiquitous, suggesting less economic importance but still used to mark status (Skowronek 1998). Regardless, contraband trading was an activity almost impossible to control, letting people get access to wide variety of material culture. This increased access to imported goods reflects agency in the early colonial period. It is expressed throughout Hacienda Pancota and other households during this period. 


\section{CHAPTER III \\ REVIEW OF ARCHAEOLOGICAL INVESTIGATIONS INTO \\ DOMESTIC LIFE AND CONSUMPTION}

\section{The Archaeology of Haciendas}

Since Hacienda Pancota is a special kind of setting that requires the careful explanation of social structures with its material culture assemblage, the following section pulls together both archaeological and historical sources defining a wide ranging spectrum of place and space known as the hacienda.

According to Tutino (1975:496), a Spanish hacienda is the crossroad of indigenous resistance and Spanish power. This special place comprised of a location where market driven agriculture formed a combination of both a resident and rural workforce (Kicza 1985). It was a place where people lived and worked, consuming and producing under a capitalist system and hierarchical power structure. In the beginning of its tenure, haciendas connected two specific and complex types of people: urban Spanish elite and rural indigenous peoples. Over time and generations, the urban Spanish elite became rural landed elite while rural indigenous peoples were urged into Ladinized lifeways and cultural diversity (MacLeod 1979). Haciendas employed and organized rural peoples while simultaneously supplying workers and communities with surplus grains for an often unfair and non-negotiable fee (Tutino 1975:498-501). The style of 
workforce management at haciendas inhibited economic independence and commercial potential for native economies to compete with Spanish economies (Grieshaber 1979:124). This led to underground and subversive behavior to become a necessity for residents of an early colonial hacienda. Contemporaneously with another structure of the Spanish socioeconomics, the encomienda system, the hacienda's function was both necessary and paternalistic with the rise of centralized urban populations. This system was critical for providing an essential economic link in early colonial social hierarchies (MacLeod 1979; Meyers 1998). Likewise, haciendas emphasized paternalistic relations through their social control structure, the adoption of a set rules, and support system for many indigenous peoples looking for post reduccion support. Adding to the intent of reduccion, the "pacification, conversion, [and] ordering" of indigenous peoples (Hanks 2010:xic), the Spanish hacienda provided spiritual guidance as well as social order within the Spanish colonial system.

Haciendas were both centers of residence and places for work, but usually less specialized as most definitions suggest. Although not true of all haciendas, Tutino (1975:502) argued they often comprised of four divided sections necessary for agricultural success: irrigated wheat fields, non-irrigated corn and barley fields, livestock pastures, and a forested section exploited for lumber and firewood. Haciendas in fact varied in their products and responded to market forces over time.

Although Tutino (1975) and Grieshaber (1979) define Mesoamerican haciendas a particularly oppressive and static system, Alexander $(2004,2005)$ demonstrated the tremendous variation in early and late colonial hacienda spatial and social organization. She contended they were directly reactive to the stabilization of central governments. 
MacLeod (1979) further argued they reflected boom and bust cycles of the overall agricultural industry through most the sixteenth-, seventeenth, and eighteenth-centuries. Production and consumption levels at haciendas were in a constant state of fluctuation as both on-site and off-site power structures became increasingly and decreasingly powerful (Alexander 2004, 2005).

The colonial Latin American hacienda consisted of varying levels of an hierarchical structure, potentially capable but not always successful in acculturating indigenous peoples unidirectionally towards Spanish culture. Hacienda hierarchical structures centered around the transference of wealth through power tactics. Such structures and groups included nonresident landed elite controlling the hacienda economy, estate administrators, religious affiliated persons and priests, village leaders, and indigenous workers (Tutino 1975:496).

Grieshaber (1979:107) argued the colonial hacienda did not always destroy indigenous peoples' culture, and could even enforce native ways of life during the early colonial period. For instance, if the hacienda was located in an area far removed from a densely populated Spanish urban center, rich with indigenous people and did not provide surplus products deemed important by a European market force, than the hacienda likely reinforced native traditions (Grieshaber 1979:107-108). Similar to Grieshaber's interpretation, the Izalcos region Hacienda Pancota evidenced reinforcement of native traditions but within a nonresident dictated hacienda sense of place. Cacao was likely the primary product commoditized and exported at Hacienda Pancota, connecting more intimately to a fluid, world economic system. This was achieved by an organized workforce with dedicated space for individual household activities and farming tasks. 
Defined spaces at haciendas are not always created by residents, in some cases controlled and reinforced by property managing elites or even nonresident urban elites from nearby cities.

Household Archaeology

Since this study focuses on daily consumption at the household level of the early colonial hacienda, it is necessary to further define the context of their location and discuss some of the more prominent research in this particular subfield. The function of the household is important for understanding larger issues of economic and sociocultural roles in the community. Rathje and Wilk (1982:621) asserted that the different types of functions a household performs are represented by varying size, organization, and developmental cycle cross-culturally. The main functions of the household are social and economic production, distribution, transmission, and reproduction. The household is a "unit of economic and social cooperation" that is not necessarily one complete structure (Rathje and Wilk 1986:621). In other words, the household is potentially more than a single building, but rather is the amalgamation of infrastructure and superstructure that encompasses a small-scale economy that potentially affects a larger area.

The material culture recovered at Hacienda Pancota relates to domestic function at a household scale. A household is classically defined as "people living in a house; the maintenance of that establishment; and all the goods and furniture found in it." (Allison 1998:16) Perhaps even more importantly for a Marxian study, a household concerns people and activities contributing to some level of production at the domestic level. With production in mind, the household should be examined as a task focused group (Wilk and Rathje 1982:114), producing and performing tasks contributing to the overall labor of 
house, community, and larger economies (Silliman 2001). Allison (1998) argued for archaeologists to be aware of the problems associated with interpreting the physical structure of the household as directly representative of the behavior of the people who inhabited them. She further stated that archaeologically, they can only tell you the cultural patterning of space (Allison 1998:17). The task at hand then becomes to analyze what this cultural patterning of space does the rest of the material culture influenced by the household (see also, Adams 1990; Balée 1998; Crumley and Marquardt 1990; Erickson 2010; Denevan 1992; Glassie 1972; Groover 2004; King 1984; Leone et al. 2005; Little 1998; Mrozowski 2001; Rotman and Nassaney 1997; Wernke 2008). Lockhart (1992:60) argued that the pre-Columbian Nahua family household, or chan, was likely the repository of an assortment of holy objects relating to community ancestors, lands, and possessions of relatives. Into the contact period, the Nahua patio group was organized with cardinal directions a priority, suggesting the importance of place. Multiple Nahua often communally owned more than one house. Around a central household complex, multiple family members owned and lived in separate buildings, likely dividing duties amongst themselves. It was not uncommon for a business or small store to be run out of the household complex, producing for the family unit (Lockhart 1992:67). Single family households did however exist, and were common amongst the multiple family household complexes.

All types of artifacts help define space, further defining the household and all its associated activity. Rappaport (1990) used nonverbal communicators to discuss this human occupied space, which can be defined as any and all types of artifacts. Furthermore, he contested there are designers who create houses and tend to "react to 
environments in perceptual terms" and users who react to environments by association (Rappaport 1990:17). These designers and users are the builders and occupiers, and not always the same person or family. Secondly, not all people have input in the houses they live in, or households in which they produce. Houses could have been built by other community members, family members, older societies (Blanton 1994), or controlled and built by large hacienda owners. Residents of the investigated structures at Hacienda Pancota were likely the designers and occupiers.

Allison (1998:17) argued that to look at the household as a prescriber and dictator of household behavior tends to show bias. This favors the creator of the house and marginalizes others' roles in the home, as well as other activities being performed in the home. The totality of the household is the organization of space, the patterning of use within that space, and how it is internalized and reflected to community members. These differences are only resolved when the concept of the household and its associated material within and outside the physical structure can be analyzed together, regardless of creator and occupier.

According to Hendon (2010), the household has emerged as a central focus of archaeological study beginning in the mid 1980s. She argued that activities associated within the household cannot be assumed - they differ cross-culturally and thus need to be investigated on an individual basis. However, much like Allison (1998), the activities and material culture of the household are not enough to define it. The idea of the household is equally important to an understanding of the household dynamics (Hendon 1996:46). That being said, groups tend to work in patterns, with regard to daily chores or other necessities of the functioning community. People, however, are individuals and have the 
ability to act outside patterned formats (Hendon 1996:46). Furthermore, Hendon asserted that households that look the same and act the same can potentially have very different economic processes (Hendon 1996:46). Households have their own identity, however subtle it may be. The way people act in their domestic life and all the actions that occur within a household are of larger political and economic significance because they are intrinsically connected to the community at large (Hendon 1996:47). She further argued that these actions are based in the larger community and they do not react passively to external changes (Hendon 1996:47). For example, households participate as both consumers and producers, in long distance exchange networks by the existence of exotic or imported material and craft production (Hendon 1996:48). Other than the economic nature of the household, two other areas are examined by Hendon (2010): wealth, and or, status of material culture associated with the household; and ritual life of the household.

Artifacts associated with the household are representative of both the current occupants and the past occupants, less likely from the creators of the physical house structure itself (Allison 1998:17). Although this is more common in prehistoric household analyses, historical construction technologies sometimes incorporate past pottery and material culture. Although Hacienda Pancota's setting is historical, there is still the possibility to witness the generation cycle evidenced archaeologically (Hodder and Cessford 2004) through daily consumption and agency within the household. Although infrequent, results of Hacienda Pancota's midden deposits and construction materials contained pottery diagnostic of the Late Classic and Late Postclassic, evidencing very long-term generation cycles. Smith (1992) argued that the phenomenon attempting to examine only one generation in a household glosses over multiple generations of material 
culture influence within the household's production and consumption routines. As seen at Hacienda Pancota, associated household artifacts are the result of multiple occupations, generations, and influences of earlier peoples and their material culture (Groover 2004; Tourtellot 1988). Even if their association is limited through construction fill acquisition, Late Classic and Late Postclassic sherds exemplify occupation in and around early colonial Hacienda Pancota.

Lastly, Deagan $(2011: 169,1987,1978)$ used a household scale of analysis to reveal how people with specific economic, occupational, religious, ethnic, and social identities engaged in contraband as a social strategy. Much like the main tenet of this research, Deagan argued that archaeological examination at the household scale has the potential to determine the best results on the micro-economic scale, shedding light on larger economic issues. Alexander $(1991,1993,1997)$ used ethnoarchaeological models and Mesoamerican houselot models to understand site structure in colonial Yaxcabá, Yucatán, and Mexico, as well as late pre-Columbian to early historic households. Her research regarding colonial period Mesoamerican households has focused primarily on access to resources and historical ecological approaches (see also, Hayden and Cannon 1984; Manzanilla 1986; Wilk and Ashmore 1988). Other Mesoamerican household studies focus on the organization of space and residential issues of power (Carrasco 1964; Chance 1996, 2000; Evans 2005; Hendon 2004; Hirth and Santley 1993; Lockhart 1992; Offner 1984; Spores and Flannery 2003; Spores and Robles García 2007; Weeks 1988).

The study of both household infrastructure and household superstructure puts daily material consumption into context by examining the internal material goods compared to the larger context of the early colonial world economy. These material 
goods in a household provide the medium for cultural communication to be expressed in multiple social levels. Symbolically, imported technologies and contraband wares act in the extreme forces of total inclusion and total exclusion (Blanton 1994:14). Resulting evidence at Hacienda Pancota demonstrates incorporation of pottery types and activity areas that reflect the larger spaces of the hacienda and social movements within regional pottery use. The household at Hacienda Pancota along with its associated material goods do not exist in isolation. The two identified structures exist as a piece to a larger hacienda production system. The recovered and analyzed pottery assemblages reflect trending and accessible pottery from local and regional potters.

\section{Archaeology at Hacienda Pancota, El Salvador}

Hacienda Pancota was likely one of the first haciendas in western El Salvador (Sampeck 2007:293). According to Sampeck (2007), architecture at Pancota from the López phase, 1500 to 1580 , was visible on the surface with archaeological features “organized into symmetrical pairs" displaying evidence of urban patterning. Later resident occupation in the Marroquín phase, 1580 to 1650, was less extensive and was excavated revealing wall foundations and other features. Sampeck (2007:276) conducted excavations in three parts of Pancota, one of which I focused on from the Marroquín phase (give dates here), or early colonial period. Her work undertook the investigation of changes in domestic architecture and differences in ceremonial and domestic architecture throughout the hacienda and surrounding valley (Sampeck 2007). Excavations on Hacienda Pancota took place in close proximity to a road that led to an indigo obraje, as well as the casco, plantation center. (Sampeck 2007) Both burned and unburned bajareque remains were recovered, as well as postmolds and more permanent stone 
architectural features giving insight into the spatial patterning of a likely two part household structure on the hacienda (Sampeck 2007:293-297). Lead-glazed redware, Chinese Kraak porcelain, indigenous unglazed coarse earthenware, metal fragments, glass sherds, obsidian flakes and blades, and a single circular mano comprised the assemblage recovered from Sampeck's excavation in 1995.

During the early colonial period, archaeological investigation suggests that Ming dynasty porcelain and imported tin-glazed redware from neighboring Mexico were part of the European tradition and imported pottery technologies associated with the structure (Sampeck 2007:343). Although they are evident, imported wares were drastically overshadowed in the quantity of regionally produced unglazed earthenwares. Lug handled basins, imported botijas, comales, water bottles, jars, and shallow bowls dominated this period's vessel forms in western El Salvador (Sampeck 2007:343). Furthermore, Sampeck (2007:297) postulated that residents of the Marroquín phase at Hacienda Pancota might not have been Pipil peoples, but Spanish or mestizo, adding to the complexity and importance of analysis.

Excavations comprised of seven test pits in and around two separate structures dating through both the López and Marroquín phases. The hard work recovered 1043 artifacts associated with the two structures.

\section{Description of Vessel Forms at Hacienda Pancota}

Early colonial vessel forms were defined primarily by Gasco (1992), Lister and Lister (1976, 1978), and Sampeck (2007). Interpreting vessel form aided in determining activity use within the structures at Hacienda Pancota. It further allowed the diversity of activities to be elaborated and put into context within their immediate environment at the 
hacienda. It was then possible to view vessel form at Hacienda Pancota as a necessary element to understanding production and consumption patterns and how they relate to the complexities of the early colonial period. Vessels were categorized into three primary categories: Storage, preparation/cooking, and serving. All vessel storage data is reflected by these groups.

\section{Indigenous Tradition Storage Vessel Forms}

Neckless jars, or tecomates, are known throughout the region's prehistory, from the Preclassic through the Late Postclassic and into the early colonial period. Though it is a very common form throughout Mesoamerica's ceramic history, though it is likely early colonial residents used this multipurpose vessel in similar ways to their ancestors. Archaeologists debated whether the tecomate was used primarily as a special purpose ritual container (Clark and Gosser 1995) or for cooking and serving maize or manioc (Coe and Flannery 1967; Green and Lowe 1967). It is likely Hacienda Pancota residents used it for serving or storage due to a lack of ritualistic evidence from the domestic structure.

Ollas or tinajas are typical Mesoamerican water jars, found throughout the preColumbian and New Worlds. They usually have flattened wide loop handles, but also evidence lug handles in historical periods. Their function can vary from storing to cooking and are capable to hold liquids and solids alike. They are similar to tecomates, but certain unrestricted neck varieties tend to have a larger, less opening making it easier to cook (Shepard 1980). Botellas, or colonial water bottles, are similar to ollas and tinajas. They are tall closed and short necked bottles. They have a globular middle and 
flat or curved base. Their primary function was to store liquids and dry goods in preparation for cooking and serving.

\section{Indigenous Tradition Cooking Vessel Forms}

Comals or Comales can have short, steep walls, but primarily are flat griddles.

They were used for cooking tortillas and are seen all over Mesoamerica in a wide range of prehistoric and modern time periods. Their evidence at Hacienda Pancota suggested that food preparation was an important activity in the household. Though both used for manipulating corn, the presence of comals as opposed to manos and metates is the difference between a food processing activity area and a cooking area (Flannery 1976; Hirth and Santley 1993). A comparatively high percentage of comal sherds and minimum number of vessels further evidences preparation for many people. Since they were recovered from all four level contexts, their use at Hacienda Pancota was longstanding, even during and after the adoption of European goods. good

\section{Indigenous Tradition Serving Vessel Forms}

Tazas, in Hacienda Pancota context, are usually small, handless jars. They are thin-walled and preside in both Spanish colonial and pre-Columbian indigenous forms. The only recognizable taza vessel forms were evidenced in the Late Postclassic period. Cipriano Red-on-Gray sherds were recovered from the construction materials at the domestic structure and evidence a small taza vessel form. 


\section{European Tradition and Other Imported Vessel Forms}

European tradition and Chinese porcelain ceramic styles included olive jars, creamware, kraakporcelain. European architectural ceramic types included ladrillos ( brick), and tejas (ceramic roof tile).

Botijas are generally referred to as a form designed to hold and store liquids. Archaeologically they are commonly seen in the New World as Spanish olive jars. Goggin (1964) and Marken (1994) are credited with analyzing olive jars and contributing to the creation of their typology. Escudillas were small bowls, usually wide, but varying in size. Escudillas could have ridged or straight rims with lug handles. They were often shallow and some of the first vessel forms to be sent over from Spain. Ladrillos, simply mean bricks and are characteristic of some early colonial households. They are large unglazed slabs. Tejas are thick unglazed earthenware roof tiles. Construction materials like tejas were some of the first types of ceramics transported to the New World. They provide the structure for a tejado, or tile roof. 


\section{CHAPTER IV \\ ADDRESSED RESEARCH QUESTIONS AND \\ THEORETICAL PERSPECTIVES}

\section{Review of Research Agenda}

Production and consumption patterns within Hacienda Pancota and their interactions with larger early colonial world systems become evident when examining residents' material culture and spatial patterns.

The following questions were addressed: 1) What are the indigenous, imported, and contraband ceramics in the Hacienda Pancota sample? I identified all types ceramic wares and used Sampeck (2007) as a guide. 2) What is the proportion of contraband ceramics to the rest of the ceramics in the sample? How do they fit into the assemblage as a whole? I analyzed the form and decoration of recovered Chinese ceramics in order to see how they relate to the form and decoration of other ceramics in the assemblage. 3 ) How does Hacienda Pancota compare to other early colonial Mesoamerican households? I compared the ceramic assemblages and total artifact collections reported from sites of the same time period reported in Deagan (2002), Gasco (1992), and Morandi (2010). Sample questions for comparative site analysis included: What is the spatial patterning of the ceramics in the Hacienda Pancota assemblage as compared to other sites? Which ceramic types occur together? In what proportions did they occur together? Are there significant differences/similarities in the spatial patterning of artifacts in relation to the 
household? 5) Does the possession and trade of contraband ceramics say anything about domination, resistance, or agency at the household or community level? Dawdy (2008) suggested that such things were simply part of daily life, even encouraged by some colonial powers. Does this assemblage suggest open display, like serving wares, or more personal artifacts (shown by artifact size and or location) used as part of a personal rebellion? 6) What does the general daily consumption pattern suggest about the lifestyle of Hacienda Pancota residents?

\section{Theoretical Perspectives}

Marxian approaches tend to focus around the interaction between people and social mechanisms of domination and resistance. People actively engage in external and internal forces, struggling to shed the constraints of power hierarchies funded by financially dominant institutions. The Marxist lens of analysis is well suited for examining the material and social institutions that shape people - their consumption and production patterns and ideologies invested in them. The forces extending from material and social institutions do not have to be in the typical duality of oppressor and oppressed (Paynter 1988), but can be the connection between people and their material goods as dominance and resistance are actively symbolized by two parties. Marx believed that shifting — or progressing — modes of production were the "culprit[s]" of social change (Mann 2012:15), defining activity as the dialectic between dominance and resistance. This dialectic relationship rejects Enlightenment rooted ideas that technological change happens because people want to make their lives "easier, richer, and more secure"; instead technological change occurs due to societal forces and power relations (Trigger 
1993). It is the process by which researchers measure change that the use of agency becomes a prime candidate for consumption. Within consumption patterns, the aim of this research is then able to record agency within residents of the household at Hacienda Pancota. Practices like the adoption of contraband and wide variety of local and imported pottery styles can be interpreted beyond the purely functional and investigation can expand into the realms of social resistance and dominance.

We must think of the household as a political unit—making choices that affect the many scales of the economy, initiating at a micro level. Work, and therefore production, are intimately connected to the household making it integral to the motion of societal change (Engels 2008 [1892]). The people associated with the household are social actors contributing to "the active components in the constitution of social relations." (Hendon 1996:56) For this research, households show direct evidence of both "economic and ecological processes" and are comprised of social, material, and behavioral elements (Rathje and Wilk 1982:618). The social level can be used to examine the interactions of people associated with the household. The material level is the physical structure itself and the artifacts associated with it that show any and all household activities in combination with the constructed landscape. Finally, the behavioral level concerns the activities that the household performs. It is important for understanding the household as a whole economic unit. These three elements of the household encapsulate what Carter and Merrill (1979) titled the total household. This is a "domestic strategy" that attempts to meet the productive, distributive, and reproductive needs of its members (Cater and Merrill 1979). 
Lefebvre (2002:77) proposed that the idea of social space as contains a diversity of objects that are simultaneously things and relations, an idea essential for any study attempting to make sense of artifact distributions at places with oppressed people. Symanski (2012:125) continued the idea that artifacts become evidence of the routine actions and practices of people reinforcing the constantly shifting relationship of power from social institutions and from people against social institutions. The accessibility of goods one family may purchase to produce a household meal, both receives its power from outside market forces and retains power bestowed upon them from the family meal. This constant shift of power in denial and access of material culture evidences the dual nature of an oppressed group's vulnerability.

Hirsh (1995) argued landscape embodies a dual nature in both the present and future. The landscape by which humans immerse themselves comprises a foreground of everyday social life and a background of potential existence. The foreground constitutes the concrete actuality of everyday life that embraces concepts of place, inside a place, and the image of a place. The background, in turn, constitutes an idealized potential world that projects concepts of space, outside the space, and representation of space (Hirsh 1995). Within a landscape, human experience is then a process of realizing issues, in what Hirsh (1995) calls the foreground, while they only exist as a potential solution in the background (Symanski 2012). At Hacienda Pancota, material remains inside the household structure reflect social activities defined in the foreground, while the actions of household itself produces economic and social consequences in the background.

Continual fluctuation over the control of labor and resources existed throughout Mesoamerica, especially when states attempted to control new territories, people, and 
production (Adams 1974; Freidel 1983; Lattimore 1962; Marcus 1993, 1998; Skinner 1985; Yoffee and Cowgill 1988). During this time of continual fluctuation, Adams (1974) argued there exists maximization and resilience strategies. This model applies primarily to complex societies of the Classic, Postclassic, and Colonial Maya, as well as Nahua societies. During periods of political instability and decentralized authority, lower classes of people create a resilient strategy where three motivating factors exist: long-term survival, risk management, and resource diversity. In resilient strategy, groups in power reinforce class divisions based upon access to material goods (McGuire 1988). Conversely, during periods of unified political stability and accessible centralized authority, lower classes create a maximization strategy where people intensify production of a select few resources. Investigations into Hacienda Pancota's household and its material culture remains were analyzed under the variables of Adams' (1974) maximization and resilient strategies. The adoption of contraband pottery, a diverse array of imported pottery types, and the household defined with specialized spaces supplied evidence for residents' long-term survival, risk management, and resource diversity. While understanding social adaptation within the context of colliding cultures, residents of Hacienda Pancota were examined under what Wobst (2000) defined as the parameters of action - agency. These parameters can be defined by all possible choices that become available in life's situations, i.e. How to live successfully? How to survive? How to adapt? Small decisions become overarching lifeways that tend to be defined by bigger systems and institutions like governments and business. Silliman (2008) argued that though these overarching choices are available to people, they are not made solely by themselves, but are rather a mixture of self (intentional and strategic choices) and 
routines. Other archaeologists argued that agency is defined by only intentional and strategic choices later becoming additions to routine (Blanton et al. 1996; Joyce and Winter 1996). This thesis tends to agree with both tenets of recognizing freewill and intentions of the residents of Hacienda Pancota by the agency theories of Blanton et al. (1996) and Joyce and Winter (1996), as well as Silliman's (2008) more rounded approach.

Developed out of activist feminist and race literature of the post-Reagan early 1990s, Intersectionality Theory surrounds the idea that there are multiple systems of oppression being applied to an individual or groups at any given time (Crenshaw 1989, 1994). Race, class, and gender are the fundamental institutions of oppression in our lives. Historically, they exist in a dialectical relationship of shaping social structure, while being shaped by social structure. For instance, Spanish reduccion policies as an institution were shaped by race, class, and morality masked by religion. They were not mutually exclusive components, but all components that projected themselves on the people, physical world, and material culture. Reduccion ideologies then project themselves on the individuals they are oppressing. This happens through physical relocation, the reorienting of spatial patterning, and the importation of new material culture, all intended to influence and shape individuals. Reduccion policies implemented by the Spanish hierarchy made apparent that habitation centers of migrant and local indigenous peoples felt the affects of its oppressive institution. In particular, the material culture assemblages reflect some of this oppression through the examination of agency and planned strategy, targeted within Hacienda Pancota. 


\section{CHAPTER V \\ METHODS FOR ANALYSIS}

The recovered materials of Hacienda Pancota were recorded from their original proveniences of seven total test units. Units were excavated in arbitrary units until features such as structure walls were encountered. Features and cultural deposits, such as floors, were excavated in natural levels and within accordance to context (wall clearing, pit features, etc.). Surface collections above the seven test pits were not taken into account for a likely disturbed provenience.

\section{Ceramic Analysis}

Ceramic analysis comprised the majority of the methodology, investigating issues of adaptability, economics, resistance, population demographics, and ownership. I first classified all ceramics excavated from the Hacienda Pancota's structures. I recorded characteristics of ware, form, and decoration of all sherds in the assemblage (Sampeck 2007). Lister and Lister (1976, 1982), Sampeck (2007), and Verhagen (1997) were used as guide for describing much of the early colonial pottery types. Pottery type, dimensions, decoration, and minimum vessel count were used in analysis to help answer how consumption patterns contribute to the residents' lifestyle at Hacienda Pancota.

Due to low overall frequencies, more time was applied to unique physical attributes of porcelain, creamware, and tin glazed redwares. Particularly, these selected 
wares give a well-defined chronological and comparative basis for the research.

Measurements of length, width, and thickness were added to the aforementioned recorded variables. These new approaches aided in understand microchronologies, design choices, availability, and intersite variations within selected pottery types.

\section{Typological Analysis of Ceramics}

At its simplest, the typological analysis of ceramics is the process that attempts to classify previously unidentified pottery into types for stricter control under academic investigation (Rouse 1940). In Mesoamerican ceramic archaeology, Sampeck (2007:336) argued that the type-variety system of analysis has historically been most widespread with initial typological analysis of pottery. This analytic system employs processes first

established by Smith, Willey, and Gifford (1960), Gifford (1963), and Smith and Gifford (1965). Three units of organization were used for analysis: group, type, and variety. Physical attributes such as, but not limited to, decoration, paste, use-wear, and technology are used to place into one of three categorical units of analysis. The following sections are a brief introduction to the pottery types recovered from excavations at Hacienda Pancota and later analyzed in the Spring of 2013.

\section{Indigenous Pottery: Coarse Earthenwares}

Since the majority of indigenous earthenware pottery recovered from structure excavations at Hacienda Pancota is previously unanalyzed in its specific locale, Sampeck (2007) will be the primary typological source used for this study. Other typological reports will be used from Beaudry (1983), Bove (2002), Card (2006), Charlton et al. 
(1995), Fowler (1988), Henderson (1979), Kosakowsky (2001), Lind (1967), McCafferty

(1995), Sharer (1978), Verhagen (1997), and Wauchope (1970) to verify proposed conclusions. This research attempted to isolate the late López phase and the entirety of Marroquín phase ceramics, as they pertained most accurately to the early colonial period under examination for this research. Locally produced pre-Columbian earthenwares are also placed into the ceramic typology and analyzed from the context in which they were recovered.

Following the description of ceramic classification, the pottery's spatial distribution in conjunction with the architectural structure at Hacienda Pancota was analyzed. A chloropleth map of pottery frequencies in all seven test units depict spatial variation of evidence activity space within the structures.

\section{Local and Imported Majolica}

Commonly referred to as majolica, tin-glazed wares were first imported from Spain, then produced in Mexico, Guatemala, Panama, and Peru. A Mexican variety is the only evident type occurring in the collection and will be analyzed by the works of Gasco (1981), Lister and Lister (1982), and Verhagen (1997). Majolica types first produced in Spain will be used as a comparative feature and will be analyzed by the following sources: Deagan (1987), Goggin (1968), Lister and Lister (1976, 1982), and Sampeck (2007). Site specific comparisons of Spanish majolica and Mexican majolica were defined chronologically and used for comparative basis. The decoration of tin glazed redwares recovered from Hacienda Pancota is presented in terms of color selection, brush stroke type, and patterning that was measured by comparison to other local and imported 
pottery types. The following section describes the bulk of refined earthenwares recovered at Hacienda Pancota.

\section{Refined Earthenwares}

Refined earthenwares consist of pottery fired at high temperatures, are only moderately porous allowing them to be thin in nature. According to the Delaware Department of Transportation historical ceramic typology, refined earthenwares consist of three primary groups: Creamware (1750-1820+), Pearlware (1779-1820+), and Whiteware (1820-1860+). Their existence in recovery at Hacienda Pancota is likely due to European importation. Refined earthenwares were dated in from an extensive chronology provided by the Florida Museum of Natural History. Although small in overall frequency, this category comprised of refined whitewares excavated from Hacienda Pancota. Dimensions of the sherds, decorative features, and specific types were noted and analyzed. As the rest of the pottery, refined earthenwares were assigned their spatial provenience and contributed to the overall understanding of place within the context of Hacienda Pancota. The analyzed refined earthenwares terminus ante quem date are assigned after the early colonial period, but aid in understanding the trajectory of space and place at Hacienda Pancota. The following section describes the methods for analyzing oriental porcelain at Hacienda Pancota, another pottery type with specific diagnostic dates. 


\section{Oriental Porcelain}

Chinese Kraakporcelain was the only identified type recovered from excavations at Hacienda Pancota. To help answer how the Kraak porcelains were used-whether in discrete or public ways - I compared the percentages of porcelain and their spatial distribution to other pottery types in the collection. Porcelain in the assemblage was analyzed using Kuwayama (1997), Logan (1977), Martin (1979), Sampeck (2007), and Sassoon (1984). Motif, decoration, and possible vessel forms were important in identification and decorative analysis, but the mere presence of such contraband was of critical importance for understanding agency and daily consumption at the household level. It then becomes necessary to understand how pottery becomes representative of peoples occupying Hacienda Pancota. Below describes the ways by which vessel type and size estimations reflect residents' usage of pottery within the domestic context.

\section{Qualitative Minimum Number of Vessels (MNV)}

Both the minimum number of vessels (MNV) and raw sherd counts were used in quantifying recovered pottery at Hacienda Pancota. The MNV method more accurately reflects resident population and vessel identification. Identifying the minimum number of vessels can be difficult and all identifiable variables must be taken into account for qualitative analysis. As opposed to quantitative MNV where only overall total sherd counts comprise of an MNV number, rim and handle measurements are included in this analysis. Qualitative MNV tabulation is more involved, necessitating other attributes defined by the analyst. The method is hard to replicate and more subjective than other quantitative approaches (Voss and Allen 2010). It is common for vessels to be thin, thick, 
and different colors all within the same vessel. Sherds were thus first categorized into three distinct groups argued by Voss and Allen (2010). After grouping like level and test unit, the first category comprised of sherds sharing qualities of the same vessel. The second group was defined by sherds that share no other similarities and individually represent a complete vessel. The final group consisted of sherds that could potentially represent two or more vessels. These sherds were divided by further comparisons of paste, inclusion type and frequencies, striations, decomposition, and other identifying characteristics. MNV allowed to make calculated predictions on population size and vessel types for daily consumption.

When completed vessel counts were finished, their function could not be always fully determined, so the next logical step was to investigate decoration on a selected series of pottery. This examination aided in understanding not only use, but expression and agency within the household at Hacienda Pancota.

\section{Decorative Analysis of Pottery}

Sherds displaying preserved painting and decoration were recorded and analyzed in the total collection. They were photographed as an aid in describing color, shape, and other intimate details. Their vessel form and spatial location within the context of specific activity areas was recorded. Decorative sherds included Eliseo Red-on-Natural, Bibiana Red, Apolonio Orange-Red, Teshcal Red-on-Natural, tin glazed redware, Catalina Redon-White, Kraak porcelain, Pantaleón Brown, whiteware, and Cipriano Red-on-Gray. Eliseo Red-on-Natural and Pantaleón Brown sherds were excluded due to their red wash. The reason for their exclusion was to narrow down the decorative group to a better 
manageable size. I categorized only bichrome and polychrome sherds for their distinctive decoration. No incising, engraving, or manipulation of the paste was recorded in the Hacienda Pancota ceramic collection and thus was not a decorative variable in the analysis.

The following sections of the methodology investigate Hacienda Pancota's recovered material culture besides pottery. Spatial analysis, statistical analysis, and comparative site contexts were used to further explain the resident population of the early colonial period.

\section{Other Analyzed Material Culture}

Other associated material culture from the seven test units at Hacienda Pancota used in analysis included glassware, lithics, faunal remains, and metal fragments. These artifacts similarly support evidence for agency manifested in the archaeological assemblage. Since all glassware in the assemblage was imported from Europe, glass was briefly analyzed using Deagan (1986) as reference. Assemblage metal fragments remain small in quantity and remained a presence/absence factor for the results and discussion section of this thesis. Along with glassware, metal fragments received less focus than the ceramic assemblage, but were compared against other early colonial sites. Faunal remains consist primarily of freshwater snails and were compared against sites from Morandi (2010) as the primary source. Personal discussion with Dr. Kathryn Sampeck and Dr. Warren at the Illinois State Museum contributed to the identification and brief analysis of faunal remains. All lithics, both obsidian and modified igneous rock were noted and 
recorded spatially. Their frequency and provenience was analyzed in terms of the rest of the ceramic collection.

\section{Site Comparisons}

Providing a social context for which the daily consumed artifacts recovered during excavation will be done by site comparisons of similar analyzed data. Comparative datasets were chosen by their availability, accessibility, and similarity to the analyzed collection of this thesis-Sampeck 2007. Ceramic assemblages were most heavily compared, though lithic, glass, metal, faunal, and architectural artifacts were evaluated as well. Four archaeologists' research was used for this analysis. Household contexts from Ocelocalco (Gasco 1992) in the historically noted cacao producing area of Mexico, the Maya site of Xibun (Morandi 2010) in southeastern Yucatan of Belize, and domestic contexts surrounding St. Augustine, Florida (Deagan 1978) will be used for temporal and artifactual comparison. Skowronek's (1987) analysis of late sixteenth century Spanish flotas, Espiritu Santo and San Esteban, provided historical data of early modern period trade dynamics.

\section{Artifact and Structural Spatial Analysis}

Provenience of recovered artifacts from unearthed structures at Hacienda Pancota allowed for analysis of artifact distribution, location, and midden patterning. Architectural design, technology, and patterning can be detected from site maps and test pit locales. Spatial patterning, variation of household form, and settlement comparison aided in defining the relationship between production and consumption patterns of the 
household and broader settlement patterns. The context of all artifacts was interpreted within the spatial evidence of Hacienda Pancota structures. Spatial analysis was depicted with chloropleth maps displaying data classes of total artifacts, pottery, lithics, bajareque, and faunal remains by their respective test unit in each structure.

\section{Small Scale Variation in Darío Group Ceramics}

Darío group ceramics, including Darío Plain and Bibiana Red were selected to sample agency present at Hacienda Pancota. Statistical variations within these two pottery types demonstrated daily consumption and microchronologies within the early colonial period. Darío Group ceramics were selected due to their unique nature within the pottery assemblage - they have easily identifiable physical characteristics, a large sample number, and function as possible storage vessels, which separate them from other pottery in the collection.

According to Verhagen (1997), earthenware's porous nature tends to act as cooling agent and historically viable source for water storage. Due to the comparatively small amount of recovered olive jar sherds and significantly higher proportion of temporally similar unglazed Darío Plain wares, it is likely they were used as a substitute storage for water, as well as other liquids. Vessel reconstitution and a high proportion of

sherds demonstrate just one line of evidence for a wide variety of vessel applications and residents' selection. It is possible there exists microvariation of type within the Darío group beyond Darío Plain, Bibiana Red, Buenaventura, and Bonifacio Polychrome (the later two exist in the group, but were not identified in this analysis) as suggested by Sampeck (2007). It is thus important to understand whether or not pottery variations exist 
within these two previously identified groups because the results will add to the overall complexity of agency and daily consumption within the population at Hacienda Pancota. As part of the research agenda of this thesis, pottery variations however small, mimic and are exemplary of agency in daily life. These variations similarly represent fluctuations in market supply, demand, and larger stylistic changes. Variations in the same parent type of pottery indicate wider selections and preference for pottery usage, especially if the Darío group is last in the line of a replacement in decorative pottery styles from Catalina Redon-White, to Teshcal Red-on-Natural. 


\section{CHAPTER VI}

\section{RESULTS OF MATERIAL REMAINS ANALYSIS AT HACIENDA PANCOTA}

The total artifact assemblage recovered by careful excavation methods at Hacienda Pancota comprises of ceramics, lithics, metal, construction material and fired clay, faunal remains, and glass (Table 1). All together, 1043 artifacts were analyzed, consisting primarily of pottery sherds. Described in later sections, all pottery comprised of European tradition pottery, indigenous and regional tradition pottery, and oriental imported pottery. The entire ceramic pottery analyzed accounted for more than half of the collection. Construction material, defined as fired clay daub comprised of the second most frequent analyzed artifact group and accounted for nearly a quarter of the analyzed material. All daub was weighed individually by level and test unit, then later quantified for a comparative basis against other site artifacts. Lithic material in the form of obsidian flakes, blades, and shatter followed third in total quantity. Flat modified igneous rocks were a minority of the analyzed lithic group. Glass, faunal remains, and metal fragments followed in descending order less frequency in the collection. Glass varied from colonial bottle glass to window pain fragments. Faunal remains consisted of primarily river snail shell remains. Two other very small fragments of unidentified animal bone accounted for the remainder of the faunal group. Metal fragments consisted of fence tacks and square cut nails. 


\begin{tabular}{lr} 
Hacienda Pancota Artifacts (\%) & Total (\%) \\
\hline Pottery & $69.99 \%$ \\
Fired Clay Daub & $18.55 \%$ \\
Lithics & $4.88 \%$ \\
Glass & $2.91 \%$ \\
Faunal Remains & $2.20 \%$ \\
Metal & $1.47 \%$
\end{tabular}

\section{Collection Total $\quad 100.00 \%$}

Table 1 Total Percentages of Analyzed Artifact Remains

The majority of the collection analysis was dedicated to pottery. Both glass and metal artifact inventories reflect only a sample of the entire recovered artifacts from Hacienda Pancota (personal communication with Dr. Kathryn Sampeck, 2013). The pottery component of the recovered materials was categorized as 100\% pottery sherds. No complete vessels were excavated. Some refitting was possible during preliminary identification and a total of 56 individual sherds were glued to matching pieces. The refitting process aided in vessel identification, proposed vessel use, and reaffirmed occupied time period identification. Almost two-thirds of the refitting was due to modern transportation and breakage, as opposed to breakage in an archaeological context. However, the refitting pottery process demonstrated patterns in degrees of scatter not easily detectable by other means. Most pottery was refit from their same excavated level, in the same test unit number. This concludes that most pottery was undisturbed from their original context. It reaffirmed spatial stratigraphy and aided in dating materials beyond the sole use of ceramic typologies.

Table 2 represents all the analyzed artifact data at Hacienda Pancota. The data is in raw number form, but pottery numbers and MNV share the same column to introduce 
vessel usage associated with the domestic structure at Hacienda Pancota. More thorough MNV results are interpreted later in this chapter. During analysis, artifacts were arranged by provenience in the following table. The majority of levels were excavated in $10 \mathrm{~cm}$ control intervals. Exceptions of $10 \mathrm{~cm}$ control were permitted within a few instances. Level 2 at the north corner of the western structure was excavated at a $20 \mathrm{~cm}$ depth. All three features were excavated separately, according to natural context rather than arbitrary $10 \mathrm{~cm}$ control. The northeast and southeast corners of the western structure were excavated using trenching methods and were thus noted by their own provenience.

\begin{tabular}{|c|c|c|c|c|c|c|}
\hline $\begin{array}{l}\text { Level Distribution } \\
\text { Count and (MNV) }\end{array}$ & Pottery & Metal & Lithic & $\begin{array}{l}\text { Construction } \\
\text { Material }\end{array}$ & Faunal & Glass \\
\hline Level 1 & $297(152)$ & 5 & 22 & 53 & 18 & 30 \\
\hline Level 2 & $260(138)$ & 5 & 17 & 114 & 5 & 0 \\
\hline Level 3 & $40(31)$ & 4 & 11 & 14 & 0 & 0 \\
\hline Level 4 & $18(11)$ & 0 & 0 & 2 & 0 & 0 \\
\hline Feature 1 & $52(14)$ & 0 & 0 & 0 & 0 & 0 \\
\hline Feature 2 & $12(11)$ & 0 & 0 & 2 & 0 & 0 \\
\hline Feature 3 & $1(1)$ & 0 & 0 & 4 & 0 & 0 \\
\hline TU1 Trenching & $22(17)$ & 0 & 0 & 2 & 0 & U \\
\hline TU3 Cleaning & $27(9)$ & 0 & 1 & 2 & 0 & 0 \\
\hline Interior Wall & $3(2)$ & 0 & 0 & 0 & 0 & 0 \\
\hline
\end{tabular}

Table 2 Raw counts for All Analyzed Artifact Types in Each Level 
The two aforementioned overall data tables give insight into the overall production and consumption patterns at Hacienda Pancota. They suggest that the use of pottery for either storage, cooking, or serving were significant activities for residents within specialized areas of place. The refitting process of pottery supports undisturbed archaeological context, allowing better insight into microchronologies within the early colonial residence. The heavy frequency of pottery evidences residents actively engaging in the social institutions by cooking meals together in preparation for work in the fields. A small percentage of faunal remains similarly suggested that hunting and meat preparation during the early colonial occupation was less frequent than foods that do not preserve well such as grains, vegetables, and some fruits. Low frequencies in glass and metal construction materials support Hacienda Pancota residents' lack of access, and or, willingness for many wholly European technologies. The overall data relates to Trigger's (1993) argument that people do not necessarily need to make their lives "easier, richer, and more secure" but rather rely on power relations to introduce technological change.

\section{Pottery Assemblage Analysis}

Occupation chronology and population demographics were interpreted primarily by the quantification of pottery types. Late Postclassic pottery accounted for $.76 \%$ of all pottery, and unidentified, poorly preserved Late Classic pottery totaled $2.29 \%$ of the entire Hacienda Pancota assemblage. It may seem erroneously high that $2.29 \%$ of the entire collection is Classic period pottery, but its preservation condition is extremely poor. Over $90 \%$ of the Classic period pottery was found within levels 1 and 2, alongside the highest percentages of fired clay and daub building material. On the basis of this 
evidence, they probably occurred incidentally as construction materials for Hacienda Pancota infrastructure. It is likely these poorly preserved sherds were delivered with the clay brought in for building material, not evidence of living in that exact location. Late Postclassic pottery also indicates some amount of activity, but not a heavily populated center. Overall, the broad chronological trend is of a new household being erected in a spot in the Marroquín Phase without much else going on around it architecturally.

Defined as the period beginning as early as 1502 until the late sixteenth century, contact period pottery totaled $8.60 \%$ of the assemblage. This area was densely settled during the contact period on a series of hilltops very close to the location of the excavations considered here. It is likely Hacienda Pancota residents used some local styles of pottery from close sources as new styles were coming into fashion and availability. This small, early historic component shows that this was an area of activity, but not particularly a central zone during this period.

Adhering to Sampeck (2007), Verhagen (1997), and Deagan (1987) for typological ceramic dating, all analyzed pottery was given a diagnostic date (Table 6.3). The primary occupation period according to recovered pottery spanned the early colonial period, although occupation of the earlier contact period and later Republican period ceramics were both identified. Early colonial pottery accounted for $58.32 \%$ of the entire collection and $83.33 \%$ of the total ceramic assemblage. It is significant to note that the assemblage accounts for over half early colonial pottery, suggesting recurring occupation, cooking, food preparation, and food/liquid storage associated directly with the structures excavated at Hacienda Pancota. 


\begin{tabular}{lrrr}
$\begin{array}{l}\text { Major Period } \\
\text { Pottery }\end{array}$ & \multicolumn{1}{l}{$\begin{array}{l}\text { Total Counts } \\
(\boldsymbol{M N V})\end{array}$} & $\begin{array}{l}\text { vs. Pottery } \\
\text { Assemblage Total } \\
(\boldsymbol{M N V})\end{array}$ & vs. Collection Total \\
\hline Late Classic & $15(\mathrm{n} / \mathrm{a})$ & $3.28 \%(3.89 \%)$ & $2.29 \%$ \\
Late Postclassic & $8(8)$ & $1.09 \%(2.07 \%)$ & $0.76 \%$ \\
Contact Period & $90(46)$ & $12.30 \%(11.92 \%)$ & $8.62 \%$ \\
Early Colonial & $610(317)$ & $83.33 \%(82.12 \%)$ & $58.32 \%$ \\
\multicolumn{1}{r}{$\quad$ Total } & $723(371)$ & $100.00 \%(100.00 \%)$ & $69.99 \%$
\end{tabular}

Table 3 Raw Totals and Minimum Number of Vessels in Each Diagnostic Period

The chronological data depicted above demonstrates heavy early colonial occupation compared to three other diagnostic pottery periods. Late Classic and Late Postclassic wares were attributed to construction from a surrounding area likely populated prior to the early colonial period. Low in frequency, contact period pottery can be attributed to the initial population at Hacienda Pancota. It is also possible that noted contact period pottery crossed over into the early colonial period due to Hacienda Pancota's periphery location to more active urban centers like Acajutla and San Salvador.

\section{Indigenous Tradition Pottery}

Total Frequency:

$\%$ of Total Pottery:

$\%$ of Total Collection:
655 (MNV 344)

$89.48 \%($ MNV 89.12\%)

$62.62 \%(\mathrm{MNV} 32.89 \%)$

The following ceramics are chronologically grouped, all falling within indigenous tradition pottery typologies. As a whole, these ceramics in the collection have by far the widest variety of type and longest chronology. A minority of the pottery is not yet diagnostic, but almost all of the recovered indigenous tradition pottery were defined and organized by the collaborative work of Sampeck (2007) and Dr. Howard Earnest. Early 
colonial indigenous pottery comprise of the overwhelming majority of recovered sherds and minimum number of vessels from the Hacienda Pancota excavations. It is in the early colonial period that Carter and Merrill's (1979) total household begins to be defined through production, distribution, and reproduction. Early colonial residents consumed the most, though remnants of the earlier periods allow this investigation to witness the continual fluctuation over control of labor and resources.

\section{Late Classic and Late Postclassic Pottery}

Throughout analysis, unidentified Late Classic period and unidentified Late Postclassic period sherds were recovered. The sherds were identifiable by general time period due to paste characteristics and in some cases residues of slips. In general, these unidentified sherds were poorly preserved while thick and small in length and width. Of the 24 unidentified Classic period sherds, most were deep red in color, varying drastically from the rest of the analyzed collection. The one unidentified Postclassic sherd was very similar to Catalina Red-on-White, but with different red painted motif and paste to classify it securely. It is likely these sherds were used as construction fill or were part of a disturbed context during Hacienda Pancota's early colonial period. Due to the ceramics not being identifiable with confidence, there were not included in the consideration of new pottery styles of the Izalcos region. Most vessel types from the Late Classic and Late Postclassic pottery recovered at Hacienda Pancota were small, primarily serving or offertory vessels. Few possible storage vessels were identified, suggesting this was not a domestic site prior to Hacienda Pancota's historic context. It can be concluded that 
remaining pottery from the non-domestic Late Classic/Late Postclassic site was used for construction of the early colonial infrastructure.

Talcomunca Group. Catalina Red-on-White pottery has a white slip and typically weathers to a chalky softness in reaction due to deposition processes. They have red geometric designs that vary from concentric to linear lined motifs. The paste is notably hard, sandy, and reddish brown. Catalina Red-on-White is primarily diagnostic of the early Late Postclassic, or the Irarraga phase. Sampeck’s (2007) analysis proposed that Catalina Red-on-White gave way to the López phase Teshcal Red-on-Natural. Varieties of Catalina Red-on-White pottery bowls are supported at the Late Postclassic site of Naco of western Honduras (Henderson 1979). Catalina Red-on-White accounts for 5 total analyzed sherds, $(.68 \%)$ of the entire pottery assemblage, and 5 total numbers of minimum vessels. They were located in levels 1 and 2, as well as within Feature 2. Spatially, the Catalina sherds were recovered from five of seven test pits. They were not recovered from the western or eastern corners of the western structure. According to Sampeck (2007), Catalina Red-on-White's most common form is the low-walled bowl. Gavino Red wares date from 750 CE into the sixteenth century (Fowler 1988; McCafferty 1995). They can be either unslipped or evenly red slipped with a dark red interior paste. They commonly take the forms of offertory plates, ollas, and low-walled bowls. Only one sherd is represented in this assemblage and is likely the product of construction fill or a disturbed context. 
Cipriano Red-on-Gray. Cipriano Red-on-Gray is a ceramic type only identified twice in the assemblage at Hacienda Pancota. The two sherds were recovered solely from level 2 in the eastern edge of the western structure. It has a distinct gray surface with red geometric designs that preserve quite well. The red painted decorations do not flake, but fade in a similar fashion to Teshcal Red-on-Natural sherds. The decorate motifs are however more similar to Catalina Red-on-White, with thinner more precisely painted lines, rather than the thick application of red paint on Teshcal Red-on-Natural pottery. Wauchope's (1970) analysis of a Guatemalan highland site is the only ground for comparison, suggesting that the sherd date likely spans the Postclassic period. Only two sherds appeared in the identification, accounting for a mere $.27 \%$ of the pottery assemblage, and were likely two distinct vessels due to their coloring, paste, and surface treatment. It is possible they are the product of construction fill or a disturbed context.

\section{Contact Period Pottery}

The contact period pottery is the second most frequent group recovered from Hacienda Pancota. They comprise of 3 different pottery groups and 3 different pottery types within those groups. Many are transitional pottery styles that venture into stylistic forms of the early colonial period.

Gines Group. Of the Gines group, Gines Plain: Gines Variety wares date from the Mesoamerican Postclassic period to the beginning of the early colonial period. Gines Variety accounts for 31 total analyzed sherds, (4.23\%) of the entire pottery assemblage, and 20 minimum number of vessels. They were located in levels 1, 2, and 3. Gines 
Variety sherds were recovered from all test units excluding the far west corner of the western structure. With a light to dark brown paste that comprises the qualities of medium fine sand, Gines Variety sherds are quite smooth. They usually take the forms of bowls, ollas, and most frequently in the analyzed collection, comals. Gines Variety paste is discernibly friable in appearance and includes little to no visible mineral inclusions. According to Sampeck (2007), Gines Variety pottery is a diagnostic marker for López phase sites in the Izalcos region, but is evidenced by some early Marroquín phase occupation at Hacienda Pancota and is supported by Guatemalan contact period sites analyzed by Wauchope (1970). Sherds analyzed by Wauchope (1970) are similar, but likely not exactly the same compared to Gines Variety recovered from Hacienda Pancota.

Teshcal Red-on-Natural. Teshcal Red-on-Natural accounts for 41 sherds, making it $5.6 \%$ of the pottery assemblage. 18 minimum number of vessels were identified throughout analysis. Teshcal sherds were only recovered from levels 1, 2, and 3. They were located in test pits most heavily concentrated in the eastern corner of the eastern structure. Second most frequent areas included the middle and northern sections of the western structure. As previously stated, Teshcal Red-on-Natural pottery was a likely candidate that replaced much of the Catalina Red-on-White pottery. It is thus diagnostic of the contact period, or López phase, and is supported by evidence from Bove's (2002) analysis of Remanso Group pottery on the Guatemalan Pacific coast and Card's (2006) analysis of Cajete Variety pottery. Teshcal Red-on-Natural is characterized by wellsmoothed surfaces, burnishing, fireclouding, and beautifully red thick painted geometric designs. The red surface paint does not chip, but fade leaving a lingering impression of 
the vessel's original painted lines and shapes. Teshcal Red-on-Natural's medium brown paste is similar to wares with red pumice and mineral inclusions of the later phase Pantaleón Brown pottery type, but contains less total inclusions. Gavino Red's paste is similar in terms of paste color and inclusion frequency, and was used as a comparative example. Sherds ranged from medium to large in thickness and size, suggesting they were not used as delicate small vessels, but medium sized bowls, jars, and water bottles. Sampeck (2007) argued that Teshcal Red-on-Natural was a transitional pottery type, eventually replaced by Bibiana Red and Buenaventura red painted pottery in the Izalcos region.

Cuscatlán Group. The Cuscatlán Group comprises Cuscatlán Brown pottery and date through the contact period into the beginnings of the early colonial period. With the exact same distribution pattern as Telesforo Brown sherds in the early colonial context, Cuscatlán Brown sherds had 8 minimum number of vessels and were located in all the test units in the western structure, as well as in the eastern corner of the eastern structure. Cuscatlán Brown accounted for $2.46 \%$ of the pottery assemblage, with 18 total identified sherds in levels 2 and 3. They have a medium coarse surface, making them poorly smoothed. Cuscatlán Brown sherds are tan to medium reddish paste, though the majority of sherds analyzed in the assemblage were of tan friable paste. As if made in haste, Cuscatlán Brown sherds have a coarse look, beyond just their feel upon touch. Cuscatlán Brown vessel forms commonly occur in deep bowls, comals, ollas, molcajetes, or tripodfooted bowls. Although comals are a common vessel form seen at Hacienda Pancota, tripod-footed bowls and molcajetes are seen in far less frequency. A low frequency in 
these vessel forms continue to evidence that the excavated structures at Hacienda Pancota were not as heavily used for preparing and serving rather than storage.

\section{Early Colonial Pottery}

Comprising of the majority pottery, early colonial pottery has 4 different groups and 8 different pottery types. They appeared in all levels of excavation throughout both structures at Hacienda Pancota.

Teofilo Group. Pantaleón Brown pottery existed in the highest frequency at Hacienda Pancota, comprising of 200 sherds, 109 minimum number of vessels, and $27.32 \%$ of the entire pottery assemblage. They were located in all levels, features, and test units of the excavation. From the Teofilo Group, Pantaleón Brown wares are diagnostic of the early colonial period and have a striated light brown surface color with a medium reddish-brown paste. Some sherds have a slight redwash decoration and consistently take the forms of ollas, deep bowls, necked jars, and comals (Card 2006; Fowler 1988; Kosakowsky 2001; Sampeck 2007:375; Verhagen 1997). Pantaleón Brown wares look similar to Gines Variety wares, but with less friable paste and contain sporadically placed red pumice and white stone inclusions. They can have very smooth, burnished exteriors and interiors, however coarse interior striations due occur on some sherds. Sherds often feel heavier and more dense than they appear. Sherd size ranges from small to very large $(15.3 \mathrm{~cm} \times 13.1 \mathrm{~cm} \times 1.4 \mathrm{~cm})$, suggesting a larger than average vessel size and form. This is known due to a significant refitting of one particular Pantaleón Brown vessel discussed later in this chapter. Sampeck (2007) argued Pantaleón 
Brown pottery types are evident at early colonial, post-reduccion sites though they do not necessarily have to be rural. Hacienda sites, such as Hacienda Pancota may be positioned on an urban periphery, but were not isolated. In fact, their contribution to larger regional and world economies was noted by Chamberlain (1953), McLeod (1979), and Sampeck (2007). The large number of Pantaleón Brown sherds and their minimum number of vessels suggest important storage areas and highly specialized uses of space at Hacienda Pancota.

Teofilo Red-on-Natural wares are likely diagnostic of the early contact period. They are the red slipped version of Pantaleón Brown pottery and similar to sherds analyzed by Wauchope (1970) and Charlton et al. (1995) from the contact period Aztec empire. They have waxy red slip exterior banding with brown surfaces. Their paste is similar to Pantaleón Brown pottery, though some dark cores do exist (Sampeck 2007). Teofilo Red-on-Natural types of pottery usually take the form of small bowls. Though only one sherd was recovered from excavation, this clue may lead to defining Hacienda Pancota focusing its activities as a storage site, rather than strictly focused on food serving.

Raimundo Group. The Raimundo Group contains two pottery types encountered in Hacienda Pancota analysis. First, Raimundo Brown pottery dates from the Late Postclassic to the beginning period of the early colonial period according to Sampeck (2007), but is diagnostic with only the early colonial period according to Verhagen (1997). Primarily a plain utilitarian ware, Raimundo Brown vessel forms are usually tecomates or comals. They are primarily thick and large sherds similar to Pantaleón 
Brown variety, but have more inclusions and a noticeably darker inner core. Raimundo Brown sherds account for $3.83 \%$ of the total pottery assemblage, with 28 total sherds. They evidence 13 minimum number of vessels and were located within all levels, including Feature 1. Spatially, Raimundo brown sherds were recovered from three of four test units in the western structure, but a minority of sherds were in fact recovered from on test unit in the middle of the eastern structure.

Eliseo Red-on-Natural wares date similarly from the Late Postclassic through the colonial period. They are they red sipped and lighter version of Raimundo Brown vessels. They usually have a reddish surface with micaceous inclusions in its paste. Eliseo Redon-Natural is regarded as a utilitarian ware. They have medium thick walls and little to no decoration except an occasional red wash. More frequent than Raimundo Brown, this type accounts for 118 sherds and $16.12 \%$ of the analyzed assemblage. A total of 61 minimum number of vessels were identified from the sherds that were recovered from all levels and features 1 and 2 . They were distributed throughout the two structures in all test pits excluding the eastern side of the eastern structure.

Apolonio Group. From the Apolonio ceramic group, Apolonio Orange-Red has an orange-red slip and primarily comes in a low-walled bowl or water bottle vessel form. Only two sherds were recovered—one from the western side of the western structure and the other from the eastern side of the eastern structure. Apolonio Orange-Red pottery has a medium brown paste and few inclusions on the surface. They are likely an early colonial ceramic that gets replaced by other pottery choices. It occurs in other regional and temporally similar sites, but only in small frequencies as at Hacienda Pancota (Card 
2006; Sampeck 2007). Usually small frequencies of old context and poorly preserved sherds suggest they were the product of construction fill or a disturbed context, though they in fact date to the early colonial period. If Hacienda Pancota primarily was a domestic storage structure, than small bowl and low-walled bowl forms from Apolonio Orange-Red pottery would be uncommon.

Telesforo Brown. Sherds were located in all four levels at Hacienda Pancota and throughout the western structure. In the heavier concentration of deposited pottery located at the eastern corner of the eastern structure, Telesforo Brown sherds were recovered as well. Telesforo Brown is a ceramic type most commonly coarse with notable striations along the interior. Few, small inclusions exist in this sandy but coarse medium brown paste. Sherds were comparatively thick to other sherds in the collection, suggesting large and utilitarian vessel forms. Small number of MNVs made defining the recovered Hacienda Pancota vessel identification difficult, though their sherd thickness are similar sizes to thicker Pantaleón Brown and Raimundo Brown vessels. It is likely Telesforo Brown pottery is contemporaneous with pottery of the early colonial period at Hacienda Pancota due to recovered level and context. Telesforo Brown sherds totaled 28 of the identified assemblage and suggested 14 minimum number of vessels.

Darío Group. From the Darío group, Darío Plain wares are diagnostic of the early colonial period, but likely have much earlier antecedents (Card 2006; Deagan 1987; Sampeck 2007; Sharer 1978; Verhagen 1997; Wauchope 1970). A total of 58 minimum number of vessels were counted and their sherds were recovered from levels 1, 2, and 3 
and Features 1 and 2. Spatially, Dario plain sherds were recovered from all test pits in both structures excluding the western corner of the eastern structure. Often occurring as colonial water bottles, these utilitarian wares are high fired and have an orange-pinkish paste that ranges from white to pink to orange-red interior walls. Their cores can sometimes be dark or light gray. Sampeck (2007) stated that high firing of a vessel marks a turning point in ceramic technology and likely suggests the use of a kiln. The majority of sherds are notable for their vast amounts of micaceous inclusions and brittle feel. They primarily have unpolished or rough interiors and exteriors. Some sherds were strikingly different in color and inclusion type and frequency, making them suspect to different subvariety types. Although the majority of large sherds tend to evidence a water bottle vessel form, small jars and bowls are also common in the analysis. Sampeck (2007) argued the possibility that all Darío Plain wares were red slipped, but did not preserve well, and were thus defined as a plain ware. Darío Plain wares account for 89 total sherds and $12.16 \%$ of the pottery assemblage.

The Bibiana Red variety of the Darío group is the red slipped band and decorated version of Darío Plain. Bibiana Red pottery has the same temporal range as Darío Plain and accounts for 56 sherds, for $7.83 \%$ of the total pottery assemblage. There were an estimated 28 minimum number of vessels. All Bibiana Red sherds were recovered from levels 1, 2, and 3 and Feature 1. Similar to Dario Plain sherds' distribution pattern, all Bibiana pottery was recovered in both structures and all test pits excluding test pit 6 . Its slip does not preserve well, but is usually found as a band along the exterior of the vessel rim. The red slip decoration tends to flake instead of fade off the sherd. Due to all Darío 
group pottery types exact same distribution pattern it is possible the red slip faded and the sherds are misclassified as Darío Plain, when really only Bibiana Red exists.

Special Pottery Types

During analysis of Dario Group ceramics, four variants of the group were identified. Their treatment, exterior color, core color, and interior color were deemed outside the spectrum of regularly occurring Dario Group variability. Some variants had more micaceous inclusions, while other lacked a normal distribution of Dario Group mica all together. Their low frequency in the assemblage suggests that they were bought or traded from different regional areas making similar looking and functioning Dario Group wares when typical Dario Group pottery was not available. It is also possible some of the variants are of different chronological sequences, but their level and spatial distribution suggests they are early colonial. Figure 1 displays their physical characteristic differences from the rest of the Darío Group ceramics of Darío Plain Variety.

Dario Plain Variety One. The first variant (Figure 1) measures $9.5 \mathrm{~mm}$ in thickness - more than any other analyzed Dario Group ceramic. It is heavily micaceous, but not abnormally so, containing numerous white inclusions and few red pumice minerals. Its interior displays wiping striations and would be considered coarse. No decorative motifs exist on this plain sherd. It is deep red throughout - a specific color not noted during any variable color-coding in analysis. It was recovered as a single sherd, with no other like examples from Hacienda Pancota excavations. The sherd is of excellent quality and is the best preserved of the four variants and the rest of the Darío 
Group ceramics. It has physical qualities similar to Dario Group's characteristic dry, raspy, feel to the touch and brittle 'cling' sound when struck.

Darío Plain Variety Two. The second variant (Figure 1) comprises two sherds and are very thin, averaging $3 \mathrm{~mm}$ in thickness. Their color is more orange than red or pink, with the same orange color throughout—-firing the vessel did not alter any differences in core color. Both the interior and exterior sherd walls felt dry and chalky, but the exterior displays a possible eroded color slip. Very little mica inclusions were noticeable throughout the sherds and no other mineral inclusions were present. The sherds are completely flat, suggesting a vessel type of plate or flat-bottomed small bowl. No fireclouding or other manufacturing marks are noticeable. Both the exterior and interior were well smoothed, but not burnished as their heavy chalky feel persists throughout the surfaces.

Darío Plain Variety Three. Similarly orange but tremendously more vibrant and bright, the variant 3 (Figure 1) sherd was refitted from recent or transportation breaks. The sherd displays a scratch noted in the top left corner of the first broken sherd, but this is likely a bag scratch from storage. It measures $6 \mathrm{~mm}$ in thickness and has a chalky, dry feel of the previously mentioned variant. The slight curvature to the refitted sherd indicates a medium sized bowl or jar. Normal amounts of mica are noticeable throughout the paste, but no other inclusions are present. Only the drastically different color of the clay make this Darío Plain variety different than the rest of the pottery in the group. 
Darío Plain Variety Four. The final, fourth variant is depicted in Figure 1. It comprises two sherds that average $6 \mathrm{~mm}$ in thickness each. They exhibit a dark gray core with heavy amounts finely ground white inclusions. No mica is visible throughout any of the sherd. Both the interior and exterior are tannish gray, but on the left edge of the larger sherd an orange-pink hue can be seen under the tannish gray exterior. This orange-pink hue and dark gray core are characteristics of other Dario Group ceramics, leaving the tannish gray interior and exterior as the odd variables. This small sherd is very rounded and poorly preserved. It feels dry and coarse throughout, but with more smoothing on its interior rather than exterior.

All four variants demonstrate measurable levels of Dario Group attributes, but dominant outlier characteristics may well classify them as variants rather than one of the four noted Darío Group types. Variant 1's thickness, inclusions, and color, variant 2's thinness and color, variant 3's color, or variant 4's exterior firing and lack of inclusions were all attributes deemed worthy to be investigated further from their standard pottery typology. 


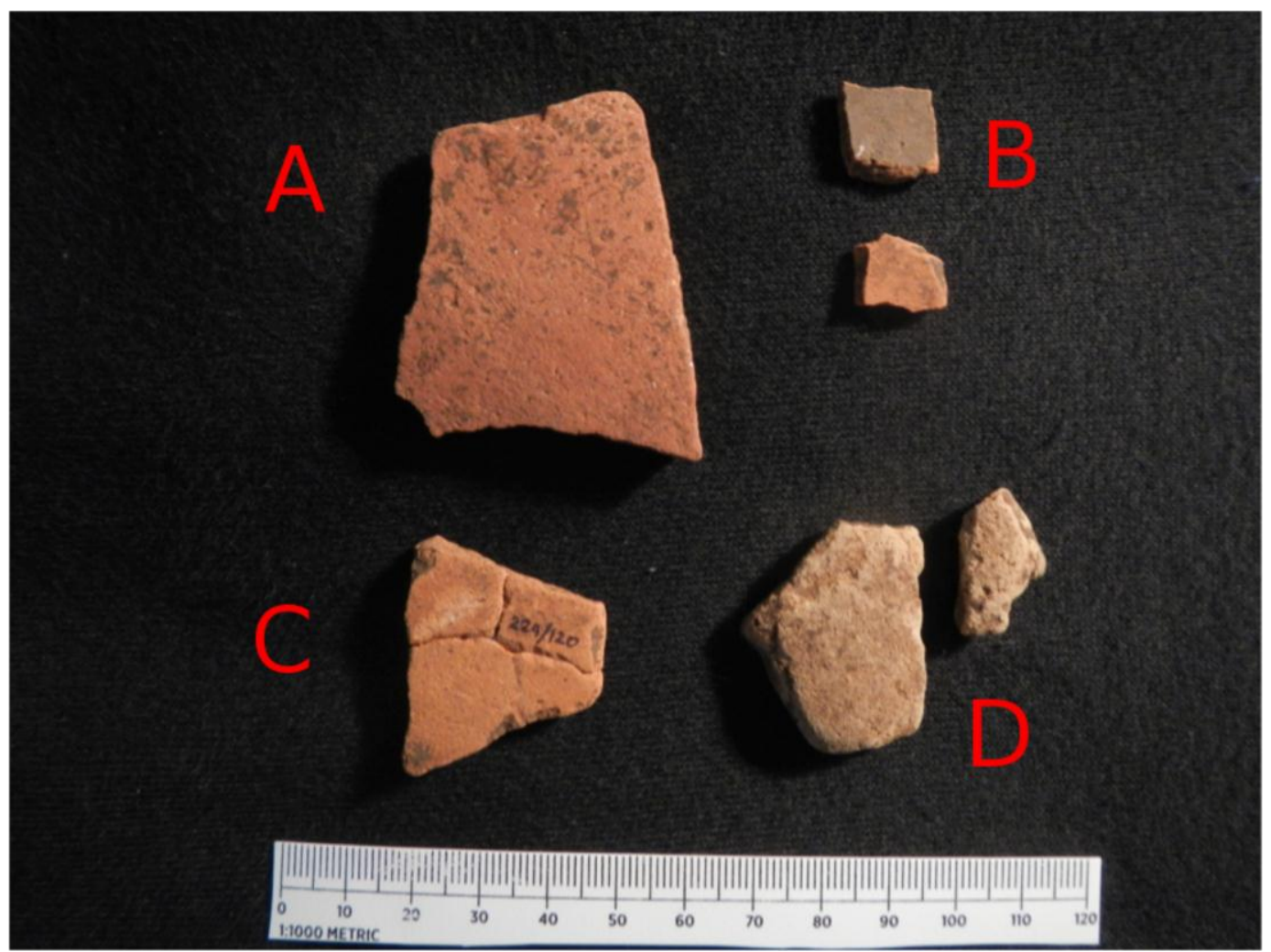

Figure 1 Dario Group Variants

\section{European Tradition Pottery}

European tradition pottery was spatially distributed in fewer test units and was recovered in far less frequency than indigenous tradition pottery at Hacienda Pancota excavations. No complete vessels existed in the analysis and refitting of sherds only accounted for two instances of the entire European tradition assemblage. Refined earthenware, olive jar, and a possible variant of majolica were the only recovered European tradition pottery sherds in the collection at Hacienda Pancota. 


\section{Majolica and Spanish Colonial Pottery}

A type diagnostic pottery located in many New World sites, but not necessarily in the Hacienda Pancota excavations is Spanish majolica, or maiolica. No pieces of majolica were recovered, though a larger sample would needed to be taken in order to potentially identify this iconic new world sherd. Domestic context collections of majolica during the early colonial period vary widely—some households contained much, while others had far less frequent quantities. Goggin (1968, in Sampeck 2007) stated there was an overall decline in exporting Spanish majolica from Spain by about 1650, because Mexican pottery manufacturing of majolica became dominant (Sampeck 2007:526). Majolica can be defined as a broad category of tin glazed earthenwares. With increasing quantities of tin added to the lead glaze, majolica vessels became more opaque and were regarded by the Spanish as better quality (Lister and Lister 1976). Spain transformed their pottery styles rapidly. Since the country's consumers and producers were influenced by a cosmopolitan new Europe with increased world trade, the Spanish colonies managed not to lose sight of the latest trends of their mother country. When tin was discovered in the middle sixteenth century, most of the pottery making in the New World took hold in Mexico, but production also existed on the Pacific coast of Panama during the late sixteenth- and early seventeenth- centuries. Soon after, Guatemala and Peru produced majolica throughout the seventeenth-century. (Lister and Lister 1976:7) Majolica is often beautifully designed and can range from polychrome to monochrome decorative motifs, sometimes including floral themes. 


\section{Lead Glazed Redware}

Total Frequency:

$\%$ of Total Pottery:

$\%$ of Total Collection:
$57(26 \mathrm{MNV})$

$7.79 \%(6.74 \% \mathrm{MNV})$

$5.45 \%(2.49 \% \mathrm{MNV})$

Lead glazed redware sherds may be considered within the same general class as majolica — however different they may be —in that they are either imported from Europe or locally produced types of European traditions in form and decoration. In fact, ware that combine attributes of both lead glazed wares and tin enameled wares include what Lister and Lister (1982) described as Indigena Ware (see also, Rodríguez-Alegría 2005). Indigena Ware dates from the middle to late sixteenth century and was manufactured in Mexico. These ceramics are decorated with a white of light yellow slip into which sgraffito designs were etched. The final coat of a typically iridescent lead glaze occurs over all surfaces of vessels.

The comparatively thin and decorated sherds that make up this lead glazed redware category reflect the description dictated from Lister and Lister (1982). Evidence of their recovery in El Salvador suggests a direct trade connection to Central Mexico (Sampeck 2007:491), making its discovery important for understanding trade networks throughout the region. These lead glazed redwares are generally regarded as pottery produced for indigenous societies, but inspired by imported Old World majolica (Rodríguez-Alegría 2005). Although the lead glazed redwares in the Hacienda Pancota collection are all small in size amongst the rest of the analyzed pottery, they remain frequent and indistinguishable from the rest. According to Lister and Lister (1982) Indigena wares, or pottery made by Indians, have a characteristically unique iridescent 
streaking that occurs on top of its lead glaze. This unique iridescent streaking occurs on some of the sherds. Common vessels types occurring within this style of pottery are plates, bowls, porringers, and straight-necked jars (Sampeck 2007; Lister and Lister 1982:35).

It is possible that the lead glazed redwares might be of a more modern manufacture. According to Brown (1982) and Hume (1978), a locally produced variant of lead glazed redwares existed throughout the entire nineteenth century in North America. They were primarily utilitarian in use and lacked or had minimal decoration. Their frequency and distribution throughout two levels and spatially in multiple test pits evidences an earlier manufacture date, but it is possible these sherds are more recent than previously argued.

Recovery of lead glazed redwares in excavations accounted for $7.79 \%$ of the pottery collection. They were located in levels 1 and 2, as well as within Feature 2. Spatially, they were distributed in the heaviest concentrations of pottery in both structures - the eastern corner of the eastern structure and the eastern corner of the western structure. They were distributed, almost evenly, within both structures but more heavily concentrated in Hacienda Pancota's eastern structure.

Unglazed Coarse Earthenwares: Olive Jars

$\begin{array}{ll}\text { Total Frequency: } & 9(7 \mathrm{MNV}) \\ \% \text { of Total Pottery: } & 1.23 \%(1.81 \% \mathrm{MNV} \%) \\ \% \text { of Total Collection: } & .86 \%(.67 \% \mathrm{MNV} \%)\end{array}$


More commonly referred to as olive jars, coarse earthenwares in the Spanish colonial context were distributed throughout the New World. Originally known for carrying and storing olive oil, olive jars were often reused as storage vessels for wine and other liquids (Verhagen 1997) in both domestic and commercial settings. They are an undecorated plain ware, but show typological and stylistic changes throughout their lifespan (Goggin 1960; Marken 1994). Their evidence at New World sites allows for cross dating and evaluation of Spanish ceramic technology influences. Hacienda Pancota excavations accounted for the recovery of $1.23 \%$ of olive jar sherds in levels 1,2 , and 3 from test pits 1,2,3, and 5. Olive jar sherds had a higher frequency distribution in the west structure, as opposed to the east structure. Sherds had a sandy, coarse-grained interior and exterior (Marken 1994). Some contained a faded white wash on both the interior and exterior. Others were plain gray or appeared to display a chalky external characteristic. No rim sherds were recovered from excavations.

\section{Refined Earthenwares}

Total Frequency:

$\%$ of Total Pottery:

$\%$ of Total Collection:

\section{$3(3 \mathrm{MNV})$}

$.41 \%(.78 \% \mathrm{MNV} \%)$

$.27 \%(.29 \% \mathrm{MNV} \%)$

Refined earthenwares recovered from excavations at Hacienda Pancota account for a comparatively small fraction of pottery. They were likely mass produced in both decorated and plain styles. Decoration of one sherd included a dark green, hand painted, vegetation motif resembling a stem and leaf. Their location in three test units distributed throughout both structures, including the most dense artifact concentrations, places them 
spatially in both the eastern and western structures. Their composition suggests a much later manufacture and occupation than the majority of the excavated collection. Due to their small sherd size, averaging $1.3 \times 9 \times 3.5(\mathrm{~mm})$, minimal decoration, lack of shell edging or diagnostic rim design, and surface coloring, it is possible they are creamwares dating to the late eighteenth century (Brown 1982). However, their context suggests continuous occupation did not necessarily flourish at Hacienda Pancota, but might have been sporadically populated with less dense occupation through to the twentieth century. A nineteenth century or twentieth century occupation and manufacture date would evidence these minimally distributed sherds reflect a style of mass produced modern creamwares.

\section{Other Imported Pottery: Oriental Porcelain}

$$
\begin{array}{ll}
\text { Total Frequency: } & 6(4 \mathrm{MNV}) \\
\% \text { of Total Pottery: } & .82 \%(1.04 \% \mathrm{MNV} \%) \\
\% \text { of Total Collection: } & .57 \%(.38 \% \mathrm{MNV} \%)
\end{array}
$$

There are two variants of Chinese porcelain recovered from western El Salvador's Hacienda Pancota that are likely diagnostic of the early colonial period: Kraak and Swatow (Sampeck 2007). These porcelains are typical products of Ming Dynasty (1368 CE-1644 CE) manufacturing. Kraak porcelain was a non-commissioned Chinese ware that was made primarily for export. Based on conclusions from Rinaldi (1987, in Sampeck 2007:511), Kraak porcelain was quite cheaply made with "sloppy" design patterns. It was most popular from 1560-1640 and recovered in early colonial period Latin American archaeological sites and shipwrecks (Card 2007; Deagan 1978, 1987, 2011; Gasco 1992; Marken 1994; Sampeck 2007). 
Next, Swatow ware can be considered coarse porcelain, similar to stoneware and very durable (Sampeck 2007:520). This style of ware has not been located outside of El Salvador through any other archaeological investigation (Sampeck 2007:520). These wares cost less to produce than Kraak porcelain and were popular in Japan and Indonesia during the seventeenth-century (Sampeck 2007:520). They date from approximately the sixteenth- to seventeenth- centuries according to Rinaldi (1987, in Sampeck 2007). Varying iconography, such as bamboo and other floral elements, are depicted on the Swatow ware than those found on Kraak.

Due to their export history, it is presumed that four porcelain sherds recovered in the Hacienda Pancota excavations are of the Kraak porcelain variety and two of Swatow. The relatively small appear to be from four different vessels. The Kraak sherds were recovered from levels 1 and 2. Of the six total porcelain sherds and four probable vessels, it is unclear whether or not the vessels displayed any artistic motifs. There are no maker's marks and little hand painted decoration on one of the sherds. Four of the six sherds occur in Level 2 deposits.

Only one of the sherds in the group displayed a polychrome pattern on its exterior surface. Light pink, black, light green, and light yellow colors depict an abstract design motif. This sherd was located in the $20 \mathrm{~cm}$ level 2 in the middle of the western structure. The sherds were too small to be absolutely sure regarding their vessel type, but three sherds were absolutely flat evidencing a plate, two were slightly curved suggesting a small drinking cup, and one sherd was too small to make any conclusion regarding form. 


\section{Summary of Pottery Type Results}

Of the 24 identified pottery types recovered and analyzed from Hacienda Pancota, upwards of four additional variants were identified. Based upon the ceramic recovery, the residents of Hacienda Pancota tended to favor locally made unglazed indigenous wares as their main source of pottery. Fourteen (70\%) of the pottery types were identified as locally and regionally produced indigenous wares. Unidentified Late Classic pottery, unidentified Late Postclassic pottery, Cipriano Red on Gray, Catalina Red on White, Teshcal Red on Natural, Cuscatlán Brown, Gines Plain Variety, Darío Plain, Bibiana Red, Pantaleón Brown, Eliseo Red on Natural, Apolonio Orange-Red, Telesforo Brown, and Raimundo Brown were identified as the locally produced indigenous wares.

European pottery and European tradition pottery included olive jars, lead glazed redwares, tejas ceramic, ladrillos ceramic, and Creamware. Imported non-European pottery consisted of Ming dynasty era Chinese porcelain. Table 4 shows sherd counts and percentage frequencies for all three cultural traditions. The percentages are compared against their respective levels in order to witness how the relative proportions change from one level to the next. Lead glazed redwares incorporate European technology. In total, European tradition and European imported pottery account for less than a tenth of the entire pottery assemblage. Imported Chinese Kraakporcelain is even fewer in frequency and measuring less than $1 \%$ of pottery assemblage. Indigenous and locally made pottery comprises $89.48 \%$ of the pottery collection, evidencing availability, knowledge of their manufacture, and daily consumption patterns. Regardless of the influence of Spanishness, residents at Hacienda Pancota continued to use local vessel types, even if they were reconstituting them for new uses during adaption. 


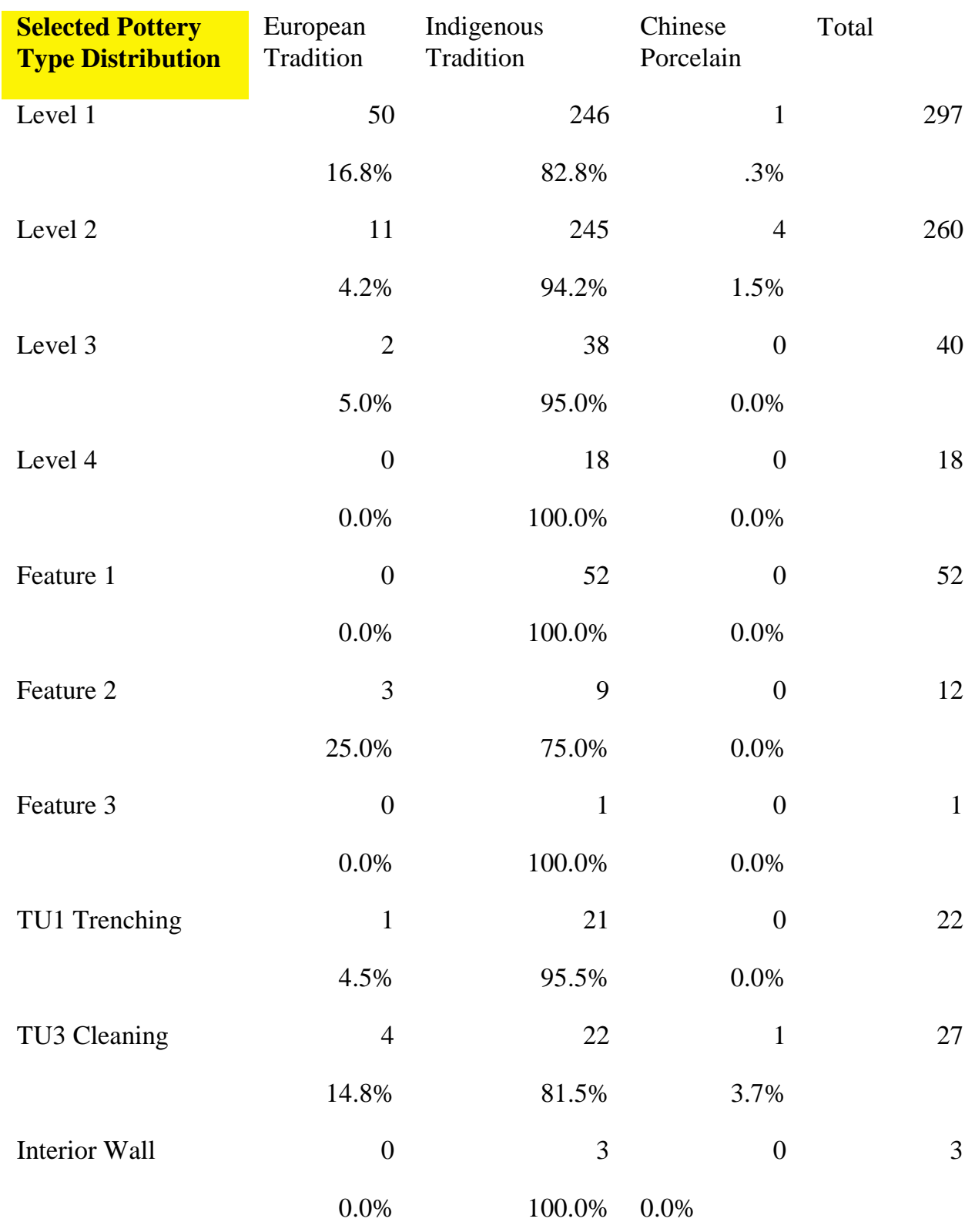

Table 4 Selected Pottery Traditions from Each Level

Figure 2 evidences changes in wares by each level. The lowest two levels contain no imported Chinese ceramics. Level 4 activities made use of only local materials in their daily consumption. European tradition pottery does not show up until Level 3, but then does not go away and is used through the most recent archaeological context. Imported goods are now an established part of consumption at Hacienda Pancota. By level 2, 
Chinese porcelains are recovered when European wares tended to decline in small amounts. The upper levels, especially in Level 1, are noted where European wares were used most frequently. The overall pattern suggests that imported pottery traditions do not overtake indigenous pottery traditions, but they are weakened due to sharing new types of goods.

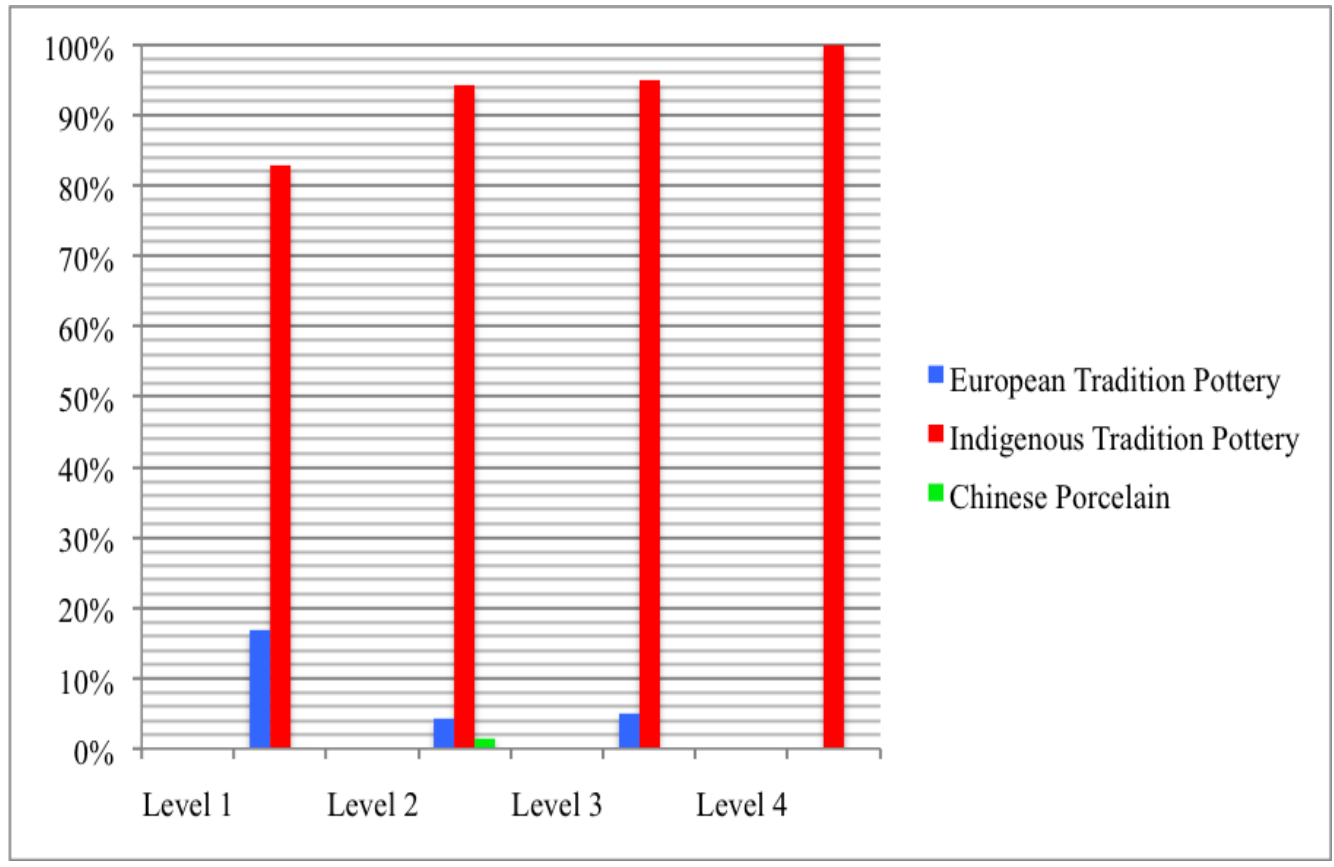

Figure 2 Relative Frequencies of Pottery Traditions

Overall Vessel Form Results and Minimum Number of Vessel Results

Every sherd was sorted by level and test pit, then by specific type. A total of 385 MNVs account for Hacienda Pancota's pottery assemblage. They were organized by provenience level and excavated feature (Appendix A.4). 
Vessel Form Results of Indigenous Tradition Pottery

Most sherds were small bodied, making the analyzing of vessel type difficult. The largest clues evidencing vessel form were ceramic type, decoration, sherd curvature, and excavation provenience. Rim sherds accounted for less than $8 \%$ of the entire pottery assemblage, thus vessel type was determined for just over half (198) of the 386 total analyzed minimum number of vessels.

Gines Variety pottery comprised of three vessel forms: comals (2), small/medium sized bowls (5), and a single tecomate. Catalina Red-on-White pottery accounted for all small body sherds measuring $2.4 \mathrm{~cm} \times 1.8 \mathrm{~cm}$ or under, with the exception of one rim sherd. The rim sherd exhibited a smoothed rim with straight profile and little convex curvature. Its profile evidences a bowl or basin, much like those supported in Sampeck (2007). Size of the vessel was difficult to determine based upon the small thickness and size of the rim sherd.

Pantaleón Brown vessel forms were primarily large ollas (41) and comals (22). Red wash was common of only 2 of the olla vessel forms. Ollas and closed necked jars were generally thicker and unsmoothed compared to a smooth finished comal pottery type. Large ollas were generally rougher than deep bowls being moderately smoothed on both the interior and exterior. Small body sherds averaging approximately $3 \mathrm{~cm} \times 3 \mathrm{~cm}$ accounted for the majority of the assemblage, but large sherds twice that size were common. A total of 47 sherds had indistinguishable vessel form characteristics for type analysis.

Raimundo Brown sherds were comparatively thick to most sherds in the Hacienda Pancota ceramic assemblage. As supported by Sampeck (2007), vessel types 
can be either comals (2) or tecomates (4). Analyzed Raimundo Brown sherds in the Hacienda Pancota assemblage likely fall into the aforementioned two categories as they are either thick and smoothed on the exterior only, suggesting a storage vessel, or they are thick, flat, and smoothed evidencing a comal. Raimundo Brown's utilitarian, unglazed, and similar paste characteristics harkened to the familiarity of Pantaleón Brown pottery forms.

Eliseo Red-on-Natural sherds were similar to Raimundo Brown-thick, likely utilitarian, and either olla (3), tecomate, or comal vessel form. One sherd evidenced a large storage vessel with a uniquely smoothed flat bottom and rough interior. Both large and small fragmentary sherds existed, with the very small fragmentary sherds causing an artificial inflation in raw count analysis. Darío Plain sherds accounted for colonial water bottles with recurved necks and unsmoothed interiors (34), small jars, and or small bowls (24) as supported by Sampeck (2007). Water bottles generally have a thicker sherd dimension with rougher interiors and smoothed exteriors than the thinner and smoother small jar or bowl sherds. Bibiana Red sherds had the same vessel forms, contributing to a definite five colonial water bottles and 12 small jars or bowls.

Apolonio Orange-Red sherds comprised of thick bowls or storage vessels, not as thin as water bottles of Darío Plain, but similar to Raimundo and Teofilo Group pottery. Only two sherds exist in the assemblage, stemming from different vessels. Teshcal Redon-Natural sherds exhibited smoothed but visible interior striations. Sampeck (2007) stated the two most common vessel forms are molcajete bowls and water bottles. Due to the high frequency of smoothed interiors and absence of neck sherds, the analyzed material evidences bowl forms (5). Only one sherd likely represents a water bottle vessel 
form, having a comparatively thicker red slip with little to no crazing. The sherd is a neck-to-body joint fragment, evidencing geometry of a closed neck vessel.

Cipriano Red-on-Gray sherds only numbered a total of two-one of which is a small rim. Too little evidence is provided from the sherds to make claims about exact vessel form other than the likelihood of a small bowl, basin, or taza. Cuscatlán Brown sherds can occur from a variety of vessel forms, but none of the sherds under analysis were large enough or of the right vessel part to clearly identify their form. Sampeck (2007) stated the 8 sherds analyzed in the Hacienda Pancota collection could be a bowl, jar, comal, olla, or molcajete basin.

\section{Results of a Pantaleón Brown Refitted Vessel}

From the many sherds refitted during pottery type identification, one vessel in particular retained much of its original form (Figure 3 and Figure 4). With a faded red wash, this tecomate or olla Pantaleón Brown vessel is pictured with smoothed wiping striations on the exterior of the vessel. According the Sampeck (2007:371), the most common vessel form of Pantaleón Brown pottery type is a recurved olla with lug handles. The midsection of this olla had no lug handles. This vessel's paste includes more than the typical amount of white inclusions, but similar frequencies of visible mica for its pottery type. The large storage container is relatively smoothed on the interior and exterior alike. The interior of the vessel appears to have leeching marks from mineral inclusions falling out or disintegrating within the entire interior's middle. Due to the olla's vessel form usage as a storage container, it is possible stored liquids contributed to partial mineral leaching. 
The vessel sherds were recovered from the eastern corner of the western structure. Originating from Level 2, this refitted partial vessel was recovered from the time when both Chinese porcelain and other assorted European goods were getting established into activities at Hacienda Pancota.

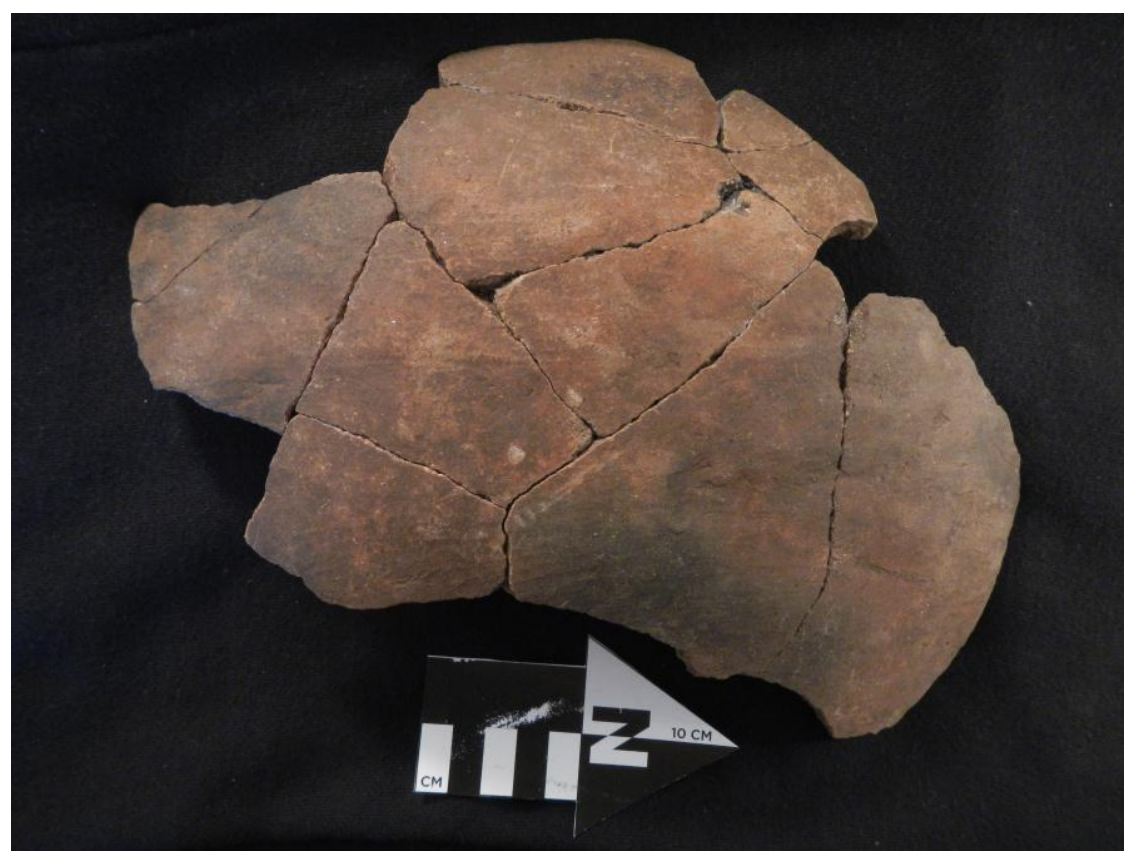

Figure 3 Exterior of Refitted Pantaleón Brown Vessel 


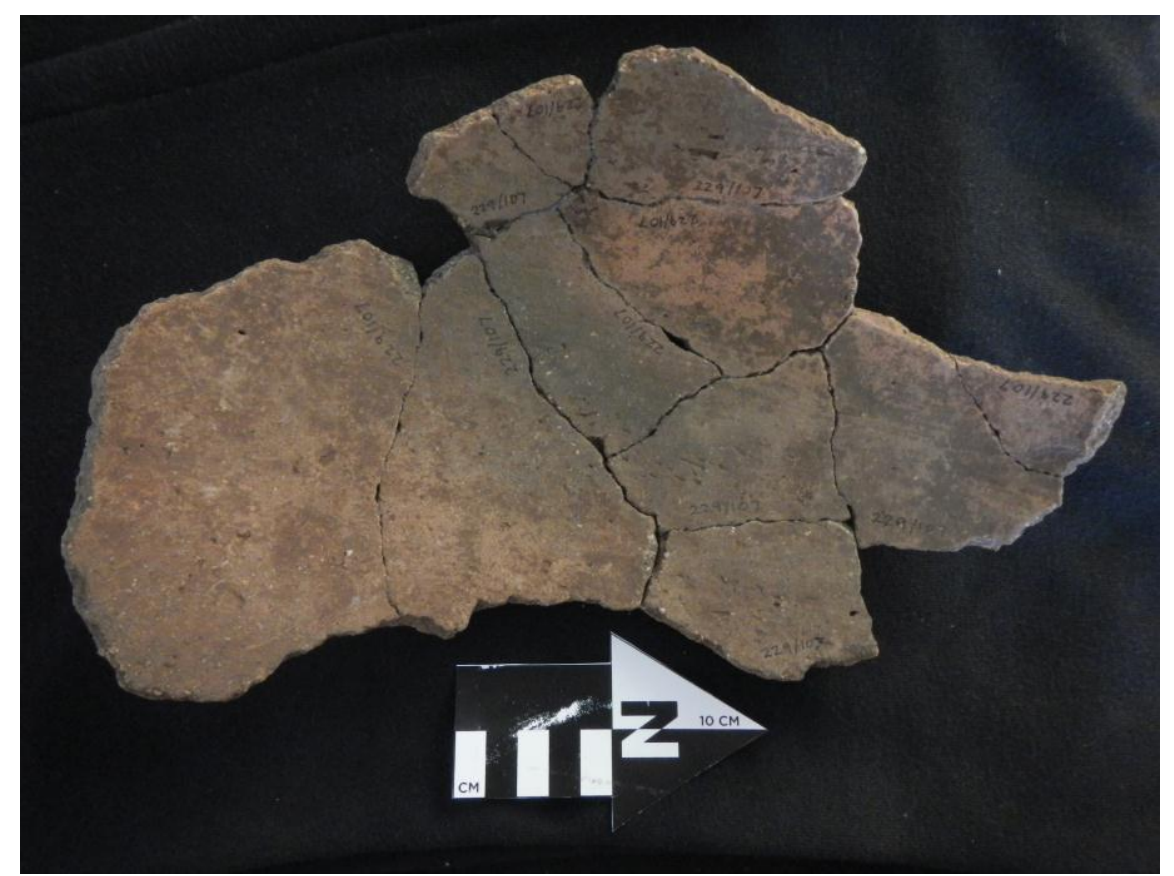

Figure 4 Interior of Refitted Pantaleón Brown Vessel

\section{European Tradition Vessel Forms and Porcelain Vessel Forms}

Olive Jar sherds accounted for an estimated 7 individual vessels from the Hacienda Pancota excavations (Table 5). Neither neck or rim sherds contribute to the assemblage. According to Goggin's (1960) olive jar chronology, it is evident the sherds recovered from Hacienda Pancota are of the middle style, dating from 1560-1800. Marken (1994) emphasized two distinct phases of Goggin's (1964) middle style olive jar, $\mathrm{A}$ and $\mathrm{B}$. These phases fall within the chronological range of the late sixteenth-century until the middle eighteenth century (phase B) and late nineteenth century (phase A).

The average sherd thickness is $8.26 \mathrm{~mm}$. One sherd from level 2 was measured at $4.8 \mathrm{~mm}$, and is likely a sherd broken horizontally with a smoothed interior due to decomposition processes on its interior. Substituted from the average, the rest average raises to $8.76 \mathrm{~mm}$. An $8.76 \mathrm{~mm}$ average of olive jar thickness is higher than Goggin's 
(1960) early style and lower than the middle style but within a close enough range to support and early colonial chronology.

$\begin{array}{lr}\text { Olive Jar Sherd Thickness } & (\mathrm{mm}) \\ \text { Trenching/TP1/124 } & 9 \\ \text { Level 2/102 } & 9 \\ \text { Level 2/102 } & 9.2 \\ \text { Level 2/110 } & 8.8 \\ \text { Level 2/120 } & 8.3 \\ \text { Level 3/106 } & 8 \\ \text { Level 1/103 } & 9 \\ \text { Level 2/102 } & 4.8 \\ & \\ \text { Average Thickness } & 8.26 \\ \text { Average Thickness w/o Outlier } & 8.76\end{array}$

Table 5 Thickness (mm) Measurements for Olive Jar Sherds

Lead Glazed Redware sherds tended to be thinner than most in the total collection, with no rim profiles available for analysis. They were likely small cups, bowls, and small jars. 6.7\% (26) of all the analyzed MNV accounted for lead glazed redwares. Most of the distribution occurred in Level 1, after European goods were well established at Hacienda Pancota.

Only 3 Creamware sherds were recovered throughout the whole assemblage of the collection. Their sherd size is small with 2 MNVs. Their vessel type can only be hypothesized. Small cups, plates, and saucers are the most common vessel types. All Chinese imported porcelain was recovered from Level 2. Plates (3) and a small teacup (1) were identified during analysis. The other 5 sherds were too small to make any vessel 
form distinctions. However, it is likely Chinese porcelain from the Ming Dynasty can to Hacienda Pancota as plates, cups, and small saucers.

\section{Vessel Form Stratigraphy}

The vertical context of vessel form was important for understanding activity use change through time. From the 386 MNVs, only 196 could be accurately identified. Figure 5 depicts this vertical change through three broad types of vessel forms. The reds, oranges, and pink colors represent storage vessels. Shades of blue represent food preparation vessels. Green colors depict serving vessels. The analysis of vessel form stratigraphy shows patterns of activity change over time due to new imported technologies and a shifting world market. Tecomate vessels clearly dominate Level 4, arguably the oldest level. They were the only identified vessel form, though other MNVs were calculated their specific vessel form was unknown. Level 3 evidences increased diversity in vessel usage at Hacienda Pancota. Storage vessels, food preparation vessels, and serving vessels were all present. An emphasis on food preparation and food storage is clear in Level 3. A clear change in Level 2-the most dense artifact concentration leveldepicts an emphasis on storage and serving vessels. Food preparation vessels were still present, but are not as significantly represented compared to the other two categories. Level 2 also sees the highest degree of European and Oriental imported wares. These newer and more accessible wares influenced the type of activity occurring at Hacienda Pancota due to an adaption towards storage and serving activities. Corresponding to Hacienda Pancota's most recent occupation in the collection, Level 1 represents strong vessel forms from all three activity types. Like Level 2 where storage vessels and serving 
vessels were high, food preparation vessels contribute a significant concentration in the specific form of comals.

The change between Level 3 and Level 4 give perhaps the most significant insight into changes at Hacienda Pancota. New adoptions of imported technology come with new population stresses from internal and external forces. Indigenous technology was still highly emphasized during the change from Level 4 to Level 3, but a far more diverse range accompanied a possible increased population and standardized agricultural practices for growing markets.

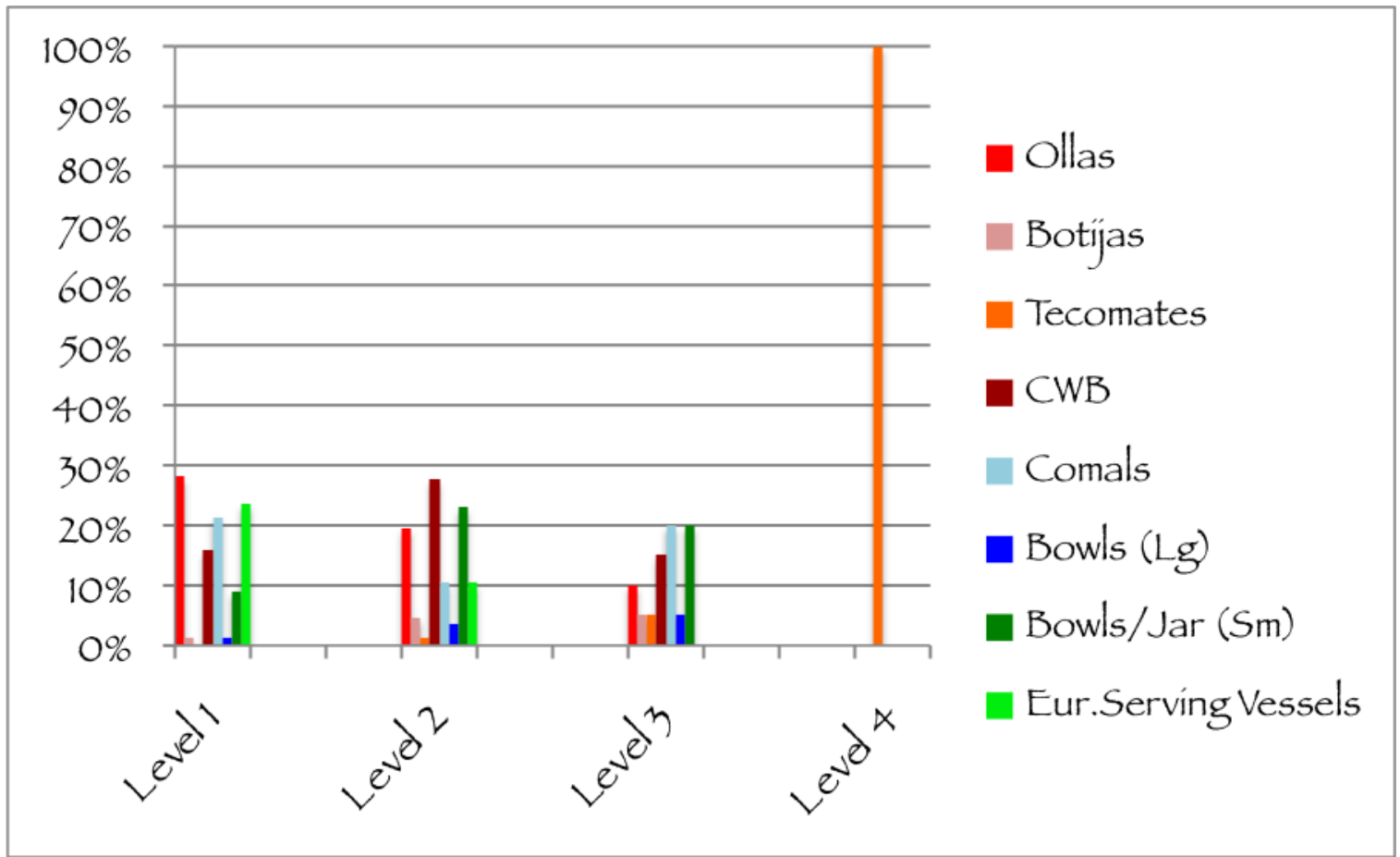

Figure 5 Vessel Form Stratigraphy 


\section{Examining Decorative Pottery}

Decorated pottery was limited to exterior paint at Hacienda Pancota. Clay manipulation was limited to wiping striations and rim variations. No engraving or cord marking were noted, although these art forms were usually done in much earlier Mesoamerican time periods. Hacienda Pancota evidences a strong record of decorated pottery throughout all its occupation periods (Table 6).

Late Classic wares accounted for $2.30 \%$ of all decorated MNVs and .52\% of all analyzed pottery MNVs. Shades of dark red, light red, and white comprised of the total Classic color scheme sample at Hacienda Pancota (Figure 6). Vessel identification of the Late Classic ware was unknown, though its decorative paint initiates a long-standing tradition of painted pottery at what would become Hacienda Pancota.

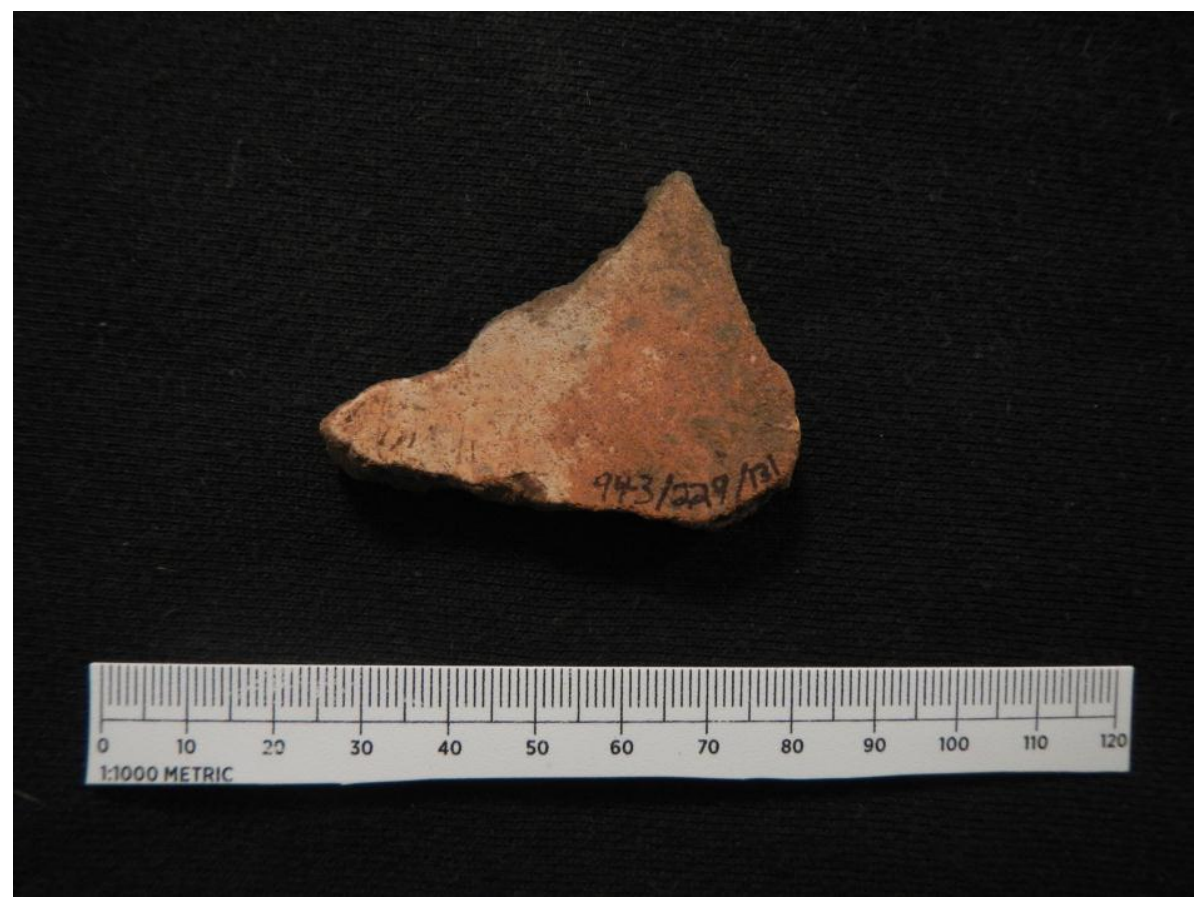

Figure 6 UID Classic Period Decorated Sherd

With a similar color scheme, Late Postclassic vessels displayed decorative exterior paint of red and white, with red linear designs throughout the body sherds. They 
accounted for $1.15 \%$ of all decorated pottery and $.26 \%$ of all analyzed ceramics in the collection (Figure 7). Geometric and linear motifs define much of the decorated Late Postclassic pottery recovered from Hacienda Pancota. These red painted lines on white slips reflect later contact period designs popular in the limited decoration of storage containers recovered from both structures of the hacienda.

Similarly, contact period painted pottery was attributed solely to Teshcal Red-onNatural vessels, attributing to $20.69 \%$ of all decorated pottery and $4.68 \%$ of the entire ceramic collection MNVs (Figure 7). These linear red painted designs reflect earlier Late Postclassic motifs. Teshcal Red-on-Natural pottery transitions into early colonial decorated pottery with similar red linear designs.

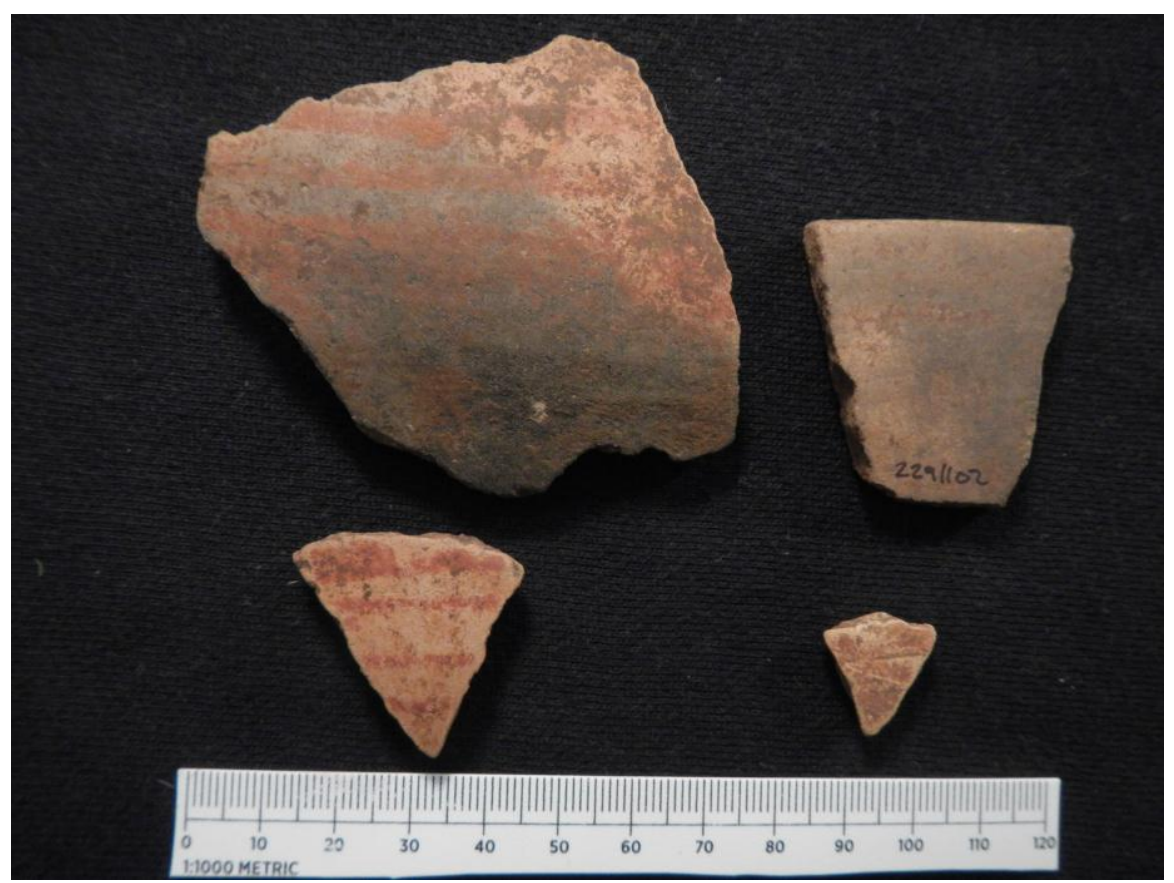

Figure 7 Postclassic and Contact Period Decorated Sherds

Early modern period pottery was most significant with its exterior paint applications. Bibiana Red, lead-glazed redware, Apolonio Orange-Red, Whiteware, and Porcelain sherds all demonstrated painted decoration diagnostic of the early modern 
occupation (Figures 8 and 9). Decorated sherds diagnostic of the early modern period accounted for $65.52 \%$ of all decorated pottery and $14.81 \%$ of all analyzed ceramics in the collection. New colors emerged from the early colonial decorated pottery as a higher frequency of imported goods became available to Hacienda Pancota residents.

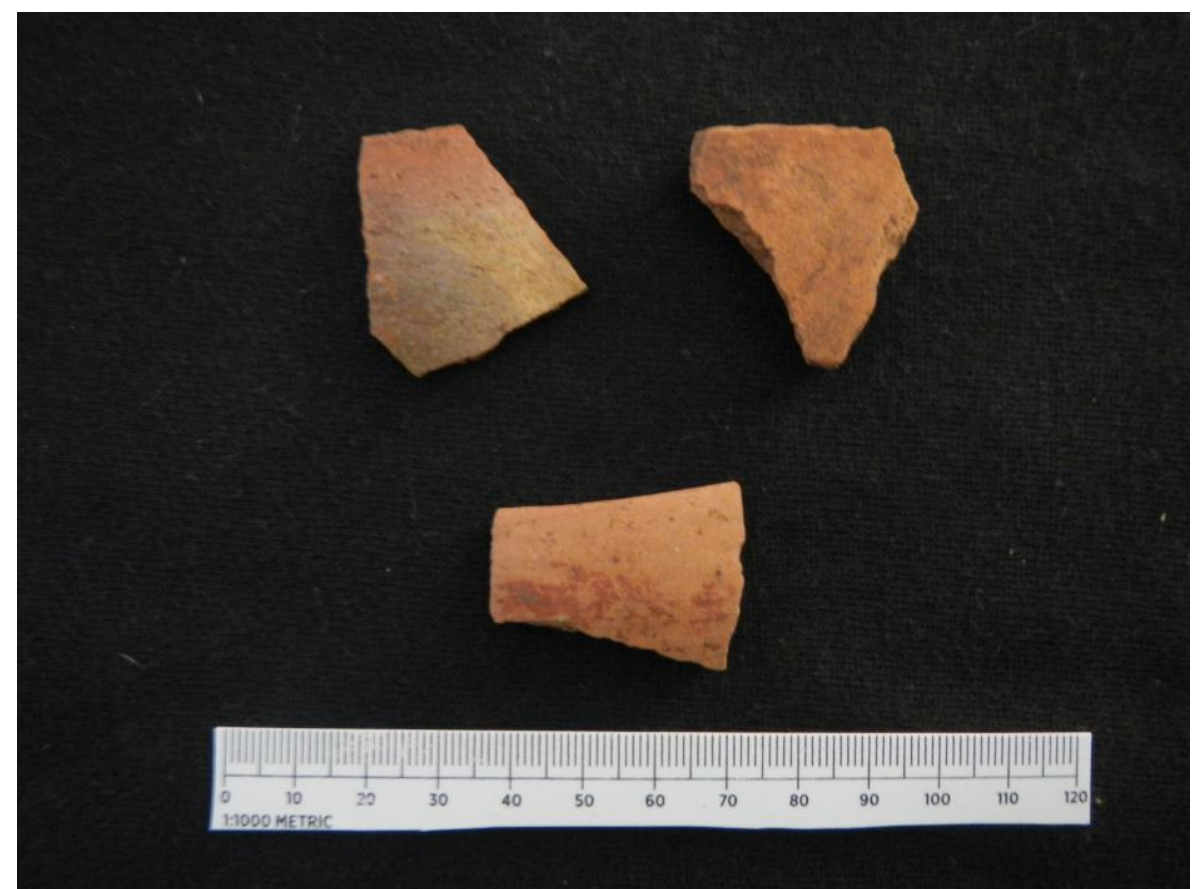

Figure 8 Early Colonial Decorated Sherds 


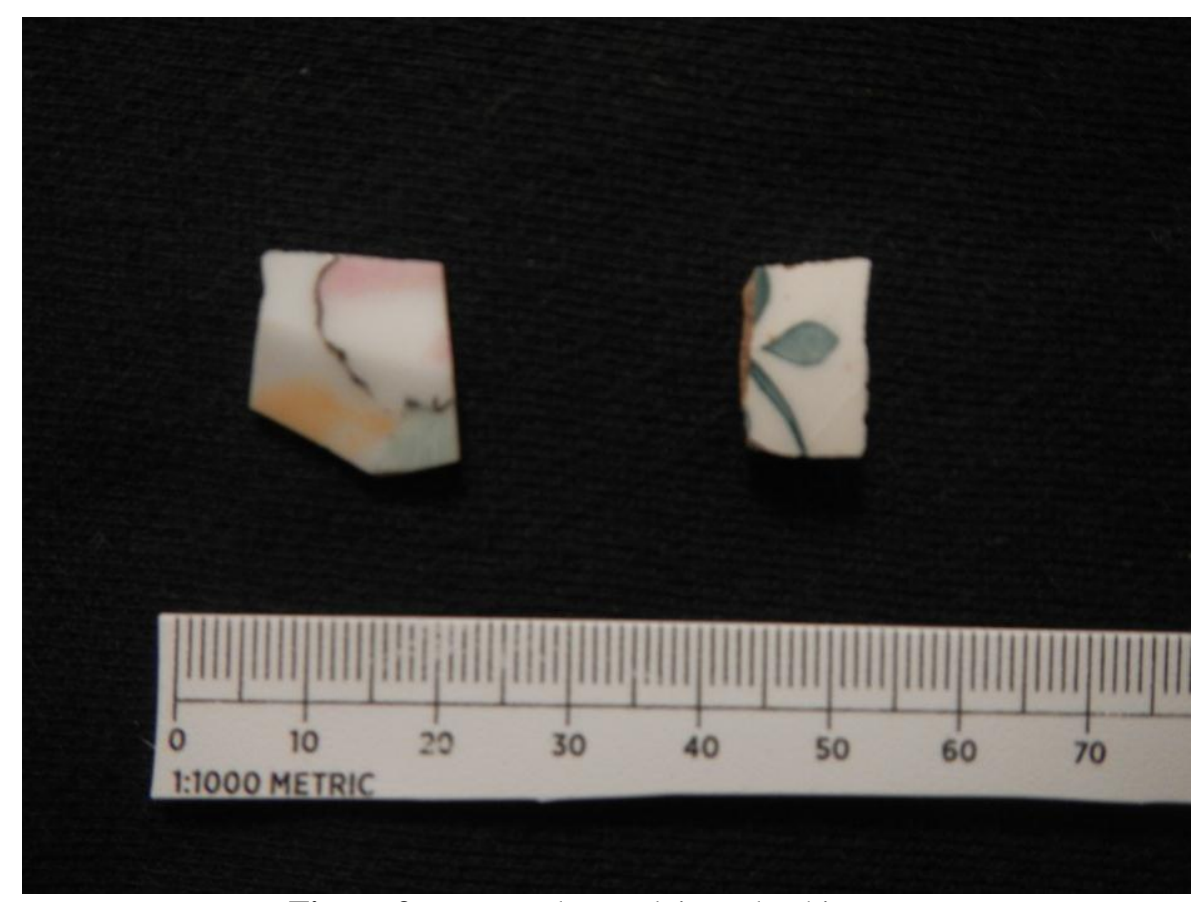

Figure 9 Decorated Porcelain and Whiteware

The largest concentration of any single pottery type of decorated sherds was leadglazed redware. As previously argued, these small serving vessels totaled 20 individual sherds $(22.98 \%)$ and were recovered from Level 1 in the eastern corner of the eastern structure. An additional 10 more undecorated redware sherds were located within the same level and test unit. The second most dense concentration of decorated sherds were Bibiana Red, located in Level 2 of the western structure's far eastern unit. This concentration of sherds totaled 12. However, Bibiana red sherds accounted for the highest total of decorated sherds in the analyzed collection, at $32.18 \%$, throughout the excavations at Hacienda Pancota. Evidence from the two highest proportions of decorated sherds was from the most populated occupation period, the early colonial period. Descending both chronologically and in frequency are contact period decorative sherds, comprising of only Teshcal Red-on-Natural. Diminishing in frequency were Late Postclassic and Late Classic sherds. The frequency of decorated sherds diminishes when 
going back in time due to sample size. It also is important to understand activity switches of vessel form chronologically. In times periods where serving vessels were being used more frequently, decoration of vessels increases. Storage vessels tended to be less decorative.

\begin{tabular}{|c|c|}
\hline Pottery with Decoration & Total \\
\hline \multirow[t]{2}{*}{ Creamware } & 2 \\
\hline & $2.30 \%$ \\
\hline \multirow[t]{2}{*}{ Porcelain } & 1 \\
\hline & $1.15 \%$ \\
\hline \multirow[t]{2}{*}{ Lead Glazed Redware } & 26 \\
\hline & $29.89 \%$ \\
\hline \multirow[t]{2}{*}{ Bibiana Red } & 28 \\
\hline & $32.18 \%$ \\
\hline \multirow[t]{2}{*}{ Apolonio Orange-Red } & 2 \\
\hline & $2.30 \%$ \\
\hline \multirow[t]{2}{*}{ Teshcal Red on Natural } & 18 \\
\hline & $20.69 \%$ \\
\hline \multirow[t]{2}{*}{ Catalina Red on White } & 5 \\
\hline & $5.75 \%$ \\
\hline \multirow[t]{2}{*}{ Cipriano Red on Gray } & 2 \\
\hline & $2.30 \%$ \\
\hline \multirow[t]{2}{*}{ UID Postclassic } & 1 \\
\hline & $1.15 \%$ \\
\hline \multirow[t]{2}{*}{ UID Classic } & 2 \\
\hline & $2.30 \%$ \\
\hline Total & 87 \\
\hline
\end{tabular}

Table 6 Raw Counts of MNVs for all Decorated Pottery 


\section{Early Colonial Water Bottles: Variation Results of Darío Plain and Bibiana Red}

With a total of 145 sherds selected for further analysis, a combination of 11 variables were selected that best defined characteristics of the Darío group pottery. The categories included: thinnest dimension $(\mathrm{mm})$, thickest dimension $(\mathrm{mm})$, mean sherd thickness (mm), exterior color, interior color, core color, mica average, red pumice average, other inclusions consisting of black, brown, and white colors, presence of interior striations, presence of burnished/smoothed exterior surface, and presence of fireclouding. All attributes were then coded as separate variables. The numbers assigned while variable coding, did not matter as much as the consistency by which they were assigned them. They were given arbitrary numerical designations that stayed consisted throughout the analysis. Color descriptions resulted in 21 possible choices.

Instead of defining much microvariation within a pottery type, all performed statistical analyses revealed spatial patterning of vessel types and vessel function within the Darío group ceramics. 'Sherd thickness' demonstrated the best application of microvariation as the independent variable. This independent variable was split into two classes: sherds thicker than $5 \mathrm{~mm}$ accounted for the first class, and sherds $5 \mathrm{~mm}$ and thinner was defined as the other.

Table 7 evidences Darío Plain sherds in the Darío group from the aforementioned classes. A general correlation that is thinner sherds are smoother, with some burnished in appearance. This smoothing was noted on both the inside and outside of the vessel. Variables such as red pumice, normal frequency of mica distribution, and other mineral inclusions were not statistically significant. 


\begin{tabular}{|c|c|c|c|c|c|c|c|}
\hline Darío & & & & & & & \\
\hline Plain & & & Normal & & White & Black & Multiple \\
\hline Sherd & & Wiping & Mica & Red & Mineral & Mineral & Different \\
\hline Thickness & Smoothed & Striations & Dist. & Pumice & Inclusions & Inclusions & Inclusions \\
\hline More than & & & & & & & \\
\hline $5 \mathrm{~mm}(42$ & & & & & & & \\
\hline total) & 9 & 9 & 31 & 8 & 13 & 0 & 2 \\
\hline $\begin{array}{l}5 \mathrm{~mm} \text { or } \\
\text { less }(58\end{array}$ & & & & & & & \\
\hline total) & 33 & 6 & 49 & 4 & 19 & 1 & 1 \\
\hline
\end{tabular}

Table 7 Results of Darío Plain Sherd Thickness

Spatially, there was little spatial distribution variation throughout the two classes of Darío Plain pottery sherds (Table 8). Neither class of Darío Plain pottery was recovered from the western side of Hacienda Pancota's east structure. The largest distribution variations occurred in the eastern corners of the western structure, where $34.88 \%$ (15) of all the sherds recovered were more than $5 \mathrm{~mm}$ thick, as opposed to $65.12 \%$ (28) of the recovered sherds measuring $5 \mathrm{~mm}$ or less. The western side and northern side of the western structure follow similar patterns, in that they represented larger samples of sherds $5 \mathrm{~mm}$ or less. These aforementioned areas all happen to be placed within the same western structure at Hacienda Pancota. The inverse is true for Darío Plain sherds recovered from the eastern structure. In the far eastern corner of the eastern structure, $100 \%$ (2) of the recovered Darío Plain sherds were thicker than $5 \mathrm{~mm}$. 


$\begin{array}{lrrrrrrrrr}\text { Spatial } & \text { TU 1 } & \text { TU 2 } & \text { TU 3 } & \text { TU 4 } & \text { TU 5 } & \text { TU 6 } & \text { TU 7 } & \text { Total } \\ \begin{array}{l}\text { More } \\ \text { than 5mm }\end{array} & 15 & 13 & 1 & 3 & 5 & 0 & 2 & \mathbf{3 9} \\ & 34.88 \% & 56.52 \% & 33.33 \% & 30.00 \% & 41.67 \% & 0.00 \% & 100.00 \% & \\ \begin{array}{l}5 \mathrm{~mm} \text { or } \\ \text { less }\end{array} & 28 & 10 & 2 & 7 & 7 & 0 & 0 & \mathbf{5 4} \\ & 65.12 \% & 43.48 \% & 66.67 \% & 70.00 \% & 58.33 \% & 0.00 \% & 0.00 \% & \end{array}$

Table 8 Darío Plain Sherd Thickness Classes by Spatiality

Within each excavated level and feature at Hacienda Pancota, Darío Plain sherds were rather equally distributed within each level by their thickness class (Table 9). This suggests similar chronology of activity use of these vessels. One exception existed within material excavated from Feature 1, located in an eastern side test unit in the western structure. Feature 1's excavation consisted of eight Darío Plain sherds $5 \mathrm{~mm}$ or less, as opposed to only one Darío Plain sherd more than $5 \mathrm{~mm}$.

$\begin{array}{lrrrrrrrr}\text { Excavated Level } & \text { Lv1 } & \text { Lv2 } & \text { Lv3 } & \text { Lv4 } & \text { F1 } & \text { F2 } & \text { F3 } & \text { Trenching } \\ \text { More than 5mm } & 16 & 18 & 2 & 2 & 1 & 1 & 0 & 1 \\ 5 \mathrm{~mm} \text { or less } & 15 & 23 & 6 & 0 & 8 & 2 & 0 & 3\end{array}$

Table 9 Darío Plain Sherds by Excavated Level

Bibiana Red pottery sherds were the second and last type of Darío group ceramics analyzed in this research (Table 10 and Table 11). The sherds demonstrated a similar patterning of their physical attributes with sherd thickness being the critical independent variable. Trends were seen in thinner sherds tending to be smoother with no internal or external wiping striations. Mineral inclusions did not evidence much patterning or outlying results, with the exception that thicker sherds tended to have more inclusions in 
every category. This is likely the cause of increased surface area and more temper needed for stronger vessel paste.

\begin{tabular}{|c|c|c|c|c|c|c|c|}
\hline $\begin{array}{l}\text { Bibiana } \\
\text { Red Sherd } \\
\text { Thickness }\end{array}$ & Smoothed & $\begin{array}{l}\text { Wiping } \\
\text { Striations }\end{array}$ & $\begin{array}{l}\text { Normal } \\
\text { Mica } \\
\text { Dist. }\end{array}$ & $\begin{array}{l}\text { Red } \\
\text { Pumice }\end{array}$ & $\begin{array}{l}\text { White } \\
\text { Mineral } \\
\text { Inclusions }\end{array}$ & $\begin{array}{l}\text { Black } \\
\text { Mineral } \\
\text { Inclusions }\end{array}$ & $\begin{array}{l}\text { Multiple } \\
\text { Different } \\
\text { Inclusions }\end{array}$ \\
\hline More than & & & & & & & \\
\hline $5 \mathrm{~mm}$ & 9 & 8 & 28 & 13 & 6 & 4 & 0 \\
\hline $5 \mathrm{~mm}$ or less & 16 & 0 & 19 & 2 & 3 & 0 & 0 \\
\hline
\end{tabular}

Table 10 Bibiana Red Thickness (mm)

$\begin{array}{lrrrrrrrr}\text { Spatial } & \text { TU 1 } & \text { TU 2 } & \text { TU 3 } & \text { TU 4 } & \text { TU 5 } & \text { TU 6 } & \text { TU 7 } & \text { Total } \\ \begin{array}{l}\text { More } \\ \text { than 5mm }\end{array} & 15 & 6 & 2 & 2 & 3 & 0 & 1 & \mathbf{3 1} \\ & 48.39 \% & 75.00 \% & 100.00 \% & 66.67 \% & 60.00 \% & 0.00 \% & 100.00 \% & \\ \begin{array}{l}5 \mathrm{~mm} \text { or } \\ \text { less }\end{array} & 16 & 2 & 0 & 1 & 2 & 0 & 0 & \mathbf{2 1} \\ & 51.61 \% & 25.00 \% & 0.00 \% & 33.33 \% & 40.00 \% & 0.00 \% & 0.00 \% & \end{array}$

Table 11 Bibiana Red Sherd Thickness by Spatiality

Faunal Remains Analysis

Evidence demonstrating roots in the indigenous lifestyle of Hacienda Pancota residents beyond the realm of pottery falls unto lithics technology, construction technology, and faunal remains. Without clear species identification of faunal remains due to the artifacts small nature, they cannot be analyzed further than a mammal. Jute (pachychilus) shells, however were clearly identifiable and confirmed by the personal 
communication by Malacologist Dr. Bob Warren of the Illinois State Museum. These freshwater snails were abundant during throughout the ancient Maya world and still remain an important food source for rural peoples in Mesoamerica. According to Halperin (2003), Healy et. al (1990), Moholy-Nagy (1978), and Sidrys (1983), jute snails were consumed by ancient Maya peoples to supplement a protein deficient diet of a high maize based ingestion.

All occurrences in the distribution of analyzed jute shells fell into Level 1 context. Level 1 provenience dates to the early colonial period. Although this is likely the most disturbed context, jute shells were recovered in two separate test units in the far western corners of both structures. Artifacts recovered from the western sides of each structure we the least frequent in the completed analysis, suggesting that jute shell distribution is different spatially that ceramic distribution at Hacienda Pancota.

\section{Lithic Assemblage Analysis}

The lithics analyzed at Hacienda Pancota were either obsidian flakes and blades or modified igneous rock. Obsidian prismatic blades were common throughout the Maya world, becoming a standard artifact found in many habitation sites Morandi (2010:161). Obsidian is a highly modifiable source for making extremely sharp tools, blades, and other cutting artifacts. In particular, most Mesoamerican blades were produced after pressure flaking from a prepared polyhedral core or linear flat-sided obsidian core (Morandi 2010). No obsidian cores were recovered from the excavation, but exist in material remains throughout Sampeck's (2007) comprehensive survey of the Izalcos region. 
All lithics were identified pertaining to one of two groups: obsidian or modified igneous rock. Obsidian was identified as flakes and knife blades. All igneous rock provided little insight into its use, but its human modification was apparent due to flat, smoothed sides. Lithics were located within human occupied contexts in bajareque rich deposits. Due to their association with the building material recovered from Hacienda Pancota, it is likely they were used for construction purposes of the infrastructure.

\section{Spatial Artifact Distribution Analysis}

In 1995, test pits were focused around a grouping of architectural structures at what was locally known as Hacienda Pancota and recorded as such in the sixteenth to eighteenth-century documents in the Caluco, El Salvador archive. Two structures, an east (Table 12) and a west (Table 13), appear to be defined separate as rock walls separated the two. Both structures contained evidence of a household, defined as a production center and living space. Due to ceramic activity from previous vessel identification, it is possible that one structure could have been added to an original structure after the first was constructed. This construction would make one entire household comprised of a newer addition. The east structure contains 187 pottery sherds and 407 total artifacts. Its recovered pottery types include all previously listed pottery except roof tiles, floor tiles, any Darío group variants, and Cipriano Red-on-Gray sherds. The west structure contains 543 sherds and 630 total artifacts. Its recovered pottery types include all but the unidentified Late Postclassic sherds.

Production and refuse areas were noted from the previous artifact distribution spatial analysis. It became clear the two structures provided two different sets of data, 
suggesting varying activity within each structure. Divided into east and west structures, it becomes simpler to visualize a patterning of usable space at Hacienda Pancota in a time when consumption and production were being critically examined throughout the early modern world.

The assortment of total artifacts associated with the stone walls on the eastern ends of both structures suggests midden patterning spanning one or two generations. Although Levels 1 and 2 in the aforementioned test units were defined as the highest artifact density levels, they were also the highest density test units compared against Hacienda Pancota's other four excavation units. The eastern sides of the both structures evidenced the discarding of broken and used items against the stone wall, away from living space, but still on the active structure floor. An inconsistency occurs under close examination of the test unit locations, their analyzed artifact densities, and the physical orientation of the housing structure. For example, test unit 7 was located on the abrupt east of the stone wall, with wood and stone architectural features continuing west and south. Without future excavations to the east of the midden in test unit 7 , it is difficult to tell if the midden location is the outside or inside of a structure. Test unit 1 poses a similar problem, but the stone and post hole feature remains enclose it - and two other test pits - on the likely inside of a housing structure.

Evidence at Hacienda Pancota suggests midden formation is associated close to the household and in a single location against stone walls, but it is unclear whether or not this unspecified location is inside or outside in either structure. Assuming that the discarding or broken pottery and other artifacts such as glass and faunal is on the inside 
of the structure, a pattern of usable space for food preparation emerges in the eastern structure.

\begin{tabular}{lrrrrrr} 
East Structure & & \multicolumn{4}{l}{ TU3 } & Interior \\
Pottery & Level 1 & Level 2 & Level 3 & Cleaning & Wall & Total \\
TP 3 & 26 & 21 & 1 & 27 & n/a & $\mathbf{7 5}$ \\
TP 6 & 23 & n/a & n/a & n/a & 3 & $\mathbf{2 6}$ \\
TP 7 & 67 & 19 & n/a & n/a & n/a & $\mathbf{8 6}$
\end{tabular}

Table 12 Eastern Structure Artifact Distribution

\begin{tabular}{|c|c|c|c|c|c|c|c|c|}
\hline $\begin{array}{l}\text { West } \\
\text { Structure } \\
\text { Pottery }\end{array}$ & $\begin{array}{l}\text { Level } \\
1\end{array}$ & $\begin{array}{l}\text { Level } \\
2\end{array}$ & $\begin{array}{l}\text { Level } \\
3\end{array}$ & $\begin{array}{l}\text { Level } \\
4\end{array}$ & $\begin{array}{l}\text { Feature } \\
1\end{array}$ & $\begin{array}{l}\text { Feature } \\
2\end{array}$ & $\begin{array}{l}\text { TP1 } \\
\text { Trenching }\end{array}$ & Total \\
\hline TP 1 & 21 & 137 & 33 & 18 & 52 & $\mathrm{n} / \mathrm{a}$ & 22 & 283 \\
\hline TP 2 & 109 & 11 & $\mathrm{n} / \mathrm{a}$ & $\mathrm{n} / \mathrm{a}$ & $\mathrm{n} / \mathrm{a}$ & 13 & $\mathrm{n} / \mathrm{a}$ & 133 \\
\hline ТP 4 & 42 & 16 & 6 & $\mathrm{n} / \mathrm{a}$ & $\mathrm{n} / \mathrm{a}$ & $\mathrm{n} / \mathrm{a}$ & $\mathrm{n} / \mathrm{a}$ & 6 \\
\hline TP 5 & 9 & 54 & $\mathrm{n} / \mathrm{a}$ & $\mathrm{n} / \mathrm{a}$ & $\mathrm{n} / \mathrm{a}$ & $\mathrm{n} / \mathrm{a}$ & $\mathrm{n} / \mathrm{a}$ & $0 \mathrm{y}$ \\
\hline
\end{tabular}

Table 13 Western Structure Artifact Distribution

The east and west structures comprised of stone, wood, and bajareque construction materials. Patterning of artifact densities seemed to be highest alongside stone walls found in both structures. The east side of the western structure accounted for $31.45 \%$ of all assemblage artifacts, resulting in the most densely recorded test unit area (Table 6.15). Level 2 was the most dense level within this east side of the western structure and contained the more pottery than any other level in any other test unit. It comprised of $18.42 \%$ (135) of the recovered pottery during excavation. Late Postclassic, contact period, and early colonial sherds were recovered in Level 2 of the western structure's east corner. European and Chinese imported vessels contributed to this highly 
concentrated level and area as well. A small percentage of olive jar sherds and $50 \%$ of the porcelain sherds were located in this area at Level 2. The overall level had a strong percentage of non-jute shell faunal remains, obsidian flakes, glass, and modified igneous rock. The east side of the western structure also contained a post hole feature, similar in dimension to the post hole feature on the structures western edge.

Following second in highest artifact density, the eastern side of the east structure accounted for $20.46 \%$ of the total assemblage. Level 1 in this test unit area seemed to have this specific unit's highest artifact density, compiling a diverse assortment of Postclassic, contact period, and early colonial artifacts. A considerably high percentage of glass and lead glazed redware comprised the level, as well as more human modified rock and associated bajareque building materials.

For more artifact distribution percentages, refer to Appendix A.

\begin{tabular}{|c|c|c|c|c|c|c|}
\hline $\begin{array}{l}\text { Total Artifacts } \\
\text { T.U. Dist. (\%) }\end{array}$ & Pottery & Metal & Lithic & Construction & Faunal & Glass \\
\hline TU 1 & $38.39 \%$ & $35.71 \%$ & $36.54 \%$ & $8.72 \%$ & $21.74 \%$ & $6.67 \%$ \\
\hline TU 2 & $18.17 \%$ & $0.00 \%$ & $13.46 \%$ & $8.21 \%$ & $0.00 \%$ & $3.33 \%$ \\
\hline TU 3 & $10.25 \%$ & $14.29 \%$ & $23.08 \%$ & $24.10 \%$ & $0.00 \%$ & $16.67 \%$ \\
\hline TU 4 & $8.74 \%$ & $35.71 \%$ & $1.92 \%$ & $2.56 \%$ & $8.70 \%$ & $0.00 \%$ \\
\hline TU 5 & $8.61 \%$ & $7.14 \%$ & $3.85 \%$ & $0.00 \%$ & $0.00 \%$ & $3.33 \%$ \\
\hline TU 6 & $3.55 \%$ & $7.14 \%$ & $1.92 \%$ & $1.03 \%$ & $69.57 \%$ & $20 \%$ \\
\hline TU 7 & $11.75 \%$ & $0.00 \%$ & $17.31 \%$ & $53.33 \%$ & $0.00 \%$ & $50 \%$ \\
\hline Total & $100 \%$ & $100 \%$ & $100 \%$ & $100 \%$ & $100 \%$ & $100 \%$ \\
\hline
\end{tabular}

The following maps display spatial densities of artifact concentration inside and within the near proximity of the two structures. The below map represents the total 
artifact distribution at Hacienda Pancota (Figure 10). This map depicts strong biases of deposited artifacts on the eastern corners of each structure. The highly concentrated deposits are near structural walls away from any western lying infrastructure.

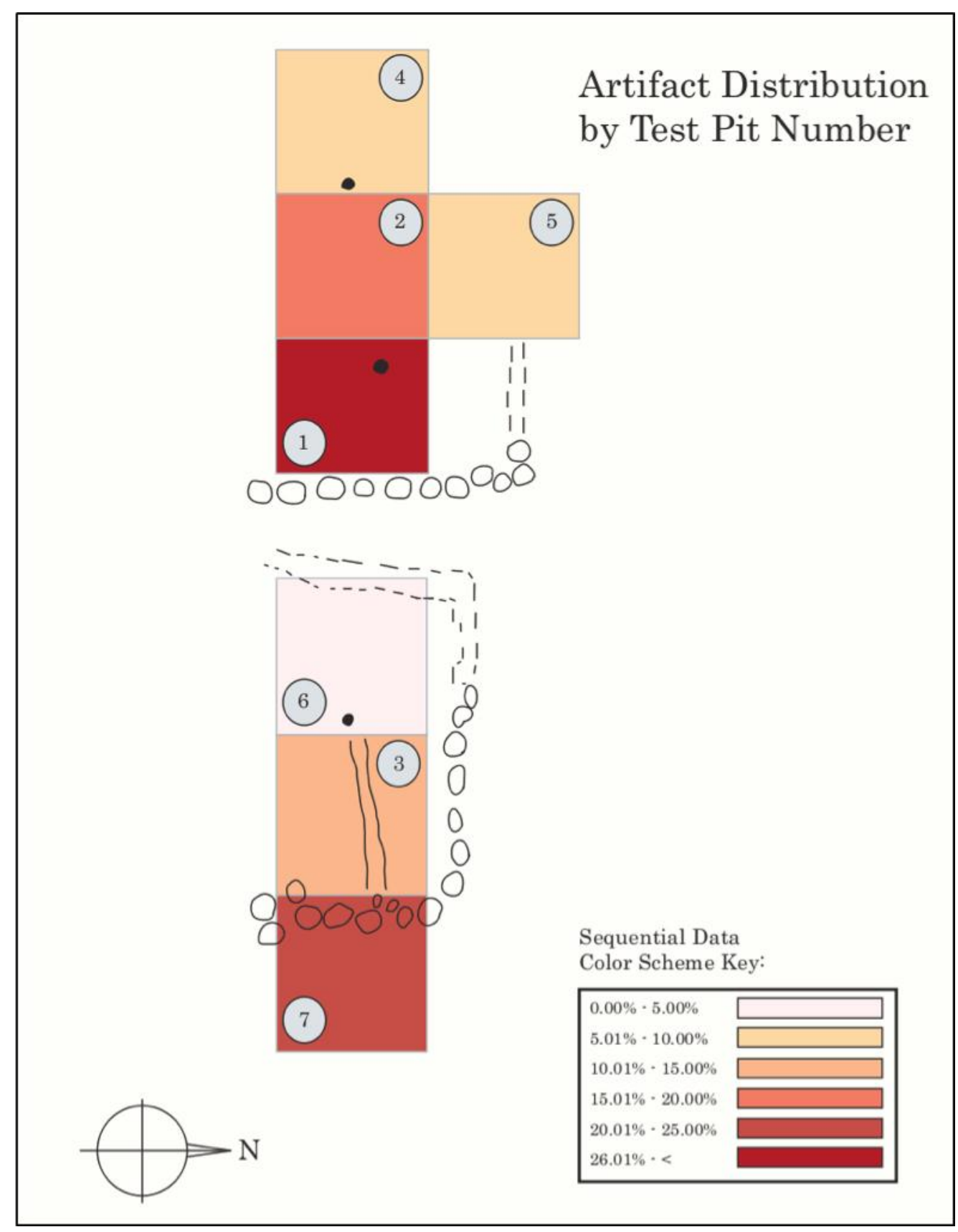

Figure 10 Total Artifact Distribution Chloropleth Map 
Spatial Pottery Distributions. Pottery is the most frequent artifact type recovered from Hacienda Pancota (Figure 11). The western structure contained the most pottery of all the analyzed pottery, with artifact concentrations highest in test units 1 and 2 . These units were located on the interior of the western structure, evidencing high domestic use inside the household.

Dating the household based upon its ceramic assemblage accounted for three factors: the frequency of any one or multiple pottery styles in one structure versus others; the assumption that Late Postclassic and Late Classic sherds are out of context within excavations and part of architectural or disturbance; that small frequencies of later occupation period ceramics suggest a reuse of the structure. Table 6.16 depicts the vessel form distribution in each test unit. The red text denotes the western structure and the blue text denotes the eastern structure. After indentifying the minimum number of vessels, form was documented and compared spatially within Hacienda Pancota.

Identified storage vessels account for, but not limited to, Pantaleón Brown, Darío Plain, Eliseo Red-on-Natural, Teshcal Red-on-Natural, Gines, Plain, Olive Jar, and Raimundo Brown. Vessel forms included were ollas, tecomates, botijas, and colonial water bottles. Though some of these pottery types have more than one vessel form category, they were individually categorized in the resulting data. There is a strong bias towards storage vessels in the western structure as compared to the eastern structure. Test unit 6, however, has a high percentage of storage vessels, it only accounts for $6 \mathrm{MNVs}$. In Table 15 and Table 16, clear variation is noted in the western structure by a statistically higher storage vessel average than in the eastern structure. 
Identified food preparation vessels were the same as the storage vessel group, with the addition of Cipriano Red-on-Gray. Vessel forms included were primarily comals and large or deep open bowls. These vessels tended to favor the eastern structure, with emphasis in the middle part of the structure in test unit 3 . There were significant trends for food preparation vessels to favor the eastern structure over the western structure.

All vessels placed into the 'serving' category incorporated lead glazed redwares, Kraak porcelain, Darío group ceramics, and imported creamwares. Vessels forms included were European serving vessels like places, cups, and saucers, tazas, small bowls, and small jars. Similar to food preparation vessel forms, serving vessels showed a strong bias for the eastern structure. Though no serving vessels were present on the far western corner of the structure, its middle and eastern counterparts had high frequencies of these vessel forms.

\begin{tabular}{|c|c|c|c|}
\hline $\begin{array}{l}\text { Vessel Form } \\
\text { Distribution }\end{array}$ & Storage Vessels & $\begin{array}{l}\text { Food Preparation } \\
\text { Vessels }\end{array}$ & Serving Vessels \\
\hline TU1 & $71.92 \%$ & $19.39 \%$ & $8.69 \%$ \\
\hline TU2 & $63.21 \%$ & $27.62 \%$ & $9.17 \%$ \\
\hline TU4 & $69.68 \%$ & $30.32 \%$ & $0.00 \%$ \\
\hline TU5 & $75.13 \%$ & $23.29 \%$ & $1.59 \%$ \\
\hline TU6 & $73.08 \%$ & $26.90 \%$ & $0.00 \%$ \\
\hline TU7 & $22.94 \%$ & $31.03 \%$ & $46.03 \%$ \\
\hline TU3 & $18.29 \%$ & $62.70 \%$ & $19.01 \%$ \\
\hline
\end{tabular}

Table 15 Vessel Form Distribution 


\begin{tabular}{lrrr} 
Total Vessel Form & \multicolumn{3}{c}{ Food Preparation } \\
Distribution by Structure & Storage Vessels & Vessels & Serving Vessels \\
\hline Western Structure & $69.99 \%$ & $25.16 \%$ & $4.86 \%$ \\
Eastern Structure & $38.10 \%$ & $40.21 \%$ & $21.68 \%$
\end{tabular}

Table 16 Total Vessel Form Distribution of Structure

The provided data tables and chloropleth map evidence the specialization of place at Hacienda Pancota. Activities are highly unique and tended to correspond with separate structures, but together define the total household domestic strategy of production and consumption areas (Carter and Merrill 1979). Though similarities exist with each structure, major trends of storing activities and preparation/serving activities can be seen by this data. Coupled with chronological stratigraphy data, it starts to become clear that specialization of place becomes more heavily emphasized with the incorporation of European goods. Though adaption has taken place throughout Mesoamerica's history, adaption methods in consuming and producing during the early colonial period give way for agency to be recognized at Hacienda Pancota. 


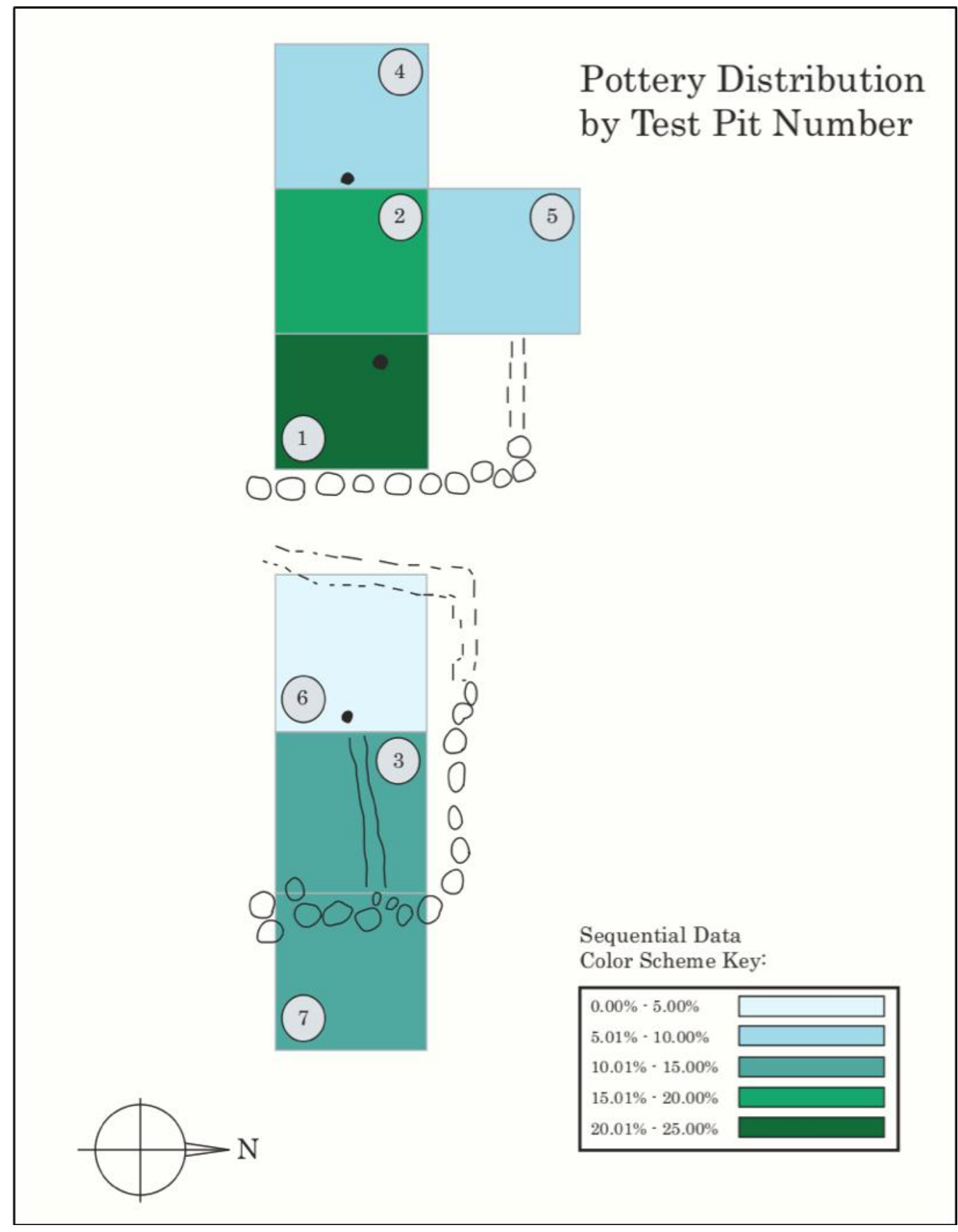

Figure 11 Pottery Distribution Chloropleth Map

Spatial Bajareque Distribution. Bajareque, better known as fired clay/daub in the US, evidences both building and demolition processes during the early colonial period. The highest concentration of bajareque was recovered from just outside the eastern 
structure's east wall in test unit 7 (Figure 12). The outside location of recovered bajareque evidences the destruction of a wall above the rock structural foundation of the east and north running wall in the east structure. Test unit 3's similarly high frequency of bajareque supports the destruction of the aforementioned wall, from interior collapse. Located in the middle of the western structure, a teja ceramic and ladrillo ceramic were recovered in proximity to a wall feature in Level 2. Though Level 2 in test unit 3 has little bajareque artifacts (2) weighing 7.11g, Level 1 directly above has a high concentration of construction material. Supporting evidence of wall collapse depositing artifacts on the top of Level 2 and floor of Level 1,57.61g of bajareque were recovered. 


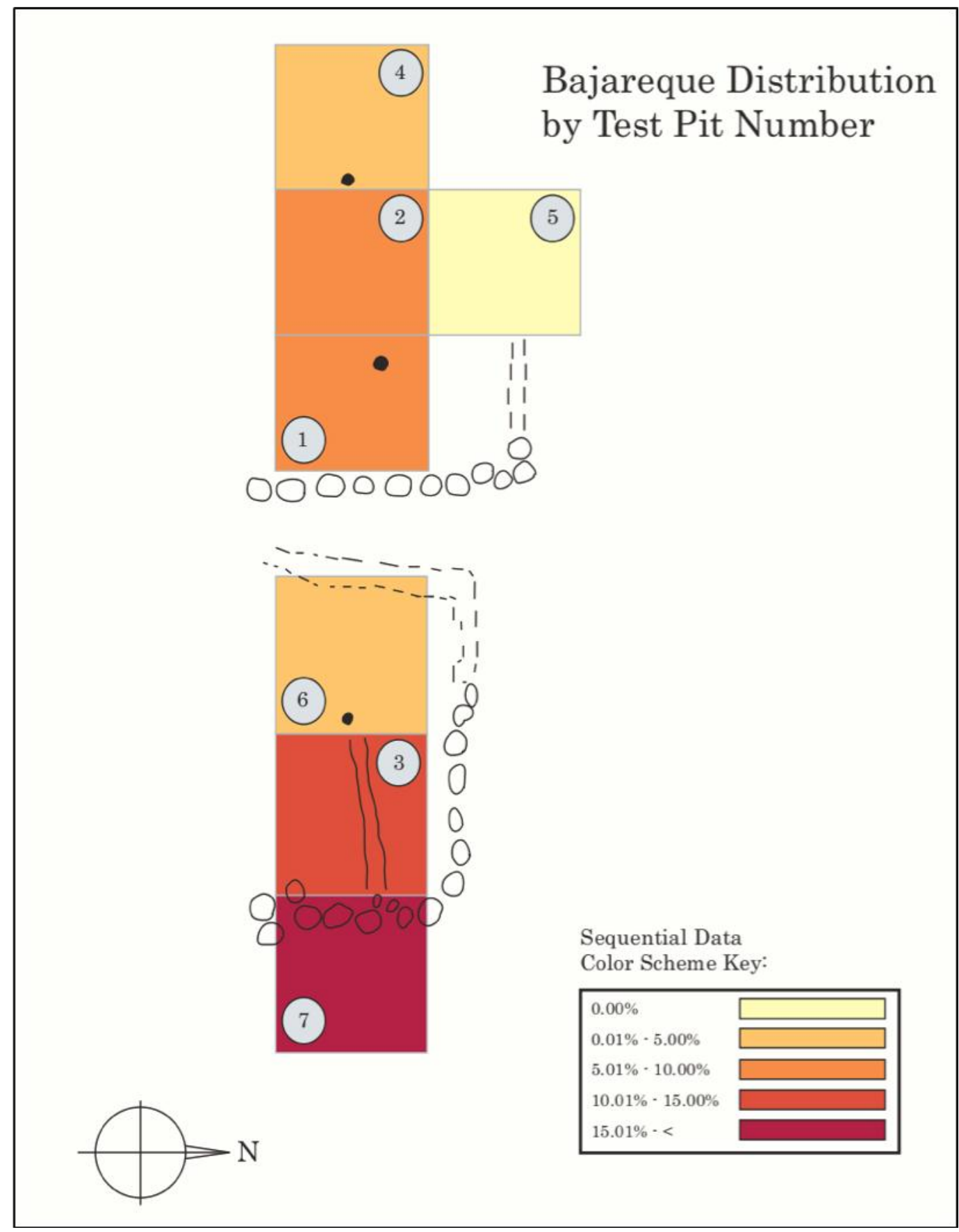

Figure 12 Bajareque Distribution Chloropleth Map

Spatial Faunal Remains Distribution. The recovered faunal remains were concentrated most in test unit 6, near the western end of the eastern structure (Figure 13). Test unit 6 comprises $88 \%$ of all recovered jute shells. This location on the west corner of 
the eastern structure did not evidence much pottery, possibly giving insight into a new activity refuse pile. The eastern structure at Hacienda Pancota primarily contained food preparation and serving vessels. With corroborating evidence of deposited faunal remains located in this same structure, it appears likely that eastern structure activities involved food preparation and serving. 


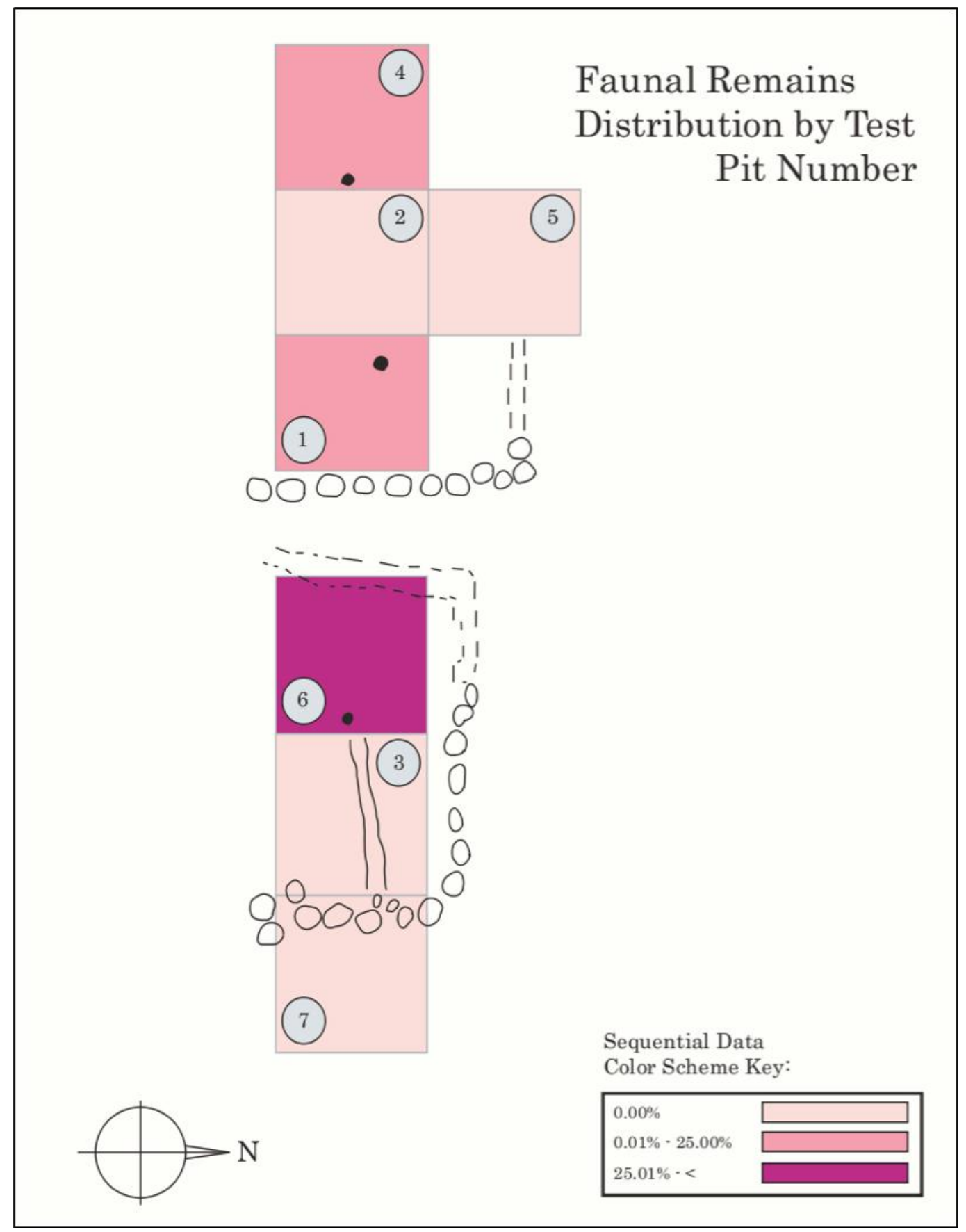

Figure 13 Faunal Remains Distribution Chloropleth Map

Spatial Lithic Distribution. Lithic artifact distributions were most highly concentrated in test unit 1 and test unit 3 (Figure 14). Both units are interior, are located in both structures, and near structure walls. There was little variation within the highest 
distribution of Obsidian flakes and partial blades, with the modified igneous rock. Lithic components to Hacienda Pancota's household production and consumption patterns played a minority role compared to food storage and preparation.

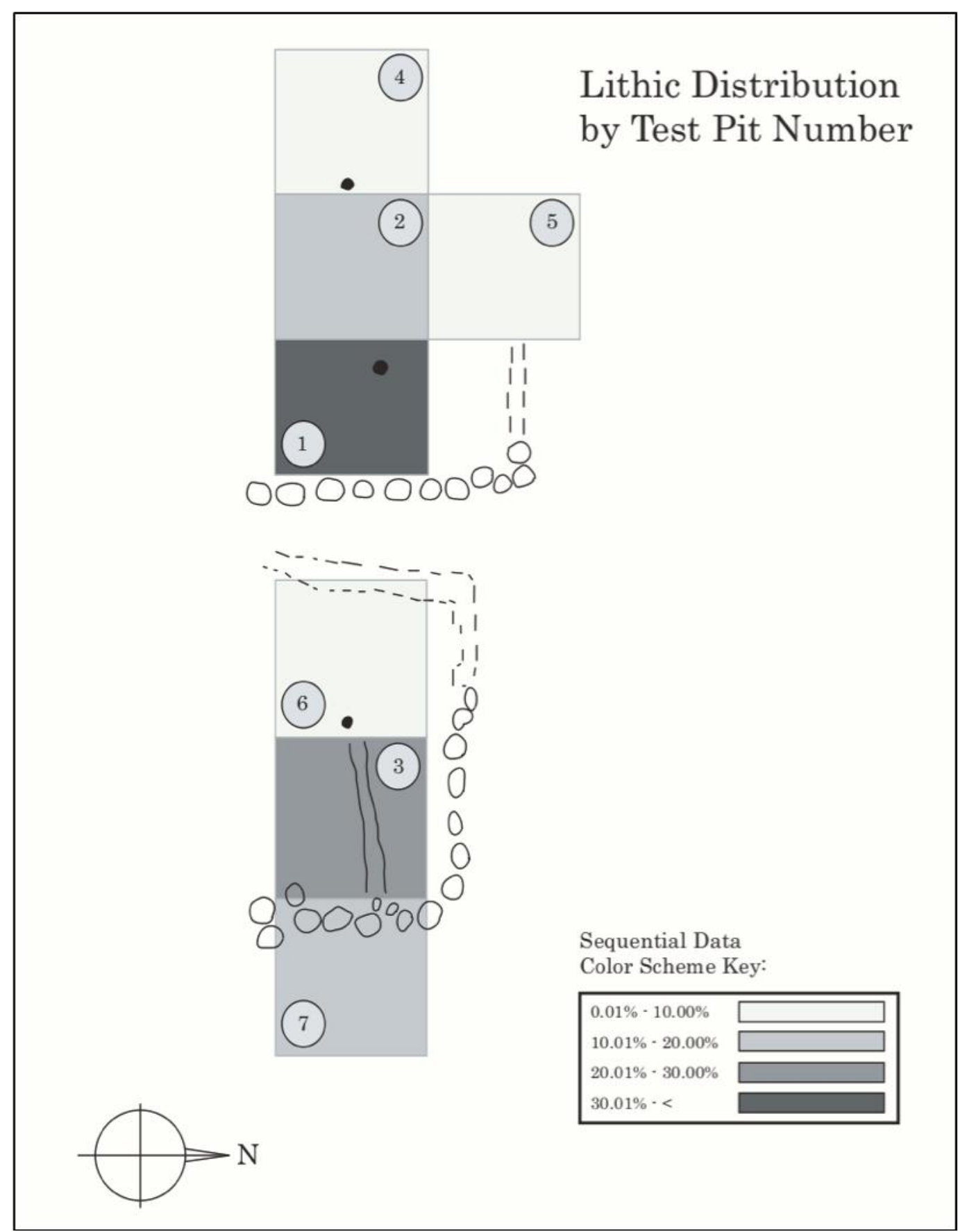

Figure 14 Lithic Distribution Chloropleth Map 
The two examined structures at Hacienda Pancota provided two important sets of data. Food storage, cooking/preparing and serving were individually identified with the aid of spatial evidence from ceramic, faunal, and lithic in situ remains. Though varying activities took place within each structure, it is important to note that the majority of specialized activities were spatially separated. While the incorporation of European goods become evident chronologically, an increased emphasis on space and its associated specialization of activities get solidified. This is evidence for continual adaptation beyond routine (Silliman 2008) and into intentional action and strategic planning (Blanton et al. 1996; Winter and Joyce 1996).

\section{Comparative Site Data Analysis}

Comparative site data provided an external context for which to examine Hacienda Pancota and all its material culture. Activities represented by residents' artifacts give insight into the inner workings of larger economies and other settlements-small and large — in the New World. Deagan (2002), Gasco (1992), Morandi (2010), and Skowronek (1987) compared to Sampeck (2007) data only slightly, but allowed resident Spanishness to be more thoroughly evaluated (Table17).

All sites used for comparative basis had their highest artifact percentages in pottery. Only two study sites revealed data emphasizing higher frequencies of European tradition pottery rather than indigenous tradition pottery. The first instance was recorded on a sixteenth century shipwreck, documented by Skowronek (1987). The second was an early Spanish colonial site in La Florida (Deagan 2002). Lithic artifacts remained consistently low, except in Morandi's (2010) early colonial Belizean site. 
When comparing contraband porcelain percentages, Sampeck (2007) yielded the highest results, though most other sites presented data showing porcelain present. Since there was a very large influx of Chinese porcelain coming through the New World by the seventeenth century, site data reflects its accessibility regardless of the material's illegal status. The access to illegal goods in the New World under the Spanish crown reflects the underground networking of trade to core and peripheral sites.

\begin{tabular}{lrrr} 
Against Total Pottery Assemblages & \multicolumn{1}{l}{$\begin{array}{l}\text { Pottery } \\
\text { (Indig) }\end{array}$} & \multicolumn{2}{l}{$\begin{array}{l}\text { Pottery (European } \\
\text { Trad.) }\end{array}$} \\
Sampeck (2007) & $89.48 \%$ & $9.70 \%$ & $0.82 \%$ \\
Skowronek (1987) & $0.00 \%$ & $100.00 \%$ & $0.00 \%$ \\
Deagan (1978) SA-26-1 & $41.89 \%$ & $57.86 \%$ & $0.25 \%$ \\
Deagan (1978) SA-34-1 & $56.16 \%$ & $43.66 \%$ & $0.18 \%$ \\
Deagan (1978) SA-36-4 & $61.41 \%$ & $38.59 \%$ & $0.00 \%$ \\
Gasco (1992) ST 9 (OP 8) & $81.26 \%$ & $18.63 \%$ & $0.11 \%$ \\
Gasco (1992) ST 12 (OP 7) & $68.05 \%$ & $31.71 \%$ & $0.24 \%$ \\
Gasco (1992) ST 37 (OP 1) & $92.15 \%$ & $7.65 \%$ & $0.20 \%$ \\
Gasco (1992) STS 68/83 (OPS 5/6) & $86.23 \%$ & $13.45 \%$ & $0.32 \%$ \\
Gasco (1992) ST 73 (OP 3) & $83.49 \%$ & $16.51 \%$ & $0.00 \%$ \\
Gasco (1992) ST 78 (OP 17) & $87.85 \%$ & $11.81 \%$ & $0.35 \%$ \\
Gasco (1992) ST 85 (OP 16) & $90.63 \%$ & $9.38 \%$ & $0.00 \%$ \\
Gasco (1992) ST 89 (OP 12) & $91.77 \%$ & $7.59 \%$ & $0.63 \%$ \\
Morandi (2010) & $80.35 \%$ & $19.78 \%$ & $0.00 \%$
\end{tabular}

Table 17 Comparative Pottery Data Total 


\section{CHAPTER VII}

\section{DISCUSSION OF RESULTS}

The overall analyzed consumption pattern sample suggests the lifestyle of Hacienda Pancota residents were working poor, Pipil or Mestizos, with primarily subsistence level pottery. They did not require, need, want, or have access to many European or Chinese imported goods, though this does not mean these imports did not exist. The mere presence of contraband wares and a diverse array of variation among local and imported pottery alike, evidence a people committed to their own agency.

\section{The Basics: Cooking Food, Storing Drink, and Working Fields}

There were a total of 19 indigenous ceramic types identified in analysis and 5 types of European tradition and Chinese porcelain ceramic types. A significantly higher proportion of indigenous wares suggested much about European tradition and imported pottery's availability at Hacienda Pancota. This evidence can be misleading as though Hacienda Pancota was likely an Indian or Mestizo site, comparatively similar sites with different population demographics (i.e. Spanish contexts) resulted in similar material culture data. The low frequency of imported pottery and glass suggest a lifestyle and behavior more similar to Pipil Indians than to those of direct Spanish decent at first glance. When investigating the results of analysis more thoroughly, it reflects a resident population capable of quickly embracing imported technology while adequately 
balancing indigenous lifeways. The low frequency of imported goods also reflects a rural lifestyle, less bombarded by imported goods and Spanish trade networks. Daily life at Hacienda Pancota was reflected by a small sample of two structures. These structures provided the remains of what are likely a food preparation/cooking area and a food storage area. This spatial analysis is dealt with in subsequent parts of the chapter.

Historical sources (Kepecs and Alexander 2005; MacLeod 1979; Farriss 1984; Sampeck 2007) described a mixed native and imported population into the Izalcos region during the early colonial period. Starting at the beginning of the early colonial period in 1545, Spanish and Mestizo encomenderos placed themselves into vast plantations of cacao fields in the Izalcos region. The context of this region was already a cacao producing region, dating well into the pre-Columbian world. The Izalcos had a history as one of the richest areas under the audiencia of Guatemala (MacLeod 1979). Early colonial business ventures required day labor as well as full time caretakers (MacLeod 1979). Since disease, migration, and labor killed many native Indians already working in the region, constant labor was required to be imported into the Izalcos.

A strong and steady flow of money from the Izalcos region cacao fields would suggest material remains reflect a diversity of expensive goods and new imported technology, but the recovered assemblage at Hacienda Pancota evidences otherwise. There is no doubt that certain individuals reaped the rewards of the cacao booms, but remaining infrastructure and material culture excavated at Hacienda Pancota do not reflect the wealthy status of a hacienda owner. Reasoning behind the class status of Hacienda Pancota is likely its role as a supplier to a much larger world trading network. The owners of Pancota's production wealth do not necessarily distribute their commercial 
success. MacLeod (1979) argued that many hacienda landowners lived in nearby cities. Urban centers would feel the benefits of production from rural haciendas far more quickly and intense than residents tending the fields.

Both structures at Hacienda Pancota may have provided residents with a short rest before a meal after a long day, or provided shelter from the sun to people cooking inside during an early morning. Women, men, and children were likely the occupants and active users of the total household. Though the eastern and western structures were separated both physically and by activity usage areas, defining gender within the household was unlikely. If women were more associated with meal preparation and serving, all genders likely took place in the act of eating within the structure. Though it is possible that trends in acquiring European and other imported tradition goods can be attributed to specific gender roles, evidence was circumstantial at best. As argued in Deagan (1998), contact period Indian women primarily held domestic roles while married to Spanish men. These women had little contact with much Spanish material culture outside of influences from their husbands. This lack of Spanish material culture exposure heavily reinforced domestic material culture from women's indigenous culture. Using Deagan's (1998) research, it is possible that women reinforced indigenous domestic traditions while male field workers might have had more interaction with Ladinized Mestizo workers, and urban elites. This male interaction with European traditions may have influenced the domestic sphere to the small degree it is evidenced at Hacienda Pancota, as well as other early colonial sites in the comparative analysis section of this research. The total household at Hacienda Pancota demonstrated specialized activity areas that accessed 
technologies from Old and New World ancestors, as well as a gendered incorporation of imported goods.

\section{Spatial Analysis of Midden Locations}

Not all discarded artifacts made their way to the corners of each structure, but followed alternate patterns of refuse. Comparatively, trace amounts of faunal remains were identified within the proposed midden areas. Test units 4 and 6 were the primary areas of faunal deposits, evidencing a different discard pattern than those of the ceramic pottery breakage as discussed in the results section (Figures 11 and 13). This alternate discard pattern between faunal remains and broken pottery suggested a more specialized household areas or changes in generational artifact depositing (Schiffer 1987). Whereas the highest concentration of faunal remains were recovered from Level 1 of test unit 6 in the eastern structure, most of the broken pottery from the eastern structure was recovered from test unit 7. It should be noted that test unit 6 is located inside the structure and test pit 7 lies outside the structure. This thesis contends with the evidence suggesting specialized household areas, rather than generational changes in deposits, are evident at Hacienda Pancota.

Archaeologists have learned that Mesoamerican cultural groups tended to discard their material culture in predetermined spaces, rather than changing them sporadically or generationally. Though this is not true for every site, it is true for sites studied in the Late Postclassic Aztec sites of Capilco and Cuexcomate. Here, recorded midden deposits were located outside of domestic structures (Smith and Heath-Smith 2000). Formative Oaxacan household sites, however, evidence midden deposits within house structures (Flannery and Winter 2000). Whether inside or outside, there was usually a primary place 
of midden placement. At Hacienda Pancota, midden locations were likely located within the cooking, food preparation, and food storage structures.

If we look at the distribution of Darío group ceramics within their sherd thickness classes, a refuse pattern emerges according to likely vessel type. The hypothesis implemented by this thesis states a relatively basic premise: thicker sherds of the Darío group tended to originate from larger, more substantial vessels such as colonial water bottles, whereas smaller sherds of the Darío group tended to be part of thinner, more delicate vessels like small jars and small bowls. Assuming this is correct, it is then possible to define separate spatial areas of storing food or liquids and areas were food is being consumed or cooked. It also gives reasons why adaptations to imported European storage vessels (Olive Jars) become an important component to the western structure's storage activities. Bibiana red sherds tended to have more mineral inclusions, including but not limited to red pumice and mica. It is likely a factor that additional mineral inclusions in a thick utilitarian vessel allowed for the fired temper to be stronger for the creation of a larger vessel used for storage. Results from experimental archaeology suggested that larger vessels heated and cooled more evenly than smaller, thinner walled vessels (Skibo 2012; Schiffer and Skibo 1987). In conjunction with evidence of increased temper frequency and temper variability support the likelihood that thicker Darío group ceramics were used as large storage vessels, keeping contents' temperature inside more evenly distributed than thinner walled vessels (Skibo 2012).

This evidence is further supported by vessel form results from the previous chapter. The MNV analysis led to understanding spatial location of storage vessel forms, food preparation/cooking vessel forms, and serving vessel forms. Patterns of specific 
vessel types emerged within each structure, verifying the Darío group ceramic investigations. Though not all MNV's could be accurately assessed, the sample of vessels that were used to identify activity of place evidenced highly specialized areas. These specialized areas emphasized production and consumption defined by daily life habitscooking and eating.

Domestic activities provided large samples for pottery to be examined archaeologically. Pottery breakage can be attributed to heavy use of pottery during cooking, serving, and preparing in eastern structure and storing and moving large vessels in the western structure. Although breakage can occur in areas different than where they were being used, it is evident their recovery from inside each structure was the same place they were being used (Schiffer 1987). It is even more evident the residents of Hacienda Pancota swept broken pottery to the side and corner of the room, rather than breaking it outside and bringing it back in to bury, or vice versa.

Identifying vessel form refuse areas within each respected structure allow for further insight into activities occurring daily during the early colonial period that played part in larger social and economic roles. The separation of daily functioning within a single household reflects the diversification and organization of space within a microeconomy. Residents incorporated varying types of ceramics and vessels, used them for preparing, cooking, and storing foods and consumed the end result. Although the excavated structure is only a sample of its probable larger size, the quantity of discarded pottery evidences the preparation of large amounts of food. It can then be inferred that large food preparation for a group of people at Hacienda Pancota, likely corresponds with 
the amount of workers on a small early colonial cacao plantation. To produce more food for workers, evidences higher overall production at the hacienda.

\section{The Household as a Building Block to World Economic Systems}

In a list of attempts to define the human household, Wilk (1991:1) stated that for some researchers, the household is key to understanding historical transformations of the larger world system. It is difficult to study the ancient household when excavated material remains of the house can be irrespective of the people's ideologies and motivations that aided in building that said structure (Smith and Masson 2000). The architectural and artifactual evidence involved in this analysis is likely emblematic of similar, more involved household economic systems of the early colonial period, that contributed to the world systems of early modern Europe.

Early colonial Hacienda Pancota evidenced social order within a bounded landscape that became a privately owned version of post-reduccion ideologies implemented on a newer version, or shadow of the congregación. Both reduccion and private capitalist systems are based in ownership of goods and ownership over production. Hacienda Pancota's early colonial cacao production reflected Spanish ideologies of contact period congregaciónes. Both physical and ideological production do harm to people being forced to produce for upper class economies and to learn systems of adaption helping define agency. This adaption of an early colonial bounded landscape can be seen in three ways: the specialized spatial organization of the household, the adaption of imported wares, and the total diversity of the Hacienda Pancota assemblage. The house (infrastructure) and larger household (superstructure) became a hybrid space (Mundy 2011) — a place where people came to live and work because they labor under an 
oppressive system forcing them to produce. In the hacienda political structure, residents were able to adapt and choose their own strategy for future decisions. How they lived and coped within the structure and the activities that took place within defined them as actors making their own choices. If daily consuming and producing strategies failed, then overall hacienda production would fail within this hybrid space. Combining indigenous peoples from scattered rural villages with lingering Spanish colonial reduccion ideology and investing in the products, not the people, created this hybrid space.

It should be noted that this system of labor was not new to the Izalcos region, adding to the increased complexity of Hacienda Pancota's pre-Columbian ancestors. While production may be tradition in the Izalcos, resident adaptation strategies continued within changing power hierarchies. Scant evidence was documented defining Hacienda Pancota residents using imported goods, ceramic or lithic, and other material culture technologies from more densely populated urban centers. They supported the larger world economy by consuming the early modern period's production and consumption patterns rather than reaping benefits of their imported goods. Nothing in the analysis pointed to residents using and implementing much new Spanish technology into their daily habits. Glass and metal artifacts of European design were small frequencies of the collection, consisting of $1.87 \%$ and $2.34 \%$ of the total collection, respectively.

\section{Agency as an Alternative to Resistance}

Domination and resistance are very common themes concerning the analysis of colonial encounters. Proponents of agency, like Beck et al. (2011) argued that themes of resistance and dominance may muddy an already tense and complicated issues of colonialism rather than clarify the events and data archaeologists attempt to interpret. 
Furthermore, agency is not as restrictive as dominance and resistance. They can be rather restrictive terms that do not support the reality of complex past cultures. Beck et al. (2011) argued even further that agency allows the researcher to let the people they study speak for themselves through their material culture rather than simply react to colonialism and post colonial practices.

The lacking of agency, or choice, is oppression. As unlikely as pottery is in the scale of human society, limited access to imported and European tradition pottery at Hacienda Pancota is a form of cultural oppression. Maybe this it not solely about agency, but rather resisting subordination through daily material culture choices (Silliman 2001). Hacienda Pancota's 19 varieties of indigenous pottery types in two structures evidences large scale agency in daily consumption. Their continued use of obsidian lithic technology and bajareque construction methods similarly reflected agency at the household scale, while also the demonstrating the domination of wealthier classes.

It is impossible to measure acculturation simply by the quantity of European goods/technologies against indigenous goods/technologies. According to Liebmann (2010) and Wernke (2010) cultural adaptation and transculturation is an ongoing process. There is not a simple quantitative figure stating one culture has been adopted over another, or time frame, or generation gap, rather with the incorporation of new goods and technologies there can be forms of resistance and reinforcement undocumented in the archaeological record.

For instance, at Hacienda Pancota there were no certain recovered Spanish or locally produced majolicas in the excavation collection. Thin-walled lead glazed redwares were analyzed, but they did not fall into the typical majolica definition. They 
were likely the product of locally or regionally produced wares influenced by the technology of European majolicas, but could not be defined as such. This creation and use of lead glazed redware innovation allowed hacienda residents to simultaneously adopt Spanishness, all while combining these wares with indigenous designed motifs and uses. The lead glazed redwares reinforced residents' independence, all while responding to new cultural technologies.

Still, it begs to question why Hacienda Pancota residents chose the particular European tradition goods they did, implementing them into daily actions. As shown earlier in Figure 5, once European goods entered the household, they did not leave. There lasting usage at Hacienda Pancota was not a trial run, but a cultural choice warranting their daily usage as integral components to selected household activities. These activities were primarily defined by the incorporation of olive jar storage vessels and European style serving vessels. The majority of European tradition vessels added to the most public of the three activities - serving. Residents incorporated European technology at each meal, either reinforcing new ideas of Spanishness or demonstrating active resistance against Spanish culture by denying these vessels more integration through all activities in higher frequency. Though their acceptance of these wares most simply reflects their incorporation of Spanish culture within the household, the comparatively limited frequency of European tradition vessels may suggest a lasting desire for indigenous lifeways. A further assessment could show active resistance in the form day-to-day agency not incorporating these vessels the important activities of food preparation and cooking. 
Further support of this juxtaposition of responding to cultural change through adaptation is from faunal evidence. Jute snail shells remained as the majority of the faunal collection recovered at Hacienda Pancota. The locality and history of the jute snail as protein consumption in the early colonial period suggests personal choices to remain tied to local fauna. Much like their ancestors, the ancient Maya and Pipil, residents at Hacienda Pancota consumed local food rather than food imported Europe or produced with Spanish ideologies. Since only one other type of unidentified faunal remains existed in the Hacienda Pancota collection, it is likely more discard patterns await outside the excavated test units. As decaying fauna would undoubtedly taint the food preparation and serving areas of the hacienda, their lack of evidence in the collection can be accounted for elsewhere in the highly organized space.

Both faunal spatial evidence and European tradition ceramic evidence demonstrate ongoing active interpretations in their usage. A duality exists in the relationship between reinforcing past indigenous behaviors, maintaining present activities, and planning strategic cultural actions for the future. Though the definition of Spanishness may have changed generationally at Hacienda Pancota, their incorporation into daily activity remained static.

\section{Ceramics at Hacienda Pancota: Product and Producer of Social Relationships}

Artifacts have the ability to change a setting. Moreover, they have the ability to alter the space in which they are located (Symanski 2012). The ceramic variability and their location within the household structures at Hacienda Pancota represented a change in setting. No longer were the two structures a group of wood, stone, and bajareque, but rather a place where food is stored, prepared, and served to people contributing to a 
global economic system. Whereas Symanski (2012) argued that people integrate artifacts into daily life to reproduce social differences, residents of Hacienda Pancota similarly reinforced differences by the acquisition of contraband ceramics, decorative pottery, and large frequency of pottery types. Highly organized activity spaces similarly reproduced social differences within the hacienda's local environment.

Since space and place have already been discussed and contributed to agency in the daily life at Hacienda Pancota, another element of adaptation was investigated in the previous chapter. The decoration of pottery has the ability to serve different functions at different times. For instance, a magnificently decorated vessel might be used differently than a similar vessel without such noted decoration. Perhaps displayed within the home or given a gift to a neighbor, a decorated vessel has the potential for a wider interpretation of uses within the household. Whether a vessel's decoration influences status, ethnicity, or serves another technofunction (Kooiman 2012:36), their role at Hacienda Pancota is of the minority compared to plain, undecorated wares.

The majority of Hacienda Pancota's decorated indigenous pottery was recovered from the eastern structure. Vessel forms were limited to small bowls, jars, and 2 storage vessels. Teshcal Red-on-Natural and lead glazed redwares made up the majority of the eastern structure's decorative wares. Since evidence shows this structure was primarily used for food preparation and serving actives, residents would gain the most social or ethnic benefit from have their decorative pottery displayed or used. The incorporation of prestigious vessels or decorated wares adds an entirely new level to adaptation in an increasingly Spanish dominated trade world. Decorated pottery allowed residents to express variation in social settings. This social presentation of decorated pottery was not 
entirely limited to vessels in the eastern structure, but all Bibiana Red storage vessels in the western structure displayed decoration as well. Though the storage structure may have been less accessible to residents or outsiders, a level of hidden social elements remain fixed to decorating pottery regardless of outward display.

\section{Hacienda Pancota and World Cyclical Patterns}

Thomas Malthus, a proponent of private property, believed that individual ownership of agricultural land and its availability was the cause of population growth. Population growth and decay of the environment are mutually exclusive, according to Malthus (Dasgupta 1978). He concluded that the theory's application is most pronounced to early modern Western Europe and ancient pre-industrialist societies alike. Malthusian population theory, also known as Limited Resources Perspectives argued that a growing population and the environment contend against each other (Dasgupta 1978). In this contention there are two primary phases, $\mathrm{A}$ and $\mathrm{B}$. Phase $\mathrm{A}$ is the growth period that culminates with an environmental catastrophic event or destructive economic event where a stagnant or declining population of phase B is encountered (Dasgupta 1978; MacLeod 1979).

The analyzed material culture of Hacienda Pancota residents is evident of a community of people unaffiliated with much European and cosmopolitan material lifeways, but feel the effects global cacao consumption. Not a total rejection of European goods, the ceramic assemblage reflects traditional lifeways of Pipil Indians and communal, but likely oppressed workforce. Malthus' ideas predated many socialist ideologies of Marx and Engels. He neglected to address any population crisis 
perspectives critiquing a system that rewards private property. Redistributionist population (Repetto 1974; Sen and Grown 1988) theories argue population crises are an effect of systemic institutions breeding inequality and unbalanced distributions of wealth.

It is important to understand the analyzed material culture at Hacienda Pancota as a representation of a people living under a system that limits access to most exotic, international, and European material goods. With almost $70 \%$ of the assemblage consisting of indigenous technology and indigenous tradition artifacts, it is clear Hacienda Pancota residents lived under a system of oppression. Whether or not they rejected Spanish culture or embraced it but did not have access to Spanish culture, they existed under its umbrella and found ways to simultaneously embrace and deny Spanish goods.

Through historical ecological research MacLeod (1973) argued Malthusian cycles were prevalent in Mesoamerican prehistory similar to medieval and post-medieval European societies. Speaking about parts of central and western Mexico, he argued that by the time of the Spanish conquest of Mexico in 1519, there was the beginning of a phase A culmination followed by a lengthy phase B of sickness and agricultural busts on and off throughout most of the sixteenth century Mesoamerica. Believing this to be true, the early modern period was the slow rise out of phase B. However, the material culture assemblage does not reflect a phase A. Consumption at Hacienda was still highly localized, calling on pre-Columbian indigenous technologies, rather than the usage and implementation of European technologies. 


\section{Discussion of Comparative Site Assemblages}

A commonality between all of the artifact assemblages is the overall frequency of pottery sherds recovered in excavation. Although this may speak to the nature of artifact preservation in more general terms, it does seem to resonate with a common tie between early modern Spanish colonial structures. In particular, the excavated structures by Deagan (2002), Gasco (1992), and Morandi (2010) displayed places for food storage, food preparation, cooking, pottery production, pottery trade, and ultimately, discard patterns. Their percentages of European tradition pottery and indigenous pottery reflected a diverse global pattern of exchange and self-reliance. Skowronek (1987) provided data from early modern shipwrecks carrying Spanish goods, evidencing larger world systems.

Since ceramic evidence is largely the concentration of this research — and the concentration of much archaeological study - their recovered evidence suggests more than an isolated event, but rather a world in production. Creating and destroying, Skowronek's analysis of shipwreck ceramic data demonstrated the connections between local, regional, and global movement of technologies_-particularly ceramics. Skowronek (1987) provided a detailed record of archaeological remains from a 1554 flota, comprising of two ships - the Espiritu Santo and the San Esteban. Dating the flota to 1554 places the ships as part of the previously mentioned Carrera de las Indias, or West Indies trade road. Deagan (1983) argued, "Shipwreck materials serve as the gauge of this world's economic system reflecting the market preferences of the motherland and in turn provide a scale for evaluating and comparing colonial habitation sites and communities." Hacienda Pancota's data reflected Skowronek's data as primarily a counterpoint. Nowhere were European tradition goods recovered like those on the flota. Only a small 
sample of imported European and porcelain goods exist at Hacienda Pancota, suggesting the residents had either no desire or could not access these European treasures. People lived at Hacienda Pancota producing for a larger market — the cacao market — to be expedited to urban areas in the New World and abroad for global consumption. Skowronek's shipwreck data of the flotas reflect a system that Hacienda Pancota residents were contributing to, but not actively involved in much of its direct consumption.

An assumption was made prior to this discussion that the pottery recovered from the flota was of luxury status being traded to those who could afford to buy imported pottery, or pottery being sent back to Europe as imported wares from the New World. True, Skowronek's data displays a wide variety of majolicas, both beautifully decorated and plain, but the majority of transported pottery was attributed as olive jars. Coarse, unglazed earthenwares accounted for nearly $89 \%$ of the San Esteban and $94 \%$ of the Espiritu Santo's entire recovered collections. So important to peoples of the early modern period was food storage vessels, that they nearly comprised of all the pottery in both ships. Fairbanks (1973) and Goggin (1968) argued positively that majolica was a high indicator of status and an ideal cultural marker of "Spanishness" when identified at a new world site. Presently, this is not necessarily an entirely true argument as outline by Sampeck (2007) and others. Supporting the claim that majolica was not necessarily a high luxury item, is Skowronek's data. Since nearly all the recovered pottery was olive jar, it's likely that more utilitarian, undecorated, unglazed earthenwares serving a functional purpose can be attributed to more "Spanishness" during the late contact and early colonial period. As noted in earlier sections, Hacienda Pancota's olive jar sherd 
frequencies remain low, but similar vessel forms from Raimundo Brown, Pantaleón Brown, and thicker vessels of the Dario Group certainly fill similar needs for liquid and food storage as a Spanish olive jar. If brought one step further, Hacienda Pancota's frequency of storage vessels, like a Spanish olive jar, is quite high, suggesting their "Spanishness" during the early colonial period was well defined, despite the lack of much European and other new world majolicas.

Identifying luxury items by their infrequency, demand, and difficulty of accessibility may well be how Chinese porcelain at indigenous sites can be labeled. Although Chinese porcelain became increasingly popular and accessible later into the early modern period and throughout the eighteenth and nineteenth centuries, its contraband nature during the early modern period made it difficult to obtain. Similar to the assemblage at Hacienda Pancota, the most minor artifact elements of Deagan's (2002) site assemblages were the porcelain components. Her three sites outside St. Augustine, nor Skowronek's data, nor Morandi's (2010) data displayed results with early colonial imported Chinese porcelain. Ming dynasty Chinese porcelain was part of the Manila galleons and shipped back to Spanish to enter the global economy. During the early colonial period, it was recovered in rural sites, but only as contraband. Hacienda Pancota's minimal amounts of Chinese porcelain verify its difficulty in acquiring the imported wares. Its presence, however, indicates a certain level of colonial subversion. Acquiring even a trace amount of Chinese porcelain during its period of illegality aids the argument that residents of Hacienda Pancota may have been subjected to work cacao fields under a colonial system, but a considerable level of agency exists in the mere presence of such an artifact. 
Both collections of Deagan (2002) and Sampeck (2007) have a considerable amount of wares Deagan defines as "subsistence wares", rather than pure luxury or ornamental wares. This is only true if we discount small variations in indigenous decorated wares and the small frequencies of Chinese porcelain at both sites. If we go back to examining Darío Group ceramics at Hacienda Pancota and compare them to similar orange clay earthenware recovered from Deagan's St. Augustine sites, a pattern of outstanding variability jumps out. Deagan's (2002) artifact collection comprised of locally produced, indigenous tradition coarse earthenware known as Orange Micaceous ware. It totaled 4.6\% of Deagan's coarse earthenwares of the three sites at St. Augustine. She defined vessel types as small bowls or cups, but she argued they were too small and thin walled to represent a major utilitarian usage for cooking. Similar at Hacienda Pancota, the very small Darío Group ceramics, especially the painted Bibiana Red wares demonstrate a minority. It is possible these fragile, thin walled wares might not have been used for utilitarian cooking and food preparation, but were attributed an elevated status in the kitchen or during meals. MNVs of Darío Group ceramics in the eastern structure suggest they were potentially serving vessels.

Gasco (1992) excavated structures in an early colonial cacao hacienda setting, similar to Sampeck (2007), in southern Chiapas, Mexico. Her data reflected similar results of high percentages of indigenous tradition pottery with comparatively low percentages of European tradition pottery associated with household structures. Morandi (2010) tells yet again similar resulting data of high indigenous tradition pottery with low percentages of European tradition pottery at a Maya site in early colonial Belize. The patterns seem to make sense when grouped together, one after another. Rural sites 
coupled with agency of indigenous peoples, multiple generations after Spanish contact can be defined as reactionary. In order to delay and resist the corruption and control of urban Spanish powers in large cities like Mexico City or Merida or the port cities of Veracruz, Acapulco, or Acajutla, indigenous peoples subsisted alongside one another without much aid from the Spanish. Many lower class early colonial peoples only incorporated fragments of Spanish culture as a way to maintain indigenous lifestyles that reinforced their unique cultures without embracing powerful urban social groups. 


\section{CHAPTER VIII}

\section{CONCLUSIONS AND FUTURE RESEARCH}

The goal of analyzing the Hacienda Pancota infrastructure and activities associated within the household, was to establish comparable and measureable units of production and consumption patterns. These patterns were manifested by pottery diversity, vessel form diversity, pottery spatial organizations, and incorporation of new and old technologies. Multiple scales of analysis were used in order to focus on a well rounded picture of the residents living at Hacienda Pancota. This thesis did not become a generalization attempting to define the early colonial integration of multiple cultures, but rather an individualized look at how one small locale and its people actively lived through multiple generations within the context of Spanish contact.

Identified vessel forms at Hacienda Pancota were defined by three primary activities: the storage of food or drink, cooking of food and its preparation, and serving food. These vessel types differ morphologically, leading to identification of activity in this early colonial setting. Early colonial vessel identification leading to household activities could potentially be used within other archaeological research of early historical and lower class Mesoamerican residencies.

Based upon their artifact diversity the residents of Hacienda Pancota were an industrious people and demonstrated agency on a domestic scale. Most profound was 
their subtle differences in pottery selection and their reuse and reconstitution of pottery for construction purposes and ceramic technology in specialized areas of the structure. This only enforces their highly selective process of material culture technology during a time of colonial oppression. Similar at other early colonial sites used in the comparison analysis, further activity areas could be defined based upon three-part vessel identification of storage, food preparation, and food serving. The majority of comparative sites in this analysis—Deagan (1978), Gasco (1992), Morandi (2010)—have majority frequencies of indigenous tradition pottery, rather than European tradition and other imported tradition goods. Similar conclusions may be drawn at the aforementioned sites if material assemblages were broken down into household activities associated within a bounded landscape. The constant negotiation between the usage of imported goods and indigenous goods crosses early colonial sites in the Spanish New World. Further application of this research could be applied to early colonial sites under the influences of other colonial powers - the French, Dutch, or English for instance.

Their lifeways and household organization with all its associated material culture reflected the shifting movements of larger economies and systems during this vastly changing historical period. The microvariations in level and test unit created an organizational element not clear upon first examination. But through spatial analysis and vessel form identification, subtleties of production and consumption at Hacienda Pancota shined through. I attempted to investigate any correlation between an increase in European tradition pottery and a decrease in indigenous tradition pottery, but again I was building an argument out of a false foundation. The end resulted in examining a resilient 
people focusing on their lives, while making the best food they could with the tools they had available under a likely oppressive governing regime at the Pancota cacao hacienda. 


\section{REFERENCES}

Adams, William Hampton

1990 Landscape Archaeology, Landscape History, and the American Farmstead. Historical Archaeology 24:92-101.

Adams, Robert McCormick

1974 The Mesopotamian Social Landscape: A View from the Frontier. In Reconstructing Complex Societies: An Archaeological Colloquium, edited by Charlotte B. Moore, pp.1-12. Cambridge University Press, Cambridge.

Alexander, Rani T.

1993 Colonial Period Archaeology of the Parroquia de Yaxcabá, Yucatán, Mexico: An Ethnohistorical and Site Structural Analysis. Ph.D. diss., University of New Mexico.

1997 Haciendas and Economic Change in Yucatan: Entrepreneurial Strategies in the Parroquia de Yaxcaba, 1775-1850. Journal of Archaeological Method and Theory, Special Issue: New Approaches to Combining the Archaeological and Historical Records 4:331-351.

2003a Architecture, Haciendas, and Economic Change in Yaxcabá, Yucatán, Mexico. Ethnohistory 50:191-220.

2003b Introduction: Haciendas and Agrarian Change in Rural Mesoamerica. Ethnohistory 50:3-16.

2004 Yaxcabá and the Caste War of the Yucatán: An Archaeological Perspective. University of New Mexico Press, Albuquerque.

2005 Isla Cilvituk and the Difficulties of Spanish Colonization in Southwestern Campeche. In The Postclassic to Spanish-Era Transition in Mesoamerica, edited by Susan Kepecs and Rani Alexander. The University of New Mexico Press, Albuquerque.

2006 Maya Settlement Shifts and Agrarian Ecology in Yucatán, 1800-2000. Journal of Anthropological Research 62:449-470. 
Alexander, Rani T. and Sandra Andrade

2007 Frontier Migration and the Built Environment in Southwestern Campeche.

Estudios de Cultura Maya 30:176-196.

Allison, Penelope M.

1998 The Household in Historical Archaeology. Australasian Historical Archaeology $16-28$.

Alvarado, Pedro de

1924 An Account of the Conquest of Guatemala $n$ 1524. Edited by Sedley J. Mackie. The Cortes Society, New York.

Andrews, Anthony P.

1981 Historical Archaeology in the Yucatán: A Preliminary Framework. Historical Archaeology 15:1-18.

Balée, William

1998 Advances in Historical Ecology. Columbia University Press, New York.

Baxter, Michael

2003 Statistics in Archaeology. Oxford University Press, New York.

Baxter, M.J. and C.C. Beardah

1997 Some Archaeological Applications of Kernel Density Estimates. Journal of Archaeological Science. 24:347-354.

Beaudry, Mary

1983 The Ceramics of the Zapotitán Valley. In Archaeology and Volcanism in Central America: The Zapotitán Valley of El Salvador. Edited by Payson D. Sheets, pp. 161 190. University of Texas Press, Austin.

Beaudry, Mary and Mrozowski, Stephen A.

2001 Cultural Space and Worker Identity in the Company City: Nineteenth-Century Lowell, Massachusetts. In, The Archaeology of Urban Landscapes: Explorations in Slumland, edited by Alan Mayne and Tim Murray, pp. 118-131. Cambridge University Press, Cambridge.

Beck Jr., Robin A., Christopher B. Rodning, and David G. Moore

2011 Limiting Resistance: Juan Pardo and the Shrinking of Spanish La Florida, 1566 68. In Enduring Conquests: Rethinking the Archaeology of Resistance to Spanish Colonialism in the Americas, edited by Matthew Liebmann and Melissa S. Murphy, pp. 19-40, School for Advanced Research Press, Santa Fe.

Bender, Donald R.

1967 A Refinement of the Concept of Household: Families, Co-Residence, and Domestic Functions. American Anthropologist 69(5):493-504. 
Blanton, Richard E.

1994 Houses and Households: A Comparative Study. Springer-Verlag, New York.

Borah, Woodrow and Sherburne F. Cook

1969 Conquest and Population: A Demographic Approach to Mexican History.

Proceedings of the American Philosophical Society 113:177-183.

Card, Jeb J.

2007 The Ceramics of Colonial Ciudad Vieja, El Salvador: Culture Contact and Social Change in Mesoamerica. Ph.D. dissertation, Tulane University, New Orleans.

Carter, Anthony T. and William Merrill

1979 Household Institutions and Population Dynamics. Agency for International Development, Washington, D.C.

Carruthers, Clive

2003 Spanish Botijas or Olive Jars from the Santo Domingo Monastery, La Antigua Guatemala. Historical Archaeology 4:40-55

Casas, Bartolomé de las

1992 [1552] The Devastation of the Indies: A Brief Account. Johns Hopkins

University Press, Baltimore.

Castillero, Alfredo

1994 Arquitectura, vivienda y sociedad. La vivienda colonial en Panamá. Historia de un sueño. Biblioteca Cultural. Editado por Fondo de Promoción Cultural Shell, Panamá.

Chamberlain, Robert S.

1966 The Conquest and Colonization of Honduras, 1502-1550. Octagon Books, Inc. New York.

Charlton, Thomas H. and Patricia Fournier

2011 Pots and Plots: The Multiple Roles of Early Colonial Red Wares in the Basin of Mexico (Identity, Resistance, Negotiation, Accommodation, Aesthetic Creativity, or Just Plain Economics?). In Enduring Conquests: Rethinking the Archaeology of Resistance to Spanish Colonialism in the Americas, edited by Matthew Liebmann and Melissa S. Murphy, pp. 1940, School for Advanced Research Press, Santa Fe.

Charlton, Thomas H., Patricia Fournier, and Juan Cervantes 1995 La Cerámica del Periodo Colonial Temprano en Tlatelolco: El Caso de la Loza Roja Bruñida. In Presencias y Encuentros: Investigaciones Arquelógicas de Salvamento, pp. 135-155. Dirección de Salvamento Arqueológico, Mexico, D.F. 
Clouse, Robert Allen

1999 Interpreting Archaeological Data Through Correspondence Analysis. Historical Archaeology 33:90-107.

Clunas, Craig

1991 Superfluous Things: Material Culture and Social Status in Early Modern China. University of Hawaii Press, Honolulu.

Cohen, Jeremy David

2003 Informal Commercial Networks, Social Control, and Political Power in the Province of Venezuela, 1700-1757. Ph.D. dissertation, University of Florida, Gainesville.

Cook, Sherburne F.

1949 Soil Erosion and Population in Central Mexico. University of California Press, Berkeley.

Costin, Cathy L.

1991 Craft Specialization: Issues in Defining, Documenting, and Explaining the Organization of Production. Archaeological Method and Theory 1:1-56.

Crumley and Marquardt

1990 Landscape: A Unifying Concept in Regional Analysis. In, Interpreting Space: GIS and Archaeology, edited by Kathleen Allen, Stanton Green, and Ezra Zubrow, pp.73-79. Taylor and Francis, London.

Dasgupta, A.K.

1978 Relevance of Malthusian Economics. Indian Economic Journal 26:279-286.

Dawdy, Shannon Lee

2008 Building the Devil's Empire: French Colonial New Orleans. University of Chicago Press, Chicago.

Deagan, Kathleen

2011 Eliciting Contraband Through Archaeology: Illicit Trade in Eighteenth-Century St. Augustine. In SHA Perspectives from Archaeology: The Archaeology of Spanish Missions and Colonies in the New World, compiled by Steve A. Tomka and Timothy K. Perttula. 6:169-187.

2002 The Material Assemblage of $16^{\text {th }}$ Century Spanish Florida. Historical Archaeology 12:25-50.

1987 Artifacts of the Spanish Colonies and the Caribbean, 1500-1800, Volume I: Ceramics, Glassware, and Beads. Smithsonian Institution Press, Washington, D.C. 
Denevan, William M.

1992 The Pristine Myth: The Landscape of the Americas in 1492. Annals of the Association of American Geographers 82:369-385.

Dym, Jordana

2006 From Sovereign Villages to National States: City, State, and Federation in Central America, 1759 - 1839. University of New Mexico Press, Albuquerque.

Earnest Jr., Howard H.

1999 A Reappraisal of the Ilopango Volcanic Eruption in Central El Salvador. Ph.D. dissertation, Department of Anthropology, Harvard University.

Engels, Friedrich

2008 [1892] The Condition of the Working-Class in England in 1844. Cosimo Inc., New York.

Erickson, Clark

2010 The Transformation of Environment into Landscape: The Historical Ecology of Monumental Earthwork Construction in the Bolivian Amazon. Diversity 2:618-652.

Evans, S. T.

2005 The Aztec Palace Under Spanish Rule: Disk Motifs in the Mapa de Mexico de 1550. In, The Postclassic to Spanish-Era Transition in Mesoamerica: Archaeological Perspectives edited by S. Kepecs and R.T. Alexander. The University of New Mexico Press, Albuquerque.

Ewen, C.R.

1991 From Spaniard to Creole: The Archaeology of Cultural Formation at Puerto Real, Haiti. University of Alabama Press, Tuscaloosa.

Fish, Shirley

2011 The Manila-Acapulco Galleons: The Treasure Ships of the Pacific, With an Annotated List of Transpacific Galleons, 1565-1815. Author House, UK.

Flannery, Kent V.

1976 The Early Mesoamerican Village. Academic Press, New York.

Flemion, Philip F.

1972 Historical dictionary of El Salvador. Ayer 4A 1581. Newberry Library, Chicago.

Fowler Jr., William R.

1985 Ethnohistoric Sources on the Pipil-Nicarao of Central America: A Critical Analysis. Ethnohistory 32:37-62.

1988 La población nativa de El Salvador al momento de la conquista española. Mesoamérica 15:79-116. 
1989 The Cultural Evolution of Ancient Nahua Civilizations: The Pipil-Nicarao of Central America. University of Oklahoma Press, Norman.

Fowler Jr., William R. and Howard H. Earnest Jr.

1985 Settlement Patterns and Prehistory of the Paraíso Basin of El Salvador. Journal of Field Archaeology 12:19-32.

Fox, John

2008 Maya Postclassic State Formation. Cambridge University Press, Cambridge.

Freidel, David A. and Masson, M.

2002 Ancient Maya Political Economies. Altamira Press, Walnut Creek.

Freidel, David A. and Sabloff, Jeremy A.

1984 Cozumel: Late Maya Settlement Patterns. Academic Press, Salt Lake City.

García de Palacio, Diego

1985 Letter to the King of Spain: being a description of the ancient provinces of Guazacapan, Izalco, Cuscatlan, and Chiquimula. Ayer folio F1434.G27. Newberry Library, Chicago.

Gasco, Janine

1992 Material Culture and Colonial Indian Society in Southern Mesoamerica: The View from Coastal Chiapas, Mexico. Historical Archaeology 26:67-76.

2005 Spanish Colonialism and Processes of Social Change in Mesoamerica. In The Archaeology of Colonial Encounters: Comparative Perspectives, edited by Gil Stein, pp. 69-108. School of American Research Advanced Seminar Series, Santa Fe.

Gifford, James C.

1963 A Conceptual Approach to the Analysis of Prehistoric Pottery. Ph.D.

dissertation, Harvard University, Cambridge.

Glassie, Henry

1969 Pattern in the Material Folk Culture of the Eastern United States. University of Pennsylvania Press, Philadelphia.

Goggin, John M.

1968 Spanish Majolica in the New World: Types of the Sixteenth to Eighteenth Centuries. Yale University Publications in Anthropology Vol. 72. Yale University Press, New Haven.

Graham, Elizabeth

1998 Mission Archaeology. Annual Review of Anthropology 27:25-62. 
Grieshaber, Erwin P.

1979 Hacienda-Indian Community Relations and Indian Acculturation: An

Historiographical Essay. Latin American Research Review 14:107-128.

Groover, Mark D.

2004 Household Succession as a Catalyst of Landscape Change. Historical Archaeology 38:25-43.

Hanks, William

2010 Converting Words: Maya in the Age of the Cross. University of California Press, Berkeley.

Hayden, Brian and Cannon, Aubrey

1984 The Structure of Material Systems: Ethnoarchaeology in Maya Highlands.

Society of American Archaeology.

Hendon, Julia A.

1996 Archaeological Approaches to the Organization of Domestic Labor: Household Practice and Domestic Relations. Annual Review of Anthropology 25:45-61.

2010 Houses in a Landscape: Memory and Everyday Life in Mesoamerica. Duke University Press, Durham.

Hendon, Julia A. and Rosemary Joyce (eds.)

2004 Mesoamerican Archaeology: Theory and Practice. Wiley Publishing, Hoboken.

Hirth, Kenneth G. and Robert S. Santley

1993 Prehispanic Domestic Units in Western Mesoamerica: Studies of the Household, Compound, and Residence. CRC Press, Boca Raton.

Hodder, Ian and C. Cessford

2004 Daily Practice and Social Memory at çatalhöyük. American Antiquity 69:17-40.

Hodder, Ian and Robert W. Preucel

1996 Contemporary Archaeology in Theory: A Reader. Wiley-Blackwell Publishing Ltd., New Jersey.

Jones, David M.

1981 The Importance of the Hacienda in the $19^{\text {th }}$ Century Otumba and Apan, Basin of Mexico. Historical Archaeology 15:87-116.

Kamen, Henry

2000 Early Modern European Society. Routledge, Oxford. 
Kepecs, Susan

2005 Mayas, Spaniards, and Salt: World Systems Shift in Sixteenth-Century Yucatán. In The Postclassic to Spanish-Era Transition in Mesoamerica, edited by Susan Kepecs and Rani Alexander. University of New Mexico Press, Albuquerque, pp. 117 138.

Kicza, John E.

1985 Economic Forces and Social Development in Colonial New Spain: A Comment. Latin American Research Review. 20:176-180.

King, Leslie J.

1984 Central Place Theory. Scientific Geography Series, Vol. 1. Sage Publication, London.

Kosakowsky, Laura J.

2001 The Ceramics of the Southeastern Pacific Coast of Guatemala: A Summary View. In, Incidents of Archaeology in Central America and Yucatán: Essays in Honor of Edwin M. Shook, edited by Michael Love, Marion Popenoe de Hatch, and Héctor Excobedo, pp.129-146. University Press of America, Inc., Lanham.

Kuwayama, George

1997 Chinese Ceramics in Colonial Mexico. Los Angeles County Museum of Art, Los Angeles.

Lattimore, Owen

1962 Nomads and Commissars: Mongolia Revistsed. Oxford University Press, New York.

Lauria Santiago, Aldo A.

2003 Una Republica Agraria. Ministerio de Educacion, El Salvador.

Leone, Mark P., James M. Harmon, and Jessica L. Neuwirth

2005 Perspective and Surveillance in Eighteenth-Century Maryland Gardens, Including William Paca's Garden on Wye Island. Historical Archaeology 37:138159.

Lind, Michael D.

1967 Mixtec Polychrome Pottery: A Comparison of the Late Preconquest Polychrome Pottery from Cholula, Oaxaca, and the Chinantla. Unpublished Master's thesis, Department of Anthropology, Vanderbilt University, Nashville.

Lister, Florence C. and Robert H. Lister

1976 A Descriptive Dictionary for 500 Years of Spanish-Tradition Ceramics: $13^{\text {th }}$ Through $18^{\text {th }}$ Centuries. The Society for Historical Archaeology, Special Publication Series 1. 
1978 The First Mexican Maiolicas: Imported and Locally Produced. Historical Archaeology 12:1-24.

1981 The Recycled Pots and Potsherds of Spain. Historical Archaeology 15:66-78.

1982 Sixteenth Century Maiolica Pottery in the Valley of Mexico. Anthropological Papers of the University of Arizona, Number 39. The University of Arizona Press, Tucson.

Lockhart, J.

1992 The Nahuas After the Conquest: A Social and Cultural History of the Indians of Central Mexico, Sixteenth Through Eighteenth Centuries. Stanford University Press, Stanford, CA.

Lothrop, Samuel K.

1927 Pottery Types and Their Sequence in El Salvador. Indian Notes and Monographs, 1:164-220. Heye Foundation, Museum of the American Indian, New York.

1939 The Southeastern Frontier of the Maya. American Anthropologist 41:42-54.

Mack, Taylor E.

1998 Contraband Trade Through Trujillo, Honduras, 1720s-1782. Central Missouri State University. http://sites.maxwell.syr.edu/clag/yearbook1998/mack.htm

MacLeod, Murdo J.

1973 Spanish Central America: A Socioeconomic History, 1520-1720. University of California Press, London.

Mann, Susan

2012 Doing Feminine Theory: From Modernity to Postmodernity. Oxford University Press, Oxford.

Manzanilla, Linda

1986 Unidades habitacionales Mesoamericanas y sus áreas de actividad.

Universidad Nacional Autónoma de Mexico, Mexico City.

1996 Corporate Groups and Domestic Activities at Teotihuacan. Latin American Antiquity 7:228-246.

Marcus, Joyce

1993 Ancient Maya Political Organization. In Lowland Maya Civilization in the Eighth Century A.D., edited by Jeremy A. Sabloff and John S. Henderson, pp. 111183. Dumbarton Oaks, Washington, D.C.

1998 The Peaks and Valleys of Ancient States: An Extension of the Dynamic Model. 
In Archaic States, edited by Gary M. Feinman and Joyce Marcus, pp. 3-13. School of American Research, Santa Fe, New Mexico, SAR Press.

Marken, Mitchell

1994 Pottery from Spanish Shipwrecks 1500-1800. University Press of Florida, Gainesville.

Marx, Karl and Fredric Engels

1932 The German Ideology: Critique of Modern German Philosophy According to Its Representatives, Feuerbach, B. Bauer and Stirner, and of German Socialism According to Its Various Prophets. Volume I and II. http://www.marxists.org/archive/marx/works/1845/german-ideology/index.htm

Maxwell, Judith M. and Hill II, Robert M. (translators)

2006 Kaqchikel Chronicles: The Definitive Edition. University of Texas Press, Austin.

McCafferty, Geoffery G.

1995 The Ceramics and Chronology of Cholula, Mexico. Ancient Mesoamerica 7:325333.

McCusker, John J.

2001 Mercantilism and the Economic History of the Early Modern Atlantic World. Cambridge, England.

McGuire, Randall H.

1988 Dialogues with the Dead: Ideology in the Cemetery. In The Recovery of Meaning in Historical Archaeology, edited by Mark P. Leone and P.B. Potter Jr., pp. 435-480. Smithsonian Institution Press, Washington, D.C.

Morrison, Ken

2006 Marx, Durkheim, Weber: Formations of Modern Social Thought, $2^{\text {nd }}$ Edition. SAGE Publications Ltd, London.

Offner, J. A.

1984 Household Organization in the Texcocan Heartland: The Evidence in the Codex Vergara. In Explorations in Ethnohistory: Indians of Central Mexico in the Sixteenth Century, edited by H.R. Harvey and H.J. Prem. University of New Mexico Press, Albuquerque, pp. 127-146.

Onnekink, David and Gijs Rommelse

2011 Ideology and Foreign Policy in Early Modern Europe (1650-1750). Ashgate Publishing, Ltd., Burlington, VT.

Orellana, Sandra L.

1995 Ethnohistory of the Pacific Coast. Labyrinthos, Lancaster. 
Paynter, Robert

1989 Archaeology of Equality and Inequality. Annual Review of Anthropology

18:369-399.

Polo Sifontes, Francis

1979 Título de Alotenango. Ministerio de Educación, Guatemala.

Pons, Frank Moya

2007 History of the Caribbean. Markus Wiener Publishers, Princeton, NJ.

Pope, K.O., M.E.D. Pohl, J. G. Jones, D.L. Lentz, C von Nagy, F. J. Varga, and I.R.

Quitmyer

2001 Origin and Environmental Settings of Ancient Agricultural in the Lowlands of Mesoamerica. Science 292:1370-1373.

Rapoport, Amos

1990 The Meaning of the Built Environment: A Nonverbal Approach Communication Approach. University of Arizona Press, Tucson.

Rathje, William L. and Richard R. Wilk

1982 Household Archaeology. The American Behavioral Scientist 25(6):617-639.

Recinos, Adrian and Delia Goetz

1953 The Annals of the Cakchiquels. The Title of the Lords of Ttonicapan. Translated by José Chonay and Delia Goetz. University of Oklahoma Press, Norman.

Repetto, R.

1979 Economic Equality and Fertility in Developing Countries. Johns Hopkins

University Press, Baltimore.

Rice, Prudence M.

1996 The Archaeology of Wine: The Wine and Brandy Haciendas of Moquegua, Peru. Journal of Field Archaeology. 23:187-204.

Rinaldi, Maura

1989 Kraak Porcelain: A Moment in the History of Trade. Bamboo Publishing, Ltd., London.

Rodríguez-Alegría, Enrique

2005 Eating like an Indian: Negotiating Social Relations in the Spanish Colonies. Current Anthropology 46:551-575.

Rotman, Deborah L. and Michael S. Nassaney

1997 Class, Gender, and the Built Environment: Deriving Social Relations from Cultural Landscapes in Southwest Michigan. Historical Archaeology 31:42-63. 
Rouse, Irving

1940 Some Evidence Concerning the Origins of West Indian Pottery-Making. American Anthropologist 42:49-80

Rovira, Beatriz E.

2001 Presencia de mayólicas panameñas en el mundo colonial: algunas consideraciones acerca de su distribución y cronología. Latin American Antiquity 12:291-303.

Sampeck, Kathryn E.

2007 Late Postclassic to Colonial Landscapes and Political Economy of the Izalcos Region, El Salvador. Ph.D. dissertation, Tulane University, New Orleans.

Santley, R.S., and K.G. Hirth

1993 Prehispanic Domestic Units in Western Mesoamerica: Studies of the Household, Compound, and Residence. CRC Press, Boca Raton, FL.

Sen, Gita and Caren Grown 1988 Third World Women's Perspectives: For Development Alternatives with Women for a New Era (DAWN). Earthscan Publications Limited, London.

Sewell Jr., William H.

2005 The Logics of History: Social Theory and Social Transformation. University of Chicago Press, Chicago.

Sharer, Robert

1977 The Prehistory of Chalchuapa, El Salvador. 3 Vols. University of Pennsylvania Press, Philadelphia.

Sheather, Simon J.

2004 Density Estimation. Statistical Science 4:588-597.

Shepard, A. O.

1980 Ceramics for the Archaeologist. Braun-Brumfield, Ann Arbor.

Silliman, Stephen

2001 Agency, Practical Politics and the Archaeology of Culture Contact. Journal of Social Archaeology 1:190-209.

Skinner, G.W.

1985 Rural Marketing in China: Repression and Revival. China Q. 103:393-413.

Skowronek, Russel K.

1987 Ceramics and Commerce: The 1554 flota Revisited. Historical Archaeology 21:101-111. 
1998 The Spanish Philippines: Archaeological Perspectives on Colonial Economics and Society. International Journal of Historical Archaeology 2:45-71.

Smith, M.E.

1992 Braudel's Temporal Rhythms and Chronology Theory in Archaeology. In Archaeology, Annales, and Ethnohistory, edited by A.B. Knapp, pp. 23-34. Cambridge University Press, Cambridge.

Smith, Robert and James Gifford

1965 Archaeological Excavations at Santa Rosa de Pensacola. Florida State University in Anthropology 10. Florida State University, Tallahassee.

Smith, Robert, Gordon R. Willey, and james Gifford

1960 The Type-Variety Concept as a Basis for the Analysis of Maya Pottery. American Antiquity 25:330-340.

Spink, Mary Louise

1983 Metates as Socioeconomic Indictors During the Classic Period at Copan, Honduras. Ph.D. Dissertation, Department of Anthropology, Pennsylvania State University, Ann Arbor, MI: University Microfilms International.

Spores, Ronald and Kent V. Flannery

1983 Sixteenth-century kinship and social organization. In, The Cloud People:

Divergent Evolution of the Zapotec and Mixtec Civilizations, pp. 339-342 edited by Kent V. Flannery and J. Marcus. Percheron Press, Clinton Corners, NY

Spores, Ronald and Nelly Robles García

2007 A Prehispanic (Postclassic) Capital Center in Colonial Transition: Excavations at Yucundaa Pueblo Viejo de Teposcolula, Oaxaca, Mexico. Latin American Antiquity 18:333-353.

Spriggs, Matthew

1984 Another Way of Telling: Marxist Perspectives in Archaeology in Marxist Perspectives in Archaeology edited by Matthew Spriggs. Cambridge University Press, Cambridge.

Sol, Antonio E.

1929 Informe sobre las ruinas de Cihuatán. Revista del Departmento de História. $1: 19-23$.

Symanski, Luís Cláudio P.

2012 The Place of Strategy and the Spaces of Tactics: Structures , Artifacts, and Power Relations on Sugar Plantations of West Brazil. Historical Archaeology 46:124148. 
Thompson, J. Eric S.

1943 A Trial Survey of Northern Maya Area. American Antiquity 9:106-134.

1948 An Archaeological Reconnaissance in the Cotzumalhuapa Region, Escuintla, Guatemala. Carnegie Institution of Washington, Contributions to American Archaeology and History, No.44, Publication No. 574. Washington, D.C.

Tourtellot III, Gair

1988 Developmental Cycles of Households and Houses at Seibal. In Household and Community in the Mesoamerican Past, edited by Richard Wilk and Wendy Ashmore, pp. 97-120. University of New Mexico Press, Albuquerque.

Trigger, Bruce G.

1993 Marxism in Contemporary Western Archaeology. Archaeological Method and Theory 5:159-200.

Tutino, John

1975 Hacienda Social Relations in Mexico: The Chalco Region in the Era of Independence. The Hispanic American Historical Review. 55:496-528.

1976 Creole Mexico: Spanish Elites, Haciendas, and Indian Towns, 1750-1810. Ph.D. dissertation, The University of Texas at Austin, Austin.

Van Tilburg, Hans K.

2007 Chinese Junks on the Pacific: Views from a Different Deck. New Perspectives on Maritime History and Nautical Archaeology Series. University of Florida Press, Gainesville.

Verhagen, Inez Leontine

1997 Caluco, El Salvador: The Archaeology of a Colonial Indian Town in Comparative Perspective. Unpublished Ph.D. dissertation, Department of Anthropology, Vanderbilt University, Nashville.

Voss, Barbara L.

2012 Status and Ceramics in Spanish Colonial Archaeology. Historical Archaeology. 46:39-54.

Wauchope, Robert

1970 The Indian Background of Latin American History: The Maya, Aztec, Inca and their Predecessors. Knopf, New York.

Weeks, M. J.

1988 Residential and Local Group Organization in the Maya Lowlands of Southwestern Campeche, Mexico: The Early Seventeenth Century. In Household and Community in Mesoamerican Past, edited by R. Wilk and W. Ashmore, pp. 73-97. University of New Mexico Press, Albuquerque. 
Wernke, Steven A.

2008 Negotiating Community and Landscape in the Peruvian Andes: A Transconquest View. American Anthropologist 109:130-152.

Wilk, Richard R. and Wendy Ashmore 1988 Household and Community in the Mesoamerican Past. University of New Mexico Press, Albuquerque.

Woodfine, Philip 1998 Britannia's Glories: The Walpole Ministry and the 1739 War with Spain. Volume 6 of the Royal Historical Society Studies in History. Boydell and Brewer, Ltd., Suffolk.

Wonderley, A.W.

1985 The Land of Ulua: Postclassic Research in Naco and Sula Valleys, Honduras. In The Lowland Maya Postclassic, pp.254-269

Yoffee, Norman and George L. Cowgill

1988 The Collapse of Ancient Civilizations. University of Arizona Press, Tucson.

Zeitlin, Judith Francis

2005 Cultural Politics in Colonial Tehuantepec: Community and State Among the Isthmus Zapotec. Stanford University Press, Stanford.

Zelaya, Rodolfo Marcelino

1992 Datos históricos de los municipos de El Salvador: época precolumbina, época colonial: 259 municipos. Ayer F1482.Z45. Newberry Library, Chicago. 


\section{APPENDIX A}

\begin{tabular}{|c|c|c|c|c|c|c|c|c|c|c|c|}
\hline $\begin{array}{l}\text { MNV by } \\
\text { Level }\end{array}$ & Level 1 & Level 2 & Level 3 & Level 4 & $\begin{array}{l}\text { Feature } \\
1\end{array}$ & $\begin{array}{l}\text { Feature } \\
2\end{array}$ & $\begin{array}{l}\text { Feature } \\
3\end{array}$ & $\begin{array}{l}\text { TP1 } \\
\text { Trenching }\end{array}$ & $\begin{array}{l}\text { TP3 } \\
\text { Cleaning }\end{array}$ & $\begin{array}{l}\text { Interior } \\
\text { Wall }\end{array}$ & $\begin{array}{l}\text { Type } \\
\text { Total }\end{array}$ \\
\hline \multirow{3}{*}{$\begin{array}{l}\text { UID } \\
\text { Classic }\end{array}$} & & & & & & & & & & & \\
\hline & 7 & 7 & 1 & 0 & 0 & 0 & 0 & 0 & 0 & 0 & 15 \\
\hline & $46.67 \%$ & $46.67 \%$ & $6.67 \%$ & $0 \%$ & $0 \%$ & $0 \%$ & $0 \%$ & $0 \%$ & $0 \%$ & $0 \%$ & \\
\hline \multicolumn{12}{|l|}{ UID } \\
\hline \multirow[t]{2}{*}{ Postclassic } & 1 & 0 & 0 & 0 & 0 & 0 & 0 & 0 & 0 & 0 & 1 \\
\hline & $100.00 \%$ & $0 \%$ & $0 \%$ & $0 \%$ & $0 \%$ & $0 \%$ & $0 \%$ & $0 \%$ & $0 \%$ & $0 \%$ & \\
\hline \multicolumn{12}{|l|}{$\begin{array}{l}\text { Catalina } \\
\text { Red on }\end{array}$} \\
\hline \multirow[t]{2}{*}{ White } & 3 & 1 & 0 & 0 & 0 & 1 & 0 & 0 & 0 & 0 & 5 \\
\hline & $60.00 \%$ & $20.00 \%$ & $0 \%$ & $0 \%$ & $0 \%$ & $20.00 \%$ & $0 \%$ & $0 \%$ & $0 \%$ & $0 \%$ & \\
\hline \multicolumn{12}{|l|}{$\begin{array}{l}\text { Cipriano } \\
\text { Red on }\end{array}$} \\
\hline \multirow[t]{2}{*}{ Gray } & 0 & 2 & 0 & 0 & 0 & 0 & 0 & 0 & 0 & 0 & 2 \\
\hline & $0 \%$ & $100.00 \%$ & $0 \%$ & $0 \%$ & $0 \%$ & $0 \%$ & $0 \%$ & $0 \%$ & $0 \%$ & $0 \%$ & \\
\hline \multicolumn{12}{|l|}{ Gines } \\
\hline \multirow[t]{2}{*}{ Variety } & 6 & 10 & 3 & 0 & 0 & 0 & 0 & 0 & 1 & 0 & 20 \\
\hline & $30.00 \%$ & $50.00 \%$ & $15.00 \%$ & $0 \%$ & $0 \%$ & $0 \%$ & $0 \%$ & $0 \%$ & $5.00 \%$ & $0 \%$ & \\
\hline \multicolumn{12}{|l|}{$\begin{array}{l}\text { Teshcal } \\
\text { Red on }\end{array}$} \\
\hline \multirow[t]{2}{*}{ Nat. } & 5 & 9 & 1 & 0 & 0 & 0 & 0 & 0 & 3 & 0 & 18 \\
\hline & $27.78 \%$ & $50.00 \%$ & $5.56 \%$ & $0 \%$ & $0 \%$ & $0 \%$ & $0 \%$ & $0 \%$ & $16.67 \%$ & $0 \%$ & \\
\hline \multicolumn{12}{|l|}{ Cuscatlán } \\
\hline \multirow[t]{2}{*}{ Brown } & 0 & 4 & 1 & 0 & 0 & 0 & 0 & 1 & 1 & 1 & 8 \\
\hline & $0 \%$ & $50.00 \%$ & $12.5 \%$ & $0 \%$ & $0 \%$ & $0 \%$ & $0 \%$ & $12.5 \%$ & $12.5 \%$ & $12.5 \%$ & \\
\hline \multirow[t]{2}{*}{ Darío Plain } & 20 & 24 & 7 & 0 & 2 & 2 & 0 & 2 & 1 & 0 & 58 \\
\hline & $34.48 \%$ & $41.38 \%$ & $12.07 \%$ & $0 \%$ & $3.45 \%$ & $3.45 \%$ & $0 \%$ & $3.45 \%$ & $1.72 \%$ & $0 \%$ & \\
\hline \multicolumn{12}{|l|}{ Pantaleón } \\
\hline \multirow[t]{2}{*}{ Brown } & 51 & 31 & 6 & 8 & 5 & 3 & 1 & 4 & 0 & 1 & 110 \\
\hline & $46.36 \%$ & $28.18 \%$ & $5.45 \%$ & $2.27 \%$ & $4.55 \%$ & $2.73 \%$ & $.91 \%$ & $3.64 \%$ & $0 \%$ & $.91 \%$ & \\
\hline \multirow[t]{2}{*}{$\begin{array}{l}\text { Eliseo Red } \\
\text { on Nat }\end{array}$} & 16 & 14 & 3 & 1 & 3 & 1 & 0 & 2 & 2 & 0 & 42 \\
\hline & $38.10 \%$ & $33.33 \%$ & $7.14 \%$ & $2.34 \%$ & $7.14 \%$ & $2.34 \%$ & $0 \%$ & $4.76 \%$ & $4.76 \%$ & $0 \%$ & \\
\hline \multicolumn{12}{|l|}{ Bibiana } \\
\hline \multirow[t]{2}{*}{ Red } & 8 & 12 & 4 & 0 & 3 & 0 & 0 & 1 & 0 & 0 & 28 \\
\hline & $28.57 \%$ & $42.86 \%$ & $14.29 \%$ & $0 \%$ & $10.71 \%$ & $0 \%$ & $0 \%$ & $3.57 \%$ & $0 \%$ & $0 \%$ & \\
\hline \multicolumn{12}{|l|}{$\begin{array}{l}\text { Apolonio } \\
\text { Orange- }\end{array}$} \\
\hline Red & 0 & 1 & 1 & 0 & 0 & 0 & 0 & 0 & 0 & 0 & 2 \\
\hline
\end{tabular}




\begin{tabular}{|c|c|c|c|c|c|c|c|c|c|c|c|}
\hline & $0 \%$ & $50.00 \%$ & $50.00 \%$ & $0 \%$ & $0 \%$ & $0 \%$ & $0 \%$ & $0 \%$ & $0 \%$ & $0 \%$ & \\
\hline \multirow[t]{2}{*}{ Brown } & 5 & 6 & 1 & 0 & 0 & 0 & 0 & 2 & 0 & 0 & 14 \\
\hline & $35.71 \%$ & $42.86 \%$ & $7.14 \%$ & $0 \%$ & $0 \%$ & $0 \%$ & $0 \%$ & $14.29 \%$ & $0 \%$ & $0 \%$ & \\
\hline \multirow[t]{2}{*}{ Olive Jar } & 1 & 4 & 1 & 0 & 0 & 0 & 0 & 1 & 0 & 0 & 7 \\
\hline & $14.29 \%$ & $57.14 \%$ & $14.29 \%$ & $0 \%$ & $0 \%$ & $0 \%$ & $0 \%$ & $14.29 \%$ & $0 \%$ & $0 \%$ & \\
\hline \multirow[t]{2}{*}{$\begin{array}{l}\text { Lead Glaze } \\
\text { Redware }\end{array}$} & 20 & 5 & 0 & 0 & 0 & 1 & 0 & 0 & 0 & 0 & 26 \\
\hline & $76.92 \%$ & $19.23 \%$ & $0 \%$ & $0 \%$ & $0 \%$ & $3.85 \%$ & $0 \%$ & $0 \%$ & $0 \%$ & $0 \%$ & \\
\hline \multirow[t]{2}{*}{ Floor Tile } & 0 & 0 & 0 & 0 & 0 & 1 & 0 & 0 & 0 & 0 & 1 \\
\hline & $0 \%$ & $0 \%$ & $0 \%$ & $0 \%$ & $0 \%$ & $100.00 \%$ & $0 \%$ & $0 \%$ & $0 \%$ & $0 \%$ & \\
\hline \multirow[t]{2}{*}{ Roof Tile } & 0 & 0 & 0 & 0 & 0 & 1 & 0 & 0 & 0 & 0 & 1 \\
\hline & $0 \%$ & $0 \%$ & $0 \%$ & $0 \%$ & $0 \%$ & $100.00 \%$ & $0 \%$ & $0 \%$ & $0 \%$ & $0 \%$ & \\
\hline \multirow[t]{2}{*}{ Porcelain } & 1 & 2 & 0 & 0 & 0 & 0 & 0 & 0 & 1 & 0 & 4 \\
\hline & $25.00 \%$ & $50.00 \%$ & $0 \%$ & $0 \%$ & $0 \%$ & $0 \%$ & $0 \%$ & $0 \%$ & $25.00 \%$ & $0 \%$ & \\
\hline \multicolumn{12}{|l|}{ Raimundo } \\
\hline \multirow[t]{2}{*}{ Brown } & 5 & 2 & 1 & 1 & 1 & 0 & 0 & 3 & 0 & 0 & 13 \\
\hline & $38.46 \%$ & $15.38 \%$ & $7.69 \%$ & $7.69 \%$ & $7.69 \%$ & $0 \%$ & $0 \%$ & $23.08 \%$ & $0 \%$ & $0 \%$ & \\
\hline \multirow[t]{2}{*}{$\begin{array}{l}\text { Dario } \\
\text { Variant \#1 }\end{array}$} & 0 & 1 & 0 & 0 & 0 & 0 & 0 & 0 & 0 & 0 & 1 \\
\hline & $0 \%$ & $100.00 \%$ & $0 \%$ & $0 \%$ & $0 \%$ & $0 \%$ & $0 \%$ & $0 \%$ & $0 \%$ & $0 \%$ & \\
\hline \multicolumn{12}{|l|}{ Dario } \\
\hline \multirow[t]{2}{*}{ Variant \#2 } & 0 & 1 & 0 & 0 & 0 & 0 & 0 & 0 & 0 & 0 & 1 \\
\hline & $0 \%$ & $100.00 \%$ & $0 \%$ & $0 \%$ & $0 \%$ & $0 \%$ & $0 \%$ & $0 \%$ & $0 \%$ & $0 \%$ & \\
\hline \multicolumn{12}{|l|}{ Dario } \\
\hline \multirow[t]{2}{*}{ Variant \#3 } & 1 & 2 & 0 & 0 & 0 & 1 & 0 & 1 & 0 & 0 & $\mathbf{5}$ \\
\hline & $20.00 \%$ & $40.00 \%$ & $0 \%$ & $0 \%$ & $0 \%$ & $20.00 \%$ & $0 \%$ & $20.00 \%$ & $0 \%$ & $0 \%$ & \\
\hline \multirow[t]{2}{*}{$\begin{array}{l}\text { Dario } \\
\text { Variant \#4 }\end{array}$} & 0 & 0 & 0 & 1 & 0 & 0 & 0 & 0 & 0 & 0 & 1 \\
\hline & $0 \%$ & $0 \%$ & $0 \%$ & $100.00 \%$ & $0 \%$ & $0 \%$ & $0 \%$ & $0 \%$ & $0 \%$ & $0 \%$ & \\
\hline \multirow[t]{2}{*}{ Creamware } & 2 & 0 & 1 & 0 & 0 & 0 & 0 & 0 & 0 & 0 & 3 \\
\hline & $66.67 \%$ & $0 \%$ & $33.33 \%$ & $0 \%$ & $0 \%$ & $0 \%$ & $0 \%$ & $0 \%$ & $0 \%$ & $0 \%$ & \\
\hline $\begin{array}{r}\text { Total } \\
\text { Count }\end{array}$ & 152 & 138 & 31 & 11 & 14 & 11 & 1 & 17 & 9 & 2 & 386 \\
\hline $\begin{array}{r}\text { Total } \\
\text { Percentage }\end{array}$ & $39.38 \%$ & $35.75 \%$ & $8.03 \%$ & $2.85 \%$ & $3.63 \%$ & $2.85 \%$ & $.26 \%$ & $4.40 \%$ & $2.33 \%$ & $.52 \%$ & \\
\hline
\end{tabular}

Table A.1 


\begin{tabular}{|c|c|c|c|c|c|c|c|c|c|}
\hline $\begin{array}{l}\text { Total } \\
\text { Artifact } \\
\text { Assemblag } \\
\text { e }\end{array}$ & $\begin{array}{l}\text { Pottery } \\
\text { (Indig.) }\end{array}$ & $\begin{array}{l}\text { Pottery } \\
\text { (Europea } \\
\text { n Trad.) }\end{array}$ & $\begin{array}{l}\text { Pottery } \\
\text { (Porcelain } \\
\text { ) }\end{array}$ & $\begin{array}{l}\text { All } \\
\text { Pottery }\end{array}$ & Metal & Faunal & Glass & Lithic & Other \\
\hline $\begin{array}{l}\text { Sampeck } \\
(2007)\end{array}$ & & & & & & & & & \\
\hline Thesis & & & & & & & 2.87 & & 18.45 \\
\hline Data* & $62.62 \%$ & $6.79 \%$ & $0.57 \%$ & $69.99 \%$ & $1.34 \%$ & $2.20 \%$ & $\%$ & $4.88 \%$ & $\%$ \\
\hline $\begin{array}{l}\text { Skowronek } \\
\text { (1987) }\end{array}$ & $0.00 \%$ & $100.00 \%$ & $0.00 \%$ & $\begin{array}{r}100.00 \\
\%\end{array}$ & $\mathrm{n} / \mathrm{a}$ & $\mathrm{n} / \mathrm{a}$ & $\mathrm{n} / \mathrm{a}$ & $\mathrm{n} / \mathrm{a}$ & $\mathrm{n} / \mathrm{a}$ \\
\hline $\begin{array}{l}\text { Deagan } \\
(2002) \text { SA- } \\
26-1\end{array}$ & $38.54 \%$ & $53.24 \%$ & $0.23 \%$ & $92.01 \%$ & $4.90 \%$ & $\mathrm{n} / \mathrm{a}$ & $\begin{array}{r}1.69 \\
\%\end{array}$ & $1.40 \%$ & $\mathrm{n} / \mathrm{a}$ \\
\hline $\begin{array}{l}\text { Deagan } \\
(2002) \text { SA- } \\
34-1\end{array}$ & $48.82 \%$ & $37.95 \%$ & $0.16 \%$ & $86.93 \%$ & $\begin{array}{r}12.13 \\
\%\end{array}$ & $\mathrm{n} / \mathrm{a}$ & $\begin{array}{r}0.79 \\
\%\end{array}$ & $0.16 \%$ & $\mathrm{n} / \mathrm{a}$ \\
\hline $\begin{array}{l}\text { Deagan } \\
(2002) \text { SA- } \\
36-4\end{array}$ & $58.04 \%$ & $36.48 \%$ & $0.00 \%$ & $94.51 \%$ & $3.93 \%$ & $\mathrm{n} / \mathrm{a}$ & $\begin{array}{r}0.90 \\
\%\end{array}$ & $0.65 \%$ & $\mathrm{n} / \mathrm{a}$ \\
\hline $\begin{array}{l}\text { Gasco } \\
(1992) \text { ST } 9 \\
(\text { OP 8) }\end{array}$ & $78.57 \%$ & $18.01 \%$ & $0.11 \%$ & $96.68 \%$ & $2.03 \%$ & $\mathrm{n} / \mathrm{a}$ & $\mathrm{n} / \mathrm{a}$ & $1.28 \%$ & $\mathrm{n} / \mathrm{a}$ \\
\hline $\begin{array}{l}\text { Gasco } \\
(1992) \mathrm{ST} \\
12(\mathrm{OP} 7)\end{array}$ & $64.89 \%$ & $30.24 \%$ & $0.23 \%$ & $95.35 \%$ & $3.11 \%$ & $\mathrm{n} / \mathrm{a}$ & $\mathrm{n} / \mathrm{a}$ & $1.53 \%$ & $\mathrm{n} / \mathrm{a}$ \\
\hline $\begin{array}{l}\text { Gasco } \\
\text { (1992) ST } \\
37(\text { OP 1) }\end{array}$ & $90.25 \%$ & $7.49 \%$ & $0.20 \%$ & $97.93 \%$ & $1.38 \%$ & $\mathrm{n} / \mathrm{a}$ & $\mathrm{n} / \mathrm{a}$ & $0.69 \%$ & $\mathrm{n} / \mathrm{a}$ \\
\hline $\begin{array}{l}\text { Gasco } \\
(1992) \text { STS } \\
68 / 83 \text { (OPS } \\
5 / 6)\end{array}$ & $84.07 \%$ & $13.11 \%$ & $0.31 \%$ & $97.49 \%$ & $1.52 \%$ & $\mathrm{n} / \mathrm{a}$ & $\mathrm{n} / \mathrm{a}$ & $0.98 \%$ & $\mathrm{n} / \mathrm{a}$ \\
\hline $\begin{array}{l}\text { Gasco } \\
\text { (1992) ST } \\
73 \text { (OP 3) }\end{array}$ & $78.45 \%$ & $15.52 \%$ & $0.00 \%$ & $93.97 \%$ & $5.17 \%$ & $\mathrm{n} / \mathrm{a}$ & $\mathrm{n} / \mathrm{a}$ & $0.86 \%$ & $\mathrm{n} / \mathrm{a}$ \\
\hline $\begin{array}{l}\text { Gasco } \\
\text { (1992) ST } \\
78 \text { (OP 17) }\end{array}$ & $82.68 \%$ & $11.11 \%$ & $0.33 \%$ & $94.12 \%$ & $3.92 \%$ & $\mathrm{n} / \mathrm{a}$ & $\mathrm{n} / \mathrm{a}$ & $1.96 \%$ & $\mathrm{n} / \mathrm{a}$ \\
\hline $\begin{array}{l}\text { Gasco } \\
\text { (1992) ST } \\
85 \text { (OP 16) }\end{array}$ & $84.67 \%$ & $8.76 \%$ & $0.00 \%$ & $93.43 \%$ & $3.65 \%$ & $\mathrm{n} / \mathrm{a}$ & $\mathrm{n} / \mathrm{a}$ & $2.92 \%$ & $\mathrm{n} / \mathrm{a}$ \\
\hline $\begin{array}{l}\text { Gasco } \\
\text { (1992) ST } \\
89 \text { (OP 12) }\end{array}$ & $84.63 \%$ & $7.00 \%$ & $0.58 \%$ & $92.22 \%$ & $5.84 \%$ & $\mathrm{n} / \mathrm{a}$ & $\mathrm{n} / \mathrm{a}$ & $1.95 \%$ & $\mathrm{n} / \mathrm{a}$ \\
\hline $\begin{array}{l}\text { Morandi } \\
(2010)\end{array}$ & $35.60 \%$ & $8.71 \%$ & $0.00 \%$ & $44.31 \%$ & $1.37 \%$ & $\begin{array}{r}41.86 \\
\%\end{array}$ & $\mathrm{n} / \mathrm{a}$ & $\begin{array}{r}12.46 \\
\%\end{array}$ & $\mathrm{n} / \mathrm{a}$ \\
\hline
\end{tabular}

Table A.2 


\begin{tabular}{|c|c|c|c|c|c|c|c|c|c|c|c|}
\hline $\begin{array}{l}\text { Pot. Dist. } \\
\text { by Level } \\
\text { Total (\%) }\end{array}$ & Level 1 & Level 2 & Level 3 & Level 4 & Rasgo 1 & Rasgo 2 & Rasgo 3 & $\begin{array}{l}\text { TP1 } \\
\text { Trenching }\end{array}$ & $\begin{array}{l}\text { TP3 } \\
\text { Cleaning }\end{array}$ & $\begin{array}{l}\text { Interior } \\
\text { Wall }\end{array}$ & Tota \\
\hline $\begin{array}{l}\text { Darío } \\
\text { Plain }\end{array}$ & $10.76 \%$ & $12.69 \%$ & $22.50 \%$ & $0.00 \%$ & $17.31 \%$ & $16.67 \%$ & $0.00 \%$ & $13.63 \%$ & $3.70 \%$ & $0.00 \%$ & $12.16 \%$ \\
\hline $\begin{array}{l}\text { Pantaleón } \\
\text { Brown }\end{array}$ & $31.99 \%$ & $22.32 \%$ & $20.00 \%$ & $77.77 \%$ & $40.38 \%$ & $41.68 \%$ & $100.00 \%$ & $31.81 \%$ & $0.00 \%$ & $66.67 \%$ & $28.83 \%$ \\
\hline $\begin{array}{l}\text { Eliseo Red } \\
\text { on Nat }\end{array}$ & $16.16 \%$ & $15.38 \%$ & $10.00 \%$ & $0.00 \%$ & $25.00 \%$ & $8.33 \%$ & $0.00 \%$ & $9.09 \%$ & $37.04 \%$ & $0.00 \%$ & $16.12 \%$ \\
\hline $\begin{array}{l}\text { Bibiana } \\
\text { Red }\end{array}$ & $5.39 \%$ & $8.08 \%$ & $12.50 \%$ & $0.00 \%$ & $15.38 \%$ & $0.00 \%$ & $0.00 \%$ & $9.09 \%$ & $14.81 \%$ & $0.00 \%$ & $7.65 \%$ \\
\hline $\begin{array}{l}\text { Apolonio } \\
\text { Orange- } \\
\text { Red }\end{array}$ & $0.00 \%$ & $0.38 \%$ & $2.50 \%$ & $0.00 \%$ & $0.00 \%$ & $0.00 \%$ & $0.00 \%$ & $0.00 \%$ & $0.00 \%$ & $0.00 \%$ & $0.27 \%$ \\
\hline $\begin{array}{l}\text { Telesforo } \\
\text { Brown }\end{array}$ & $2.36 \%$ & $6.92 \%$ & $2.50 \%$ & $5.56 \%$ & $0.00 \%$ & $0.00 \%$ & $0.00 \%$ & $4.55 \%$ & $0.00 \%$ & $0.00 \%$ & $3.83 \%$ \\
\hline $\begin{array}{l}\text { Teshcal } \\
\text { Red on } \\
\text { Nat }\end{array}$ & $6.40 \%$ & $6.15 \%$ & $2.50 \%$ & $0.00 \%$ & $0.00 \%$ & $0.00 \%$ & $0.00 \%$ & $0.00 \%$ & $18.52 \%$ & $0.00 \%$ & $5.60 \%$ \\
\hline $\begin{array}{l}\text { Cuscatlan } \\
\text { Brown }\end{array}$ & $0.00 \%$ & $6.15 \%$ & $2.50 \%$ & $0.00 \%$ & $0.00 \%$ & $0.00 \%$ & $0.00 \%$ & $4.55 \%$ & $0.00 \%$ & $0.00 \%$ & $2.46 \%$ \\
\hline $\begin{array}{l}\text { Gines } \\
\text { Plain }\end{array}$ & $3.03 \%$ & $6.54 \%$ & $7.50 \%$ & $0.00 \%$ & $0.00 \%$ & $0.00 \%$ & $0.00 \%$ & $0.00 \%$ & $7.41 \%$ & $0.00 \%$ & $4.23 \%$ \\
\hline Olive Jar & $0.34 \%$ & $1.92 \%$ & $2.50 \%$ & $0.00 \%$ & $0.00 \%$ & $0.00 \%$ & $0.00 \%$ & $4.55 \%$ & $3.70 \%$ & $0.00 \%$ & $1.23 \%$ \\
\hline $\begin{array}{l}\text { Tin } \\
\text { Glazed } \\
\text { Redware }\end{array}$ & $15.81 \%$ & $2.32 \%$ & $0.00 \%$ & $0.00 \%$ & $0.00 \%$ & $8.33 \%$ & $0.00 \%$ & $0.00 \%$ & $11.12 \%$ & $0.00 \%$ & $7.79 \%$ \\
\hline Floor Tile & $0.00 \%$ & $0.00 \%$ & $0.00 \%$ & $0.00 \%$ & $0.00 \%$ & $8.33 \%$ & $0.00 \%$ & $0.00 \%$ & $0.00 \%$ & $0.00 \%$ & $0.14 \%$ \\
\hline Roof Tile & $0.00 \%$ & $0.00 \%$ & $0.00 \%$ & $0.00 \%$ & $0.00 \%$ & $8.33 \%$ & $0.00 \%$ & $0.00 \%$ & $0.00 \%$ & $0.00 \%$ & $0.14 \%$ \\
\hline $\begin{array}{l}\text { UID } \\
\text { Classic }\end{array}$ & $2.36 \%$ & $4.62 \%$ & $10.00 \%$ & $0.00 \%$ & $0.00 \%$ & $0.00 \%$ & $0.00 \%$ & $0.00 \%$ & $0.00 \%$ & $33.33 \%$ & $3.28 \%$ \\
\hline $\begin{array}{l}\text { UID } \\
\text { Postclassic }\end{array}$ & $0.34 \%$ & $0.00 \%$ & $0.00 \%$ & $0.00 \%$ & $0.00 \%$ & $0.00 \%$ & $0.00 \%$ & $0.00 \%$ & $0.00 \%$ & $0.00 \%$ & $0.14 \%$ \\
\hline $\begin{array}{l}\text { Catalina } \\
\text { Red on } \\
\text { White }\end{array}$ & $1.01 \%$ & $0.38 \%$ & $0.00 \%$ & $0.00 \%$ & $0.00 \%$ & $8.33 \%$ & $0.00 \%$ & $0.00 \%$ & $0.00 \%$ & $0.00 \%$ & $0.68 \%$ \\
\hline Porcelain & $0.34 \%$ & $1.54 \%$ & $0.00 \%$ & $0.00 \%$ & $0.00 \%$ & $0.00 \%$ & $0.00 \%$ & $0.00 \%$ & $3.70 \%$ & $0.00 \%$ & $0.82 \%$ \\
\hline $\begin{array}{l}\text { Raimundo } \\
\text { Brown }\end{array}$ & $2.70 \%$ & $1.15 \%$ & $2.50 \%$ & $5.56 \%$ & $1.93 \%$ & $0.00 \%$ & $0.00 \%$ & $13.64 \%$ & $0.00 \%$ & $0.00 \%$ & $2.32 \%$ \\
\hline $\begin{array}{l}\text { Darío } \\
\text { Variant \#1 }\end{array}$ & $0.00 \%$ & $0.38 \%$ & $0.00 \%$ & $0.00 \%$ & $0.00 \%$ & $0.00 \%$ & $0.00 \%$ & $0.00 \%$ & $0.00 \%$ & $0.00 \%$ & $0.14 \%$ \\
\hline $\begin{array}{l}\text { Darío } \\
\text { Variant \#2 }\end{array}$ & $0.00 \%$ & $0.77 \%$ & $0.00 \%$ & $0.00 \%$ & $0.00 \%$ & $0.00 \%$ & $0.00 \%$ & $0.00 \%$ & $0.00 \%$ & $0.00 \%$ & $0.27 \%$ \\
\hline $\begin{array}{l}\text { Darío } \\
\text { Variant \#3 }\end{array}$ & $0.34 \%$ & $1.54 \%$ & $0.00 \%$ & $0.00 \%$ & $0.00 \%$ & $0.00 \%$ & $0.00 \%$ & $9.09 \%$ & $0.00 \%$ & $0.00 \%$ & $0.96 \%$ \\
\hline $\begin{array}{l}\text { Darío } \\
\text { Variant \#4 }\end{array}$ & $0.00 \%$ & $0.00 \%$ & $0.00 \%$ & $11.11 \%$ & $0.00 \%$ & $0.00 \%$ & $0.00 \%$ & $0.00 \%$ & $0.00 \%$ & $0.00 \%$ & $0.27 \%$ \\
\hline Whiteware & $0.67 \%$ & $0.00 \%$ & $2.50 \%$ & $0.00 \%$ & $0.00 \%$ & $0.00 \%$ & $0.00 \%$ & $0.00 \%$ & $0.00 \%$ & $0.00 \%$ & $0.41 \%$ \\
\hline $\begin{array}{l}\text { Cipriano } \\
\text { Red on } \\
\text { Gray }\end{array}$ & $0.00 \%$ & $0.77 \%$ & $0.00 \%$ & $0.00 \%$ & $0.00 \%$ & $0.00 \%$ & $0.00 \%$ & $0.00 \%$ & $0.00 \%$ & $0.00 \%$ & $0.27 \%$ \\
\hline $\begin{array}{r}\text { Total in } \\
\text { Level }\end{array}$ & $100.00 \%$ & $100.00 \%$ & $100.00 \%$ & $100.00 \%$ & $100.00 \%$ & $100.00 \%$ & $100.00 \%$ & $100.00 \%$ & $100.00 \%$ & $100.00 \%$ & $100.00 \%$ \\
\hline
\end{tabular}


Table A.3

Tin Glazed

Redware

Size

$\underline{\text { TP1/102/Lv2 Painted Burned Rim Colors Incised }}$

$36 \times 19 \times 4$

0

$14 \times 15 \times 4$

$13 \times 14 \times 4$

$20 \times 16 \times 4$

$25 \times 20 \times 5$

1

0 yellow

0

1

1

0

$\underline{\text { TP1/101/Lv1 }}$

$\begin{array}{lcccll}20 \times 18 \times 7 & 0 & 0 & 0 & & 0 \\ 10 \times 12 \times 4 & 1 & 0 & 0 & \text { white } & 0 \\ 17 \times 14 \times 6 & 1 & 0 & 0 & \text { yellow } & 0 \\ 19 \times 19 \times 5 & 1 & 0 & 0 & \text { yellow } & 0 \\ 14 \times 9 \times 3 & 0 & 0 & 0 & & 0 \\ 18 \times 15 \times 4 & 1 & 0 & 0 & \text { yellow } & 0\end{array}$

$\underline{\mathrm{TP} 2 / 108 / \mathrm{R} 2}$

$34 \times 29 \times 4$

$10 \quad 0 \quad 0 \quad \begin{aligned} & \text { yellow, } \\ & \text { gray }\end{aligned}$

0

$\underline{\mathrm{TP} 2 / 103 / \mathrm{Lv} 1}$

\begin{tabular}{|c|c|c|c|c|}
\hline $23 \times 15 \times 6$ & 0 & 0 & 0 & \\
\hline $24 \times 23 \times 5$ & 1 & 0 & 0 & white \\
\hline $19 \times 16 \times 3$ & 0 & 1 & 0 & \\
\hline $25 \times 23 \times 5$ & 0 & 0 & 0 & \\
\hline $27 \times 26 \times 4$ & 0 & 0 & 0 & \\
\hline $18 \times 12 \times 4$ & 0 & 0 & 0 & \\
\hline $24 \times 16 \times 4$ & 1 & 0 & 0 & yellow \\
\hline
\end{tabular}




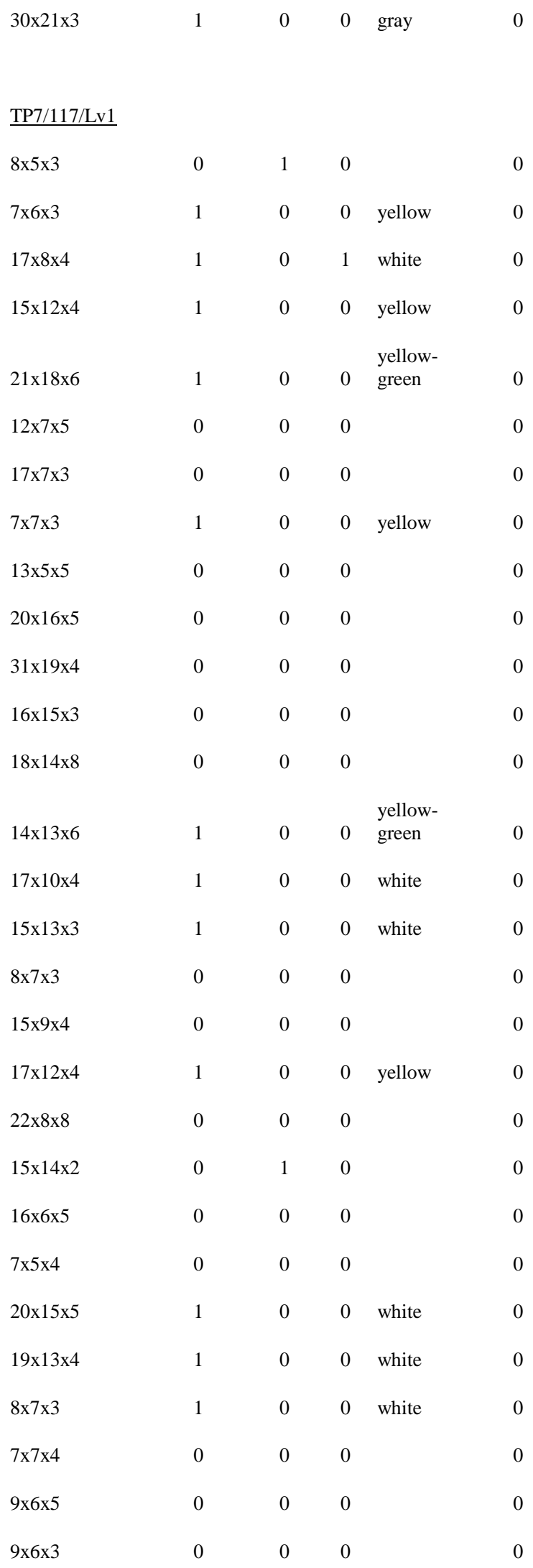




$\begin{array}{lccclc}10 \times 9 \times 4 & 0 & 0 & 0 & & 0 \\ & & & & \begin{array}{l}\text { yellow- } \\ \text { green, }\end{array} \\ 22 \times 15 \times 4 & 1 & 0 & 0 & \text { white } & 0 \\ 8 \times 7 \times 4 & 0 & 0 & 0 & & 0 \\ 11 \times 11 \times 4 & 1 & 0 & 0 & \text { white } & 0\end{array}$

Table A.4

\begin{tabular}{|c|c|c|c|c|c|c|c|c|c|c|c|}
\hline $\begin{array}{l}\text { Pot. Dist. } \\
\text { By } \\
\text { Type/Level } \\
\text { Total (\%) }\end{array}$ & Level 1 & Level 2 & Level 3 & Level 4 & $\begin{array}{l}\text { Rasgo } \\
1\end{array}$ & Rasgo 2 & $\begin{array}{l}\text { Rasgo } \\
3\end{array}$ & $\begin{array}{l}\text { TP1 } \\
\text { Trenching }\end{array}$ & $\begin{array}{l}\text { TP3 } \\
\text { Cleaning }\end{array}$ & $\begin{array}{l}\text { Interior } \\
\text { Wall }\end{array}$ & $\begin{array}{l}\text { Type } \\
\text { Total }\end{array}$ \\
\hline Darío Plain & $35.96 \%$ & $37.08 \%$ & $10.11 \%$ & $0.00 \%$ & $10.11 \%$ & $2.25 \%$ & $0.00 \%$ & $3.37 \%$ & $1.12 \%$ & $0.00 \%$ & $100.00 \%$ \\
\hline $\begin{array}{l}\text { Pantaleón } \\
\text { Brown }\end{array}$ & $45.02 \%$ & $27.49 \%$ & $3.79 \%$ & $6.64 \%$ & $9.95 \%$ & $2.37 \%$ & $0.47 \%$ & $3.32 \%$ & $0.00 \%$ & $0.95 \%$ & $100.00 \%$ \\
\hline $\begin{array}{l}\text { Eliseo Red } \\
\text { on Nat }\end{array}$ & $40.68 \%$ & $33.90 \%$ & $3.39 \%$ & $0.00 \%$ & $11.02 \%$ & $0.85 \%$ & $0.00 \%$ & $1.69 \%$ & $8.47 \%$ & $0.00 \%$ & $100.00 \%$ \\
\hline $\begin{array}{l}\text { Bibiana } \\
\text { Red }\end{array}$ & $28.57 \%$ & $37.50 \%$ & $8.93 \%$ & $0.00 \%$ & $14.29 \%$ & $0.00 \%$ & $0.00 \%$ & $3.57 \%$ & $7.14 \%$ & $0.00 \%$ & $100.00 \%$ \\
\hline $\begin{array}{l}\text { Apolonio } \\
\text { Orange- } \\
\text { Red }\end{array}$ & $0.00 \%$ & $50.00 \%$ & $50.00 \%$ & $0.00 \%$ & $0.00 \%$ & $0.00 \%$ & $0.00 \%$ & $0.00 \%$ & $0.00 \%$ & $0.00 \%$ & $100.00 \%$ \\
\hline $\begin{array}{l}\text { Telesforo } \\
\text { Brown }\end{array}$ & $25.00 \%$ & $64.29 \%$ & $3.57 \%$ & $3.57 \%$ & $0.00 \%$ & $0.00 \%$ & $0.00 \%$ & $3.57 \%$ & $0.00 \%$ & $0.00 \%$ & $100.00 \%$ \\
\hline $\begin{array}{l}\text { Teshcal } \\
\text { Red on Nat }\end{array}$ & $46.34 \%$ & $39.02 \%$ & $2.44 \%$ & $0.00 \%$ & $0.00 \%$ & $0.00 \%$ & $0.00 \%$ & $0.00 \%$ & $12.20 \%$ & $0.00 \%$ & $100.00 \%$ \\
\hline $\begin{array}{l}\text { Cuscatlan } \\
\text { Brown }\end{array}$ & $0.00 \%$ & $88.89 \%$ & $5.56 \%$ & $0.00 \%$ & $0.00 \%$ & $0.00 \%$ & $0.00 \%$ & $5.56 \%$ & $0.00 \%$ & $0.00 \%$ & $100 \%$ \\
\hline Gines Plain & $29.03 \%$ & $54.84 \%$ & $9.68 \%$ & $0.00 \%$ & $0.00 \%$ & $0.00 \%$ & $0.00 \%$ & $0.00 \%$ & $6.45 \%$ & $0.00 \%$ & $100 \%$ \\
\hline Olive Jar & $11.11 \%$ & $55.56 \%$ & $11.11 \%$ & $0.00 \%$ & $0.00 \%$ & $0.00 \%$ & $0.00 \%$ & $11.11 \%$ & $11.11 \%$ & $0.00 \%$ & $100 \%$ \\
\hline $\begin{array}{l}\text { Tin Glazed } \\
\text { Redware }\end{array}$ & $82.46 \%$ & $10.53 \%$ & $0.00 \%$ & $0.00 \%$ & $0.00 \%$ & $1.75 \%$ & $0.00 \%$ & $0.00 \%$ & $5.26 \%$ & $0.00 \%$ & $100 \%$ \\
\hline Floor Tile & $0.00 \%$ & $0.00 \%$ & $0.00 \%$ & $0.00 \%$ & $0.00 \%$ & $100.00 \%$ & $0.00 \%$ & $0.00 \%$ & $0.00 \%$ & $0.00 \%$ & $100 \%$ \\
\hline Roof Tile & $0.00 \%$ & $0.00 \%$ & $0.00 \%$ & $0.00 \%$ & $0.00 \%$ & $100.00 \%$ & $0.00 \%$ & $0.00 \%$ & $0.00 \%$ & $0.00 \%$ & $100 \%$ \\
\hline $\begin{array}{l}\text { UID } \\
\text { Classic }\end{array}$ & $29.17 \%$ & $50.00 \%$ & $16.67 \%$ & $0.00 \%$ & $0.00 \%$ & $0.00 \%$ & $0.00 \%$ & $0.00 \%$ & $0.00 \%$ & $4.17 \%$ & $100 \%$ \\
\hline $\begin{array}{l}\text { UID } \\
\text { Postclassic }\end{array}$ & $100.00 \%$ & $0.00 \%$ & $0.00 \%$ & $0.00 \%$ & $0.00 \%$ & $0.00 \%$ & $0.00 \%$ & $0.00 \%$ & $0.00 \%$ & $0.00 \%$ & $100 \%$ \\
\hline $\begin{array}{l}\text { Catalina } \\
\text { Red on Wte }\end{array}$ & $60.00 \%$ & $20.00 \%$ & $0.00 \%$ & $0.00 \%$ & $0.00 \%$ & $20.00 \%$ & $0.00 \%$ & $0.00 \%$ & $0.00 \%$ & $0.00 \%$ & $100 \%$ \\
\hline Porcelain & $16.67 \%$ & $66.67 \%$ & $0.00 \%$ & $0.00 \%$ & $0.00 \%$ & $0.00 \%$ & $0.00 \%$ & $0.00 \%$ & $16.67 \%$ & $0.00 \%$ & $100 \%$ \\
\hline $\begin{array}{l}\text { Raimundo } \\
\text { Brown }\end{array}$ & $28.57 \%$ & $10.71 \%$ & $3.57 \%$ & $3.57 \%$ & $42.86 \%$ & $0.00 \%$ & $0.00 \%$ & $10.71 \%$ & $0.00 \%$ & $0.00 \%$ & $100 \%$ \\
\hline $\begin{array}{l}\text { Darío } \\
\text { Variant \#1 }\end{array}$ & $0.00 \%$ & $100.00 \%$ & $0.00 \%$ & $0.00 \%$ & $0.00 \%$ & $0.00 \%$ & $0.00 \%$ & $0.00 \%$ & $0.00 \%$ & $0.00 \%$ & $100 \%$ \\
\hline $\begin{array}{l}\text { Darío } \\
\text { Variant \#2 }\end{array}$ & $0.00 \%$ & $100.00 \%$ & $0.00 \%$ & $0.00 \%$ & $0.00 \%$ & $0.00 \%$ & $0.00 \%$ & $0.00 \%$ & $0.00 \%$ & $0.00 \%$ & $100 \%$ \\
\hline
\end{tabular}




\begin{tabular}{|c|c|c|c|c|c|c|c|c|c|c|c|}
\hline $\begin{array}{l}\text { Darío } \\
\text { Variant \#3 }\end{array}$ & $14.29 \%$ & $57.14 \%$ & $0.00 \%$ & $0.00 \%$ & $0.00 \%$ & $0.00 \%$ & $0.00 \%$ & $28.57 \%$ & $0.00 \%$ & $0.00 \%$ & $100 \%$ \\
\hline \multicolumn{12}{|l|}{ Darío } \\
\hline Variant \#4 & $0.00 \%$ & $0.00 \%$ & $0.00 \%$ & $100.00 \%$ & $0.00 \%$ & $0.00 \%$ & $0.00 \%$ & $0.00 \%$ & $0.00 \%$ & $0.00 \%$ & $100 \%$ \\
\hline Whiteware & $66.67 \%$ & $0.00 \%$ & $33.33 \%$ & $0.00 \%$ & $0.00 \%$ & $0.00 \%$ & $0.00 \%$ & $0.00 \%$ & $0.00 \%$ & $0.00 \%$ & $100 \%$ \\
\hline $\begin{array}{l}\text { Cipriano } \\
\text { Red on }\end{array}$ & & & & & & & & & & & \\
\hline Gray & $0.00 \%$ & $100.00 \%$ & $0.00 \%$ & $0.00 \%$ & $0.00 \%$ & $0.00 \%$ & $0.00 \%$ & $0.00 \%$ & $0.00 \%$ & $0.00 \%$ & $100 \%$ \\
\hline
\end{tabular}

Table A.5 


\section{APPENDIX B}

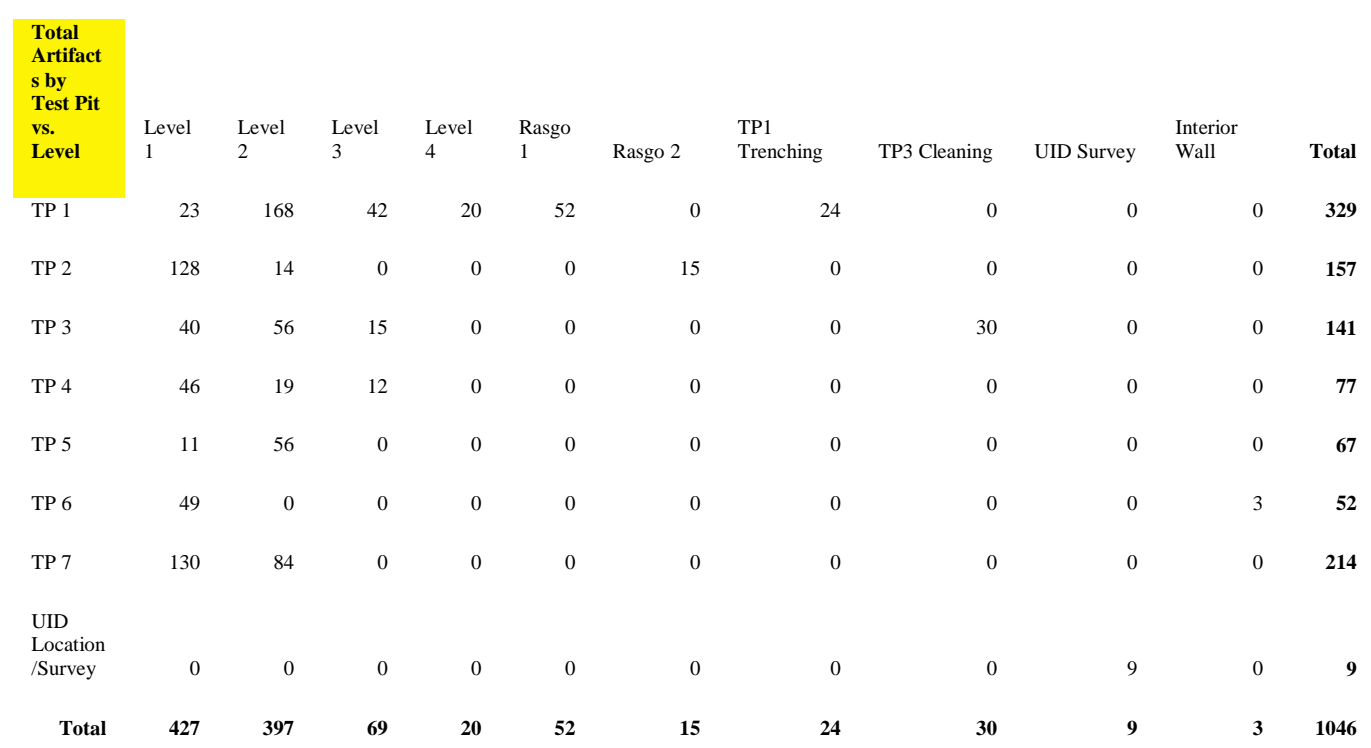

Table B.1

\begin{tabular}{|c|c|c|c|c|c|c|c|c|c|c|c|}
\hline $\begin{array}{l}\text { Pottery } \\
\text { by Test } \\
\text { Pit vs. } \\
\text { Level }\end{array}$ & Level 1 & Level 2 & $\begin{array}{l}\text { Level } \\
3\end{array}$ & $\begin{array}{l}\text { Level } \\
4\end{array}$ & $\begin{array}{l}\text { Rasgo } \\
1\end{array}$ & $\begin{array}{l}\text { Rasgo } \\
2\end{array}$ & $\begin{array}{l}\text { TP1 } \\
\text { Trenching }\end{array}$ & $\begin{array}{l}\text { TP3 } \\
\text { Cleaning }\end{array}$ & UID/Survey & $\begin{array}{l}\text { Interior } \\
\text { Wall }\end{array}$ & Total \\
\hline TP 1 & 21 & 135 & 33 & 18 & 52 & 0 & 22 & 0 & 0 & 0 & 281 \\
\hline TP 2 & 109 & 11 & 0 & 0 & 0 & 13 & 0 & 0 & 0 & 0 & 133 \\
\hline TP 3 & 26 & 21 & 1 & 0 & 0 & 0 & 0 & 27 & 0 & 0 & 75 \\
\hline $\mathrm{TP} 4$ & 42 & 16 & 6 & 0 & 0 & 0 & 0 & 0 & 0 & 0 & 64 \\
\hline TP 5 & 9 & 54 & 0 & 0 & 0 & 0 & 0 & 0 & 0 & 0 & 63 \\
\hline TP 6 & 23 & 0 & 0 & 0 & 0 & 0 & 0 & 0 & 0 & 3 & 26 \\
\hline TP 7 & 67 & 19 & 0 & 0 & 0 & 0 & 0 & 0 & 0 & 0 & 86 \\
\hline \multicolumn{12}{|l|}{$\begin{array}{l}\text { UID } \\
\text { Locatio } \\
\mathrm{n} / \mathrm{Surve}\end{array}$} \\
\hline y & 0 & 0 & 0 & 0 & 0 & 0 & 0 & 0 & 4 & 0 & 4 \\
\hline Total & 297 & 256 & 40 & 18 & 52 & 13 & 22 & 27 & 4 & 3 & 732 \\
\hline
\end{tabular}

Table B.2 